\title{
Interventions for replacing missing teeth: horizontal and vertical bone augmentation techniques for dental implant treatment
}

\section{(Review)}

Esposito M, Grusovin MG, Felice P, Karatzopoulos G, Worthington HV, Coulthard P

Esposito M, Grusovin MG, Felice P, Karatzopoulos G, Worthington HV, Coulthard P.

Interventions for replacing missing teeth: horizontal and vertical bone augmentation techniques for dental implant treatment.

Cochrane Database of Systematic Reviews 2009, Issue 4. Art. No.: CD003607.

DOI: 10.1002/14651858.CD003607.pub4.

www.cochranelibrary.com

Interventions for replacing missing teeth: horizontal and vertical bone augmentation techniques for dental 
TABLE OF CONTENTS

HEADER 1

ABSTRACT

PLAIN LANGUAGE SUMMARY

BACKGROUND

OBJECTIVES

METHODS

RESULTS

DISCUSSION

AUTHORS' CONCLUSIONS

ACKNOWLEDGEMENTS

REFERENCES

CHARACTERISTICS OF STUDIES

DATA AND ANALYSES

Analysis 1.1. Comparison 1 Vertical augmentation versus no augmentation, Outcome 1 Inlay bone grafts versus short implants in atrophic mandibles.

Analysis 2.1. Comparison 2 Horizontal augmentation versus horizontal augmentation, Outcome 1 Horizontal augmentation: bone versus $100 \%$ Bio-Oss + barrier.

Analysis 2.2. Comparison 2 Horizontal augmentation versus horizontal augmentation, Outcome 2 Horizontal augmentation: bone + barrier versus 100\% Bio-Oss + barrier.

Analysis 3.1. Comparison 3 Vertical augmentation versus vertical augmentation, Outcome 1 Osteodistraction versus inlay bone graft (binary).

Analysis 3.2. Comparison 3 Vertical augmentation versus vertical augmentation, Outcome 2 Osteodistraction versus inlay bone graft (continuous).

Analysis 3.3. Comparison 3 Vertical augmentation versus vertical augmentation, Outcome 3 Osteodistraction versus onlay bone graft (binary).

Analysis 3.4. Comparison 3 Vertical augmentation versus vertical augmentation, Outcome 4 Osteodistraction versus onlay bone graft (continuous).

Analysis 3.5. Comparison 3 Vertical augmentation versus vertical augmentation, Outcome 5 Osteodistraction versus GBR (binary).

Analysis 3.6. Comparison 3 Vertical augmentation versus vertical augmentation, Outcome 6 GBR: autogenous bone versus bone substitute (continuous).

Analysis 3.7. Comparison 3 Vertical augmentation versus vertical augmentation, Outcome 7 GBR: non-resorbable versus resorbable barriers (binary).

Analysis 3.8. Comparison 3 Vertical augmentation versus vertical augmentation, Outcome 8 GBR: non-resorbable versus resorbable barriers (continuous).

Analysis 3.9. Comparison 3 Vertical augmentation versus vertical augmentation, Outcome 9 Inlay graft: autogenous bone versus bone substitute (continuous).

Analysis 3.10. Comparison 3 Vertical augmentation versus vertical augmentation, Outcome 10 Inlay graft: autogenous bone versus bone substitute (binary).

Analysis 3.11. Comparison 3 Vertical augmentation versus vertical augmentation, Outcome 11 Autogenous bone: inlay versus onlay (binary).

Analysis 3.12. Comparison 3 Vertical augmentation versus vertical augmentation, Outcome 12 Autogenous bone: inlay versus onlay (continuous).

ADDITIONAL TABLES

APPENDICES

WHAT'S NEW

HISTORY

CONTRIBUTIONS OF AUTHORS

DECLARATIONS OF INTEREST

SOURCES OF SUPPORT

NOTES

INDEX TERMS

1

2

3

4 
[Intervention Review]

\section{Interventions for replacing missing teeth: horizontal and vertical bone augmentation techniques for dental implant treatment}

Marco Esposito ${ }^{1}$, Maria Gabriella Grusovin², Pietro Felice ${ }^{3}$, Georgios Karatzopoulos ${ }^{4}$, Helen V Worthington ${ }^{1}$, Paul Coulthard 5

1Cochrane Oral Health, Division of Dentistry, School of Medical Sciences, Faculty of Biology, Medicine and Health, The University of Manchester, Manchester, UK. 2 Private practice, Gorizia, Italy. ${ }^{3}$ Department of Oral and Dental Sciences, University of Bologna, Bologna, Italy. ${ }^{4}$ The Acle Dental Surgery, Norwich, UK. 5 Institute of Dentistry, Queen Mary University of London, London, UK

Contact address: Marco Esposito, Cochrane Oral Health, Division of Dentistry, School of Medical Sciences, Faculty of Biology, Medicine and Health, The University of Manchester, Coupland Building 3, Oxford Road, Manchester, M13 9PL, UK. espositomarco@hotmail.com.

Editorial group: Cochrane Oral Health Group

Publication status and date: Stable (no update expected for reasons given in 'What's new'), published in Issue 10, 2019.

Citation: Esposito M, Grusovin MG, Felice P, Karatzopoulos G, Worthington HV, Coulthard P. Interventions for replacing missing teeth: horizontal and vertical bone augmentation techniques for dental implant treatment. Cochrane Database of Systematic Reviews 2009, Issue 4. Art. No.: CD003607. DOI: 10.1002/14651858.CD003607.pub4.

Copyright ( 2019 The Cochrane Collaboration. Published by John Wiley \& Sons, Ltd.

\section{A B S T R A C T}

\section{Background}

Dental implants require sufficient bone to be adequately stabilised. For some patients implant treatment would not be an option without horizontal or vertical bone augmentation. A variety of materials and surgical techniques are available for bone augmentation.

\section{Objectives}

To test whether and when augmentation procedures are necessary and which is the most effective technique for horizontal and vertical bone augmentation.

\section{Search methods}

The Cochrane Oral Health Group's Trials Register, CENTRAL, MEDLINE and EMBASE were searched. Several dental journals were handsearched. The bibliographies of review articles were checked, and personal references were searched. More than 55 implant manufacturing companies were also contacted. Last electronic search was conducted on 11 June 2009.

\section{Selection criteria}

Randomised controlled trials (RCTs) of different techniques and materials for augmenting bone horizontally or vertically or both for implant treatment reporting the outcome of implant therapy at least to abutment connection. Trials were divided into two broad categories: horizontal augmentation and vertical augmentation techniques.

\section{Data collection and analysis}

Screening of eligible studies, assessment of the methodological quality of the trials and data extraction were conducted independently and in duplicate. Authors were contacted for any missing information. Results were expressed as random-effects models using mean differences for continuous outcomes and odd ratios for dichotomous outcomes with $95 \%$ confidence intervals. The statistical unit of the analysis was the patient.

\section{Main results}

Thirteen RCTs out of 18 potentially eligible trials were suitable for inclusion. Three RCTs (106 patients) dealt with horizontal and 10 trials (218 patients) with vertical augmentation. Since different techniques were evaluated in different trials, only one meta-analysis could be performed. When comparing whether vertical augmentation procedures are advantageous over short implants, a meta-analysis of two 
trials resulted in more implant failures odds ratio $(\mathrm{OR})=5.74(95 \%$ confidence interval $(\mathrm{Cl}) 0.92$ to 35.82 ; borderline significance, $\mathrm{P}=$ 0.06 ) and statistically more complications $\mathrm{OR}=4.97(95 \% \mathrm{Cl} 1.10$ to 22.40$)$ in the vertically augmented group. When comparing various horizontal augmentation techniques (three trials) no statistically significant differences were observed. When comparing various vertical bone augmentation techniques (eight trials) no statistically significant differences were observed with the exception of three trials which showed that more vertical bone gain could be obtained with osteodistraction than with inlay autogenous grafts (mean difference $3.25 \mathrm{~mm}$; $95 \% \mathrm{Cl} 1.66$ to 4.84 ), and with a bone substitute rather than autogenous bone in guided bone regeneration (mean difference $0.60 \mathrm{~mm} ; 95 \%$ $\mathrm{Cl} 0.21$ to 0.99 ) in posterior atrophic mandibles, and that patients preferred a bone substitute block than a block of autogenous bone taken from the iliac crest $(\mathrm{OR}=0.03 ; 95 \% \mathrm{Cl} 0.00$ to $0.64 ; \mathrm{P}=0.02)$.

\section{Authors' conclusions}

These conclusions are based on few trials including few patients, sometimes having short follow-up, and often being judged to be at high risk of bias. Various techniques can augment bone horizontally and vertically, but it is unclear which are the most efficient. Short implants appear to be a better alternative to vertical bone grafting of resorbed mandibles. Complications, especially for vertical augmentation, are common. Some bone substitutes could be a preferable alternative to autogenous bone. Osteodistraction osteogenesis allows for more vertical bone augmentation than other techniques which on the other hand can allow for horizontal augmentation at the same time. Titanium screws may be preferable to resorbable screws to fixate onlay bone grafts.

\section{PLAIN LANGUAGE SUMMARY}

\section{Interventions for replacing missing teeth: horizontal and vertical bone augmentation techniques for dental implant treatment}

Some patients may have insufficient bone to place dental implants but there are many surgical techniques to increase the bone volume making implant treatment possible.

Short implants appear to be more effective and cause less complications than conventional implants placed in resorbed lower jaws (mandibles) augmented with bone from the hip or bone substitutes (cow bone blocks). Bone can be regenerated in a horizontal and vertical direction using various techniques, but it is unclear which techniques are preferable, and complications especially for augmenting bone in a vertical direction are frequent. Some bone substitutes may cause less complications and pain than taking the own bone from various parts of the body. 


\section{B A C K G R O U N D}

Missing teeth and supporting oral tissues have traditionally been replaced with dentures or bridges permitting restoration of chewing function, speech, and aesthetics. Dental implants offer an alternative. These implants are inserted into the jawbones to support a dental prosthesis and are retained because of the intimacy of bone growth on to their surface. This direct structural and functional connection between living bone and implant surface, termed osseointegration, was first described by Branemark 1977 and has undoubtedly been one of the most significant scientific breakthroughs in dentistry over the past 40 years.

Teeth may have been lost through dental disease or trauma or they may be congenitally absent. In addition, teeth may be lost as part of a surgical procedure to resect part of a jaw because of pathology such as cancer. Sometimes, there is a lack of supporting bone in addition to the absent teeth due to atrophy, trauma, failure to develop or surgical resection. Dental implants can only be placed if there is sufficient bone to adequately stabilise them, and bone augmentation permits implant treatment that would otherwise not be an option for some of these patients. Bone augmentation procedures may be carried out some time prior to implant placement (two-stage procedure), or at the same time as implant placement (one-stage procedure), using various materials and techniques. When carried out prior to placement, this necessitates an additional surgical episode and then the area is left to heal for a period of time before the implants are placed.

There are different indications, numerous alternative techniques, and various 'biologically active' agents and biomaterials currently used to augment bone. Some materials used to augment the bone volume may be described as follows:

\section{- Autogenous bone grafts}

These are bone grafts taken from an adjacent or remote site in the same patient and used to build up the deficient area and are considered to be the material of choice (Palmer 2000) i.e. the 'gold standard'. They are biologically compatible as they are from the same patient and provide a scaffold into which new bone may grow. Sites from within the mouth may be used for relatively small graft requirements or sites such as the hip bone (iliac crest) for larger bone volumes. All of these require surgery at a second site and therefore the morbidity must be considered. Of the many possible sites, each has its own merits and disadvantages. Sometimes it may be possible to recycle bone taken from the site of implant placement when preparing the hole also by using a special filter to collect bone particles that would otherwise be lost and use this to build up a deficient area.

\section{- Allografts}

These are bone grafts harvested from cadavers and processed by methods such as freezing or demineralising and freezing. The grafts are then sterilised and supplied by specially licensed tissue banks in several convenient ways such as bone particles or large blocks. They are resorbable. There may be some concern regarding their absolute non-infectivity.

\section{- Xenografts}

These are graft materials derived from animals such as cow or coral. Animal bone, usually bovine bone, is processed to completely remove the organic component. There has been concern regarding the absolute non-infectivity of bovine-derived materials although this has been disputed (Wenz 2001).

\section{- Alloplastic graft materials}

These synthetic bone substitutes include calcium phosphates and bioactive glasses. Alloplasts provide a physical framework for bone ingrowth. Some surgeons use these materials in combination with autogenous bone grafts. These materials resorb completely or to some degree or not at all with time.

\section{- Barrier membranes for guided bone regeneration (GBR)}

This technique uses special barrier membranes to protect defects from the ingrowth of soft tissue cells so that bone progenitor cells may develop bone uninhibited. Ingrowth of soft tissue may disturb or totally prevent osteogenesis in a defect or wound. Examples of membranes are expanded polytetrafluoroethylene, porcine collagen, and polyglactin. Membranes can be resorbable or non-resorbable.

\section{- Bone promoting proteins (BMPs) and platelet rich plasma (PRP)}

BMPs are a family of proteins naturally present in bone and responsible for activation of bone development (Valentin-Opran 2002). BMPs may encourage bone formation. They may be incorporated into any of the above graft types. Growth factors and PRP are used to promote bone formation.

Some surgical techniques used to augment bone volume include:

\section{- Onlay grafting}

The graft material is laid over the defective area to increase width, or height or both of the alveolar jawbone. The host bed is usually perforated with a small bur to encourage the formation of a blood clot between the graft and recipient bed. The graft is immobilised with screws and plates or with dental implants (Kahnberg 1989).

\section{- Inlay grafting}

A section of jawbone is surgically separated and graft material sandwiched between two sections. Le Fort I osteotomy and interpositional bone graft procedure (Obwegeser 1969) has been used for patients requiring implant treatment (Keller 1992).

\section{- Ridge expansion}

The alveolar ridge is split longitudinally and parted to widen it and allow placement of an implant or graft material or both in the void. The longitudinal split can be limited by placing transverse cuts in the bone.

\section{- Distraction osteogenesis}

The principals of distraction osteogenesis in which a gradual, controlled displacement of a surgically prepared fracture is used to increase bone volume, are not new but have recently been introduced into implant surgery to increase alveolar bone volume (Chin 1999). The gap created during the displacement of the bone segment is filled with immature non-calcified bone that matures during a subsequent fixation period. The associated soft tissues are also expanded as the bone segment is transported. 
Each type of augmentation material may be used in combination with a variety of different surgical techniques, so many permutations of treatment are possible and the situation is rather complicated. In addition, new techniques and 'active agents' are continuously introduced in clinical practice. Particular treatment options have strong proponents with surgeons claiming that a particular material or technique offers improved implant success.

There are some clinical situations in which the utility of augmentation procedures is questionable with some authors proposing as alternatives the use of short implants $(8.5$ to $5 \mathrm{~mm}$ long) or implants with smaller diameters ( $3 \mathrm{~mm}$ or less). Also zygomatic implants have been proposed as alternative to bone grafting procedures of the atrophic maxilla. Zygomatic implants are about $4 \mathrm{~cm}$ long implants passing through the sinus and engaged into the body of the zygomatic bone (Branemark 2004). Zygomatic implants are evaluated in another Cochrane review (Esposito 2005).

This review will focus exclusively on techniques aimed at augmenting the bone in a horizontal or vertical direction. Several reviews have been published on this topic (Tolman 1995; Esposito 1998; Fiorellini 2003; Rocchietta 2008), though their findings were not based on the most reliable clinical trials, therefore the information presented has to be interpreted with a great deal of caution. The reader can find information on the procedures for augmenting the maxillary sinus, post-extractive sites, bone fenestrations at implants in the previous version of this review (Esposito 2008c). Information about bone augmentation at implants affected by perimplantitis can be found in another Cochrane review (Esposito 2008b).

\section{O B J E C T I VES}

To test (a) whether and when horizontal and vertical bone augmentation procedures are necessary and (b) which are the most effective horizontal and vertical bone augmentation techniques.

Augmentation procedures were divided into two broad categories. (1) Horizontal bone augmentation procedures: any technique aimed at making the recipient bone wider or thicker in order to receive dental implants of adequate diameter (usually of a $3.5 \mathrm{~mm}$ diameter or wider).

(2) Vertical bone augmentation procedures: any technique aimed at making the recipient bone higher in a vertical dimension in order to receive dental implants of adequate length (usually $9 \mathrm{~mm}$ or longer). In many instances a combination of horizontal and vertical bone augmentation is needed and these procedures were included in the vertical augmentation group.

\section{METHODS}

\section{Criteria for considering studies for this review \\ Types of studies}

Randomised controlled clinical trials (RCTs) including split-mouth studies.

\section{Types of participants}

Patients with missing teeth who may require horizontal and/or vertical alveolar bone augmentation prior to or during dental implant placement procedures.

\section{Types of interventions}

Any bone augmentation technique, active agent (such as bone morphogenetic proteins, platelet rich plasma) or biomaterials used in relation with osseointegrated, root-formed dental implants. For trials to be considered in this review, implants have to be placed and the outcome of the implant therapy has to be reported at least at the endpoint of the abutment connection procedure. The following time points were considered: abutment connection, 1, 3 and 5 years after loading.

\section{Types of outcome measures}

Outcome measures included.

- Prosthesis failure: planned prosthesis which could not be placed due to implant failure(s) and loss of the prosthesis secondary to implant failure(s).

- Implant failure: implant mobility and removal of stable implants dictated by progressive marginal bone loss or infection (biological failures). Biological failures were grouped as early (failure to establish osseointegration) and late failures (failure to maintain the established osseointegration). Failures that occurred before prosthesis placement were considered early failures. Implant mobility could be assessed manually or with instruments such as Periotest (Siemens AG, Benshein, Germany) or resonance frequency (Osstell, Integration Diagnostics, Göteborg, Sweden).

- Augmentation procedure failure: failure of the augmentation procedure (i.e. of the bone graft or the guided bone regeneration (GBR) procedure, etc.) not affecting the success of the implant.

- Major complications at treated/augmented sites (e.g. infection, nerve injury, haemorrhage, etc.).

- Major complications at bone donor sites (e.g. nerve injury, gait disturbance, infection, etc.).

- Patient satisfaction including aesthetics.

- Patient preference including aesthetics (only in split-mouth trials).

- Bone gain vertically or horizontally or both expressed in $\mathrm{mm}$ or percentage, including bone level changes over time.

- Aesthetics evaluated by dentist.

- Duration of the treatment time starting from the first intervention to the functional loading of the implants.

- Treatment costs.

Trials evaluating only histological outcomes were not considered in this review.

\section{Search methods for identification of studies}

For the identification of studies included or considered for this review we developed detailed search strategies for each database searched. These were based on the search strategy developed for MEDLINE via OVID but revised appropriately for each database (see Appendix 1). The search strategy used a combination of controlled vocabulary and free text terms. The subject search for MEDLINE was combined with the Cochrane Highly Sensitive Search Strategy for identifying reports of randomised controlled trials (RCTs) (as published in Box 6.4.c in the Cochrane Handbook for Systematic Reviews of Interventions version 5.0.1 updated September 2008) (Higgins 2008). 


\section{Searched databases}

- The Cochrane Oral Health Group's Trials Register (to 10 June 2009) (seeAppendix 2)

- The Cochrane Central Register of Controlled Trials (CENTRAL) (The Cochrane Library 2009, Issue 2) (seeAppendix 3)

- MEDLINE (1966 to 11 June 2009) (seeAppendix 1)

- EMBASE (1980 to 11 June 2009) (seeAppendix 4).

The most recent electronic search was undertaken on 11 June 2009.

\section{Language}

There were no language restrictions.

\section{Unpublished studies}

We wrote to all the authors of the identified RCTs, we checked the bibliographies of all identified RCTs and relevant review articles, and we used personal contacts in an attempt to identify unpublished or ongoing RCTs. In the first version of this review we also wrote to more than 55 oral implant manufacturers and we requested information on trials through an Internet discussion group (implantology@yahoogroups.com), however we discontinued this due to poor yield.

\section{Handsearching}

Details of the journals being handsearched by the Cochrane Oral Health Group's ongoing programme are given on the website: www.ohg.cochrane.org/.

The following journals have been identified as being potentially important to be handsearched for this review: British Journal of Oral and Maxillofacial Surgery, Clinical Implant Dentistry and Related Research, Clinical Oral Implants Research, European Journal of Oral Implantology, Implant Dentistry, International Journal of Oral and Maxillofacial Implants, International Journal of Oral and Maxillofacial Surgery, International Journal of Periodontics and Restorative Dentistry, International Journal of Prosthodontics, Journal of Clinical Periodontology, Journal of Dental Research, Journal of Oral Implantology, Journal of Oral and Maxillofacial Surgery, Journal of Periodontology, and Journal of Prosthetic Dentistry. Where these have not already been searched as part of the Cochrane Journal Handsearching Programme, the journals were handsearched by one review author up to the month in which the last electronic search was undertaken.

\section{Data collection and analysis}

\section{Study selection}

The titles and abstracts (when available) of all reports identified through the electronic searches were scanned independently by two review authors. For studies appearing to meet the inclusion criteria, or for which there were insufficient data in the title and abstract to make a clear decision, the full report was obtained. The full reports obtained from all the electronic and other methods of searching were assessed independently by two review authors to establish whether the studies met the inclusion criteria or not. Disagreements were resolved by discussion. Where resolution was not possible, a third review author was consulted. All studies meeting the inclusion criteria then underwent validity assessment and data extraction. Studies rejected at this or subsequent stages were recorded in the table of excluded studies, and reasons for exclusion recorded.

\section{Data extraction}

Data were extracted independently by two review authors using specially designed data extraction forms. The data extraction forms were piloted on several papers and modified as required before use. Any disagreement was discussed and a third review author consulted where necessary. All authors were contacted for clarification or missing information. Data were excluded until further clarification was available if agreement could not be reached.

For each trial the following data were recorded.

- Year of publication, country of origin and source of study funding.

- Details of the participants including demographic characteristics, source of recruitment and criteria for inclusion.

- Details of the type of intervention.

- Details of the outcomes reported, including method of assessment, and time intervals.

\section{Assessment of risk of bias in included studies}

An assessment of the risk of bias in included studies was undertaken following the recommendations as described in Chapter 8 of the Cochrane Handbook for Systematic Reviews of Interventions 5.0.1 (Higgins 2008). Two review authors independently and in duplicate assessed the risk of bias of all included studies. Any disagreement was discussed and where necessary a third review author was consulted to achieve consensus. Authors were contacted directly for clarification. In the case that the paper to be assessed had one or more review authors in the authors list, it was independently evaluated only by those review authors not involved in the trials.

A specific tool for assessing risk of bias in each included study was adopted. This comprised a description and a judgement for each entry in a risk of bias table, where each entry addressed a specific feature of the study:

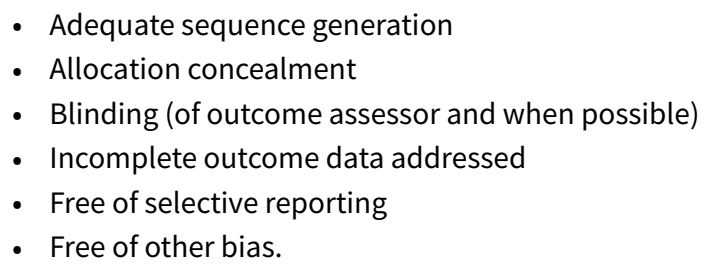

The judgement for each entry involved answering a question, with answers 'Yes' indicating low risk of bias, 'No' indicating high risk of bias, and 'Unclear' indicating either lack of information or uncertainty over the potential for bias.

After taking into account the additional information provided by the authors of the trials, the overall risk of bias in included studies was assessed using three key domains: allocation concealment, blinding of outcome assessors (when possible) and completeness of follow-up. Studies were graded into the following categories.

- Low risk of bias (plausible bias unlikely to seriously alter the results) if all three key domains were met.

- High risk of bias (plausible bias that seriously weakens confidence in the results) if one or more key domains were not met. 
Further quality assessment was carried out to assess sample size calculations, definition of exclusion/inclusion criteria, and comparability of control and test groups at entry. The quality assessment criteria were pilot tested using several articles.

\section{Data synthesis}

For dichotomous outcomes, the estimate of effect of an intervention was expressed as odds ratios (OR) together with 95\% confidence intervals (Cls). For continuous outcomes, mean differences and standard deviations were used to summarise the data for each group using mean differences and 95\% Cls. The statistical unit was the patient and not the augmentation procedure or the implants.

A meta-analysis was made only if there were studies of similar comparisons reporting the same outcome measures. Odds ratios were to be combined for dichotomous data, and mean differences for continuous data, using random-effects models. Data from splitmouth studies were to be combined with data from parallel group trials with the method outlined by Elbourne (Elbourne 2002), using the generic inverse variance method in Review Manager (RevMan).

The significance of any discrepancies in the estimates of the treatment effects from the different trials was to be assessed by means of Cochran's test for heterogeneity and the $\mathrm{I}^{2}$ statistic, which describes the percentage total variation across studies that is due to heterogeneity rather than chance. Clinical heterogeneity was to be assessed by examining the types of participants and interventions for all outcomes in each study. It was planned to undertake sensitivity analyses to examine the effect of the study quality assessment on the overall estimates of effect. In addition, the effect of including unpublished literature on the review's findings was also to be examined.

We decided not to formulate any hypotheses to be investigated with subgroup analyses since no comprehensive meta-analysis was expected. However, this may be done in future updates of this review.

\section{RE S U L T S}

\section{Description of studies}

\section{Characteristics of the trial setting and investigators}

- Of the 18 potentially eligible trials (Antoun 2001; Friedmann 2002; Stellingsma 2003; Chiapasco 2004; Van der Zee 2004; Raghoebar 2005; Schortinghuis 2005; Raghoebar 2006; Chiapasco 2007; Meijndert 2007; Merli 2007; Roccuzzo 2007; Bianchi 2008; Felice 2008; Fontana 2008; Schortinghuis 2008; Felice 2009a; Felice 2009b), four were excluded because they reported only histological outcomes without reporting any implant related outcomes (Antoun 2001; Friedmann 2002; Schortinghuis 2005; Roccuzzo 2007) and one (Van der Zee 2004) because it presented the data of the various group combined.

- Of the 13 included trials, eight were conducted in Italy (Chiapasco 2004; Chiapasco 2007; Merli 2007; Bianchi 2008; Felice 2008; Fontana 2008; Felice 2009a; Felice 2009b) and five in the Netherlands (Stellingsma 2003; Raghoebar 2005; Raghoebar 2006; Meijndert 2007; Schortinghuis 2008).

- Nine trials had a parallel group study design and four had a splitmouth design (Raghoebar 2005; Raghoebar 2006; Fontana 2008; Felice 2008). One study (Bianchi 2008) included one patient treated bilaterally and only data from a randomly selected side were included in this review.

- For six trials it was declared that support was received from industry directly involved in the product being tested also in the form of free material (Stellingsma 2003; Raghoebar 2005; Raghoebar 2006; Meijndert 2007; Felice 2008; Felice 2009a). One trial received support from the implant manufacturer, however the trial was not designed to test the implants, but the augmentation techniques (Merli 2007). The authors of six trials declared that no support was received from commercial parties whose products were being tested in the trials (Chiapasco 2004; Chiapasco 2007; Bianchi 2008; Fontana 2008; Schortinghuis 2008; Felice 2009b).

- Eleven trials were conducted at university, hospital or specialist dental clinics and two trials in private practices (Merli 2007; Felice 2009a).

\section{Characteristics of the interventions}

The following interventions were tested.

\section{Different techniques for horizontal bone augmentation}

Is horizontal augmentation procedure necessary? (no trial)

Which is the most effective horizontal augmentation technique? (3 trials with 106 patients)

- Two-stage sinus lift with autogenous blocks and particulate bone together with buccal onlay monocortico-cancellous bone grafts, to reconstruct the width of the maxilla, fixed with titanium screws harvested from the iliac crest with or without platelet rich plasma (PRP) left to heal for 3 months in a split-mouth trial (Raghoebar 2005). Barriers were not used. PRP was made using the Platelet Concentration Collection System kit (PCCS kit, 3i Implant Innovations Inc. Palm Beach Gardens, FL, USA). $54 \mathrm{ml}$ of blood were mixed with $6 \mathrm{ml}$ of anticoagulant (citrate dextrose) and processed with the platelet concentration system. To promote the release of growth factors from the platelets, $10 \%$ calcium chloride solution and the patient's serum, as a source of autologous thrombin, were added before actual reconstruction of the defect with the bone graft. The resulting gel was mixed with the bone graft and some gel was applied at the closure of the wound at the side treated with PRP. Three implants were inserted into the healed graft of each side and were left to heal for additional 6 months. All the augmentation procedures were performed under general anaesthesia. Surgical templates were used to optimise implant insertion. All implants were turned titanium self tapping (Nobel Biocare, Göteborg, Sweden) and were rehabilitated with two implant-supported prostheses.

- Two-stage buccal onlay monocortico-cancellous bone grafts fixed with two titanium (diameter $1.5 \mathrm{~mm}$, Martin Medizin Technik, Tuttlingen, Germany) or resorbable poly (D, L-lactide) acid (PDLLA, diameter $2.1 \mathrm{~mm}$, Resorb X, Martin Medizin Technik) screws in a split-mouth trial, to reconstruct the width of the maxilla (Raghoebar 2006). Grafts were covered with resorbable barriers (Bio-Gide, Geistlich Pharmaceutical, Wolhusen, Switzerland). Grafts were harvested from the iliac crest and bilateral sinus lifts were performed at the same time with autogenous blocks and particulate bone. After 3 months, implants were inserted into the healed graft of each side and were left to heal for an additional 6 months. All the augmentation procedures were performed under general anaesthesia. Surgical templates were used to optimise implant 
insertion. All implants were turned titanium self tapping (Nobel Biocare, Göteborg, Sweden) and were rehabilitated with implant-supported overdentures.

- Three different techniques to horizontally augment local ridge maxillary defects (from 1st to 1st premolars) for allowing placement of single implants were tested (Meijndert 2007): (1) bone graft from the chin; (2) bone graft from the chin with a resorbable barrier (Bio-Gide, Geistlich Pharma, Wolhusen, Switzerland); and (3) 100\% bovine anorganic bone (Bio-Oss, spongiosa granules of 0.25 to $1 \mathrm{~mm}$, Geistlich Pharma) with a Bio-Gide resorbable barrier. The cortical bone of the recipient sites was perforated to create a bleeding bone surface and to open the cancellous bone. Bone blocks from the chin were fixed with a $1.5 \mathrm{~mm}$ diameter titanium screw (Martin Medizin Technik, Tuttlingen, Germany) and particulate bone from the chin was placed around the fixed bone grafts. Implants were placed 3 months after autogenous bone grafting and 6 months after augmenting sites with Bio-Oss. Single ITI-EstheticPlus implants (Institut Straumann AG, Waldenburg, Switzerland) were placed using templates and left healing submerged for 6 months. On the day of uncovering provisional single crowns were screwed on the implants and were replaced 1 month later by final porcelain crowns with a zirconium oxide core (Procera, Nobel Biocare, Göteborg, Sweden).

\section{Different techniques for vertical bone augmentation}

\section{Is vertical augmentation procedure necessary? ( 2 trials with 100 patients)}

- One trial addressed the issue of which is the best treatment alternative to provide an overdenture to patients with a resorbed mandible, i.e. symphyseal height 6 to $12 \mathrm{~mm}$ measured on lateral radiographs (Stellingsma 2003). Three procedures were tested: (1) installation of four short implants ( 8 or 11 $\mathrm{mm}$ ) left to heal for 3 months; (2) mandibular augmentation with an autologous bone graft from the iliac crest and (3) transmandibular Bosker implants. We were only interested in the former two procedures. Mandibles were augmented under general anaesthesia using the interpositional technique. In brief, the mandible was sectioned in the interforaminal area, and a bone block taken from the anterior ilium was positioned between the two segments which were stabilized with osteosynthesis wires and left to heal for 3 months. The wires were then removed, and four 13 to $18 \mathrm{~mm}$ long implants were placed and left to heal for an additional 3 months. Patients were not allowed to wear their dentures for the entire healing period (about 6 months). The short implants used were Twin Plus IMZ implants (Friatec, Mannheim, Germany), whereas the augmented mandibles were treated with four specially designed IMZ apical screw implants. No explanation was given why two different types of implants were used. Patients were rehabilitated with overdentures supported by an egg-shaped triple bar with a Dolder-clip retention system. The bars did not have cantilever extensions.

- One trial compared the $7 \mathrm{~mm}$ short implants versus $10 \mathrm{~mm}$ or longer implants placed in atrophic posterior mandibles augmented with a bone substitute block (Bio-Oss, Geistlich Pharma, Wolhusen, Switzerland) placed according to an inlay technique (Felice 2009a). Posterior mandibles with 7 to 8 $\mathrm{mm}$ of bone height above the mandibular canal and a width of at least $5.5 \mathrm{~mm}$ as measured on CT scans were treated under local anaesthesia. In brief, after a paracrestal buccal incision, a horizontal osteotomy was made 2 to $4 \mathrm{~mm}$ above the mandibular canal. Two oblique cuts were made, the bone segment was raised sparing the lingual periosteum, and a Bio-Oss block was modelled and positioned between the two segments which were stabilized with osteosynthesis miniplates, covered with a resorbable membrane (Bio-Gide, Geistlich Pharma) and left to heal for 5 months. Patients were not allowed to wear their removable prostheses for 1 month after the augmentation procedure. Two to three implants (NanoTite, parallel walled, with external connection, Biomet 3i, Palm Beach, FL, USA) were placed $0.6 \mathrm{~mm}$ supracrestally and left to heal for 4 months in both groups. Provisional screw-retained acrylic restorations were delivered and replaced after 4 months by screw-retained metal ceramic restorations.

\section{Which is the most effective vertical augmentation technique? ( 8 trials} with 118 patients)

- Vertical guided bone regeneration (GBR) with non-resorbable titanium reinforced ePTFE barriers (Gore-Tex, WL Gore and Associates, Inc., Flagstone, USA) supported by particulate autogenous bone harvested from the mandibular ramus and when the bone was not sufficient also from the chin (two patients) versus vertical distraction osteogenesis (Chiapasco 2004). Two different vertical GBR procedures were used: six patients were treated with a one-stage approach (implants were inserted protruding 2 to $7 \mathrm{~mm}$ from the bone level and the augmentation procedure was performed on the same occasion; the abutment connection was performed after 6 to 7 months) whereas five patients were treated with a twostage approach (first the bone at site was augmented and after healing of 6 to 7 months the implants were placed and left submerged for an additional 3 to 5 months). The two-stage approach was used when the risk of insufficient primary implant stability of implants was subjectively expected. With the two-stage approach, one or two titanium miniscrews were used as additional support for the titanium reinforced barriers. All barriers were stabilized with titanium fixating pins (Frios, Friadent $\mathrm{GmbH}$, Mannheim, Germany) or miniscrews (Gebrüder Martin GmbH \& Co., Tuttlingen, Germany) or both. The distraction procedure was accomplished by using osteodistractors (Gebrüder Martin $\mathrm{GmbH} \& \mathrm{Co}$.) fixed to the bone segments with $1.5 \mathrm{~mm}$ diameter titanium screws. The distraction devices were activated after 1 week, twice a day $(0.5$ $\mathrm{mm}$ every 12 hours) until the desired amount of distraction was obtained ( 4 to $9 \mathrm{~mm}$ ). The bone segments were then left to consolidate for 2 to 3 months, the osteodistractors were then removed and dental implants placed and left submerged for 3 to 6 months. The augmentation procedures were performed under local anaesthesia, local anaesthesia with intravenous sedation and general anaesthesia according to operator and patient preferences. Surgical templates were used to optimise implant insertion. Two implant systems were used: Brånemark Mark III implants (Nobel Biocare, Göteborg, Sweden) in 19 patients and ITI SLA implants (Institut Straumann AG, Waldenburg, Switzerland) in two patients. The choice of two different implant systems was dictated by the system used by the referring dentists. All patients were rehabilitated with screw-retained metal-ceramic fixed prostheses.

- Autogenous onlay bone grafts harvested from the mandibular ramus versus vertical distraction osteogenesis (Chiapasco 2007) to vertically augment deficient mandibles. Patients were grafted 
with a two-stage approach: first bone blocks were fixed with $1.5 \mathrm{~mm}$ diameter miniscrews (Gebrüder Martin $\mathrm{GmbH}$ \& Co., Tuttlingen, Germany). Empty spaces were filled with cancellous bone chips. In case of severe vertical resorption, grafts were assembled in a multilayered fashion. No barriers were used. Bone grafts were harvested from the mandibular ramus of the same side of reconstruction in six patients, while in two patients, where larger defects were present, bone was harvested bilaterally. After 4 to 5 months, implants were placed and left submerged for an additional 3 to 4 months. The distraction procedure was accomplished by using osteodistractors (Gebrüder Martin $\mathrm{GmbH} \& \mathrm{Co}$.) fixed to the bone segments with $1.5 \mathrm{~mm}$ large titanium screws. The distraction devices were activated after 1 week, twice a day $(0.5 \mathrm{~mm}$ every 12 hours) until the desired amount of distraction was obtained ( 2 to $7 \mathrm{~mm}$ ). The bone segments were then left to consolidate for 2 to 3 months, the osteodistractors were then removed and dental implants placed and left submerged for 3 to 4 months. The augmentation procedures were performed under local anaesthesia, local anaesthesia with intravenous sedation and general anaesthesia according to operator and patient preferences. Surgical templates were used to optimise implant insertion. ITI SLA implants (Institut Straumann AG, Waldenburg, Switzerland) were used. All patients were rehabilitated with screw-retained metal-ceramic fixed prostheses.

- One-stage vertical GBR using particulate autogenous bone harvested from intraoral locations covered with non-resorbable titanium reinforced ePTFE barriers (Gore-Tex, WL Gore and Associates, Inc., Flagstone, USA), stabilized with miniscrews, versus osteosynthesis plates (Gebrüder Martin $\mathrm{GmbH} \&$ Co., Tuttlingen, Germany), appropriately adapted and fixed with miniscrews, supporting resorbable collagen barriers (BioGide $^{\circledR}$, Geistlich Pharma AG, Wolhusen, Switzerland) (Merli 2007). The augmentation procedures were performed under local anaesthesia or local anaesthesia with intravenous sedation according to operator and patient preferences. XiVe ${ }^{\circledR S}$ CELLplus (Friadent GmbH, Mannheim, Germany) implants were used. All patients were rehabilitated with provisional resin fixed prostheses replaced then by metal-ceramic definitive prostheses. One implant from each patient was used for the statistical calculations.

- Autogenous inlay bone grafts harvested from the iliac crest versus vertical distraction osteogenesis to vertically augment deficient posterior mandibles (Bianchi 2008). Patients were grafted with a two-stage approach: first a monocortical bone block was interposed between the basal bone and an osteotomised segment raised coronally without flap elevation at the lingual side to preserve blood supply and fixed with titanium miniplates and miniscrews (KLS Martin, Tuttlingen, Germany). No barriers were used. After 3 to 4 months, miniplates were removed and implants were placed and left submerged for 3 to 4 months. The distraction procedure was accomplished by using osteodistractors of various brands (Track by KLS Martin, AlMar by Cizeta, LactoSorb by Wakterl Lorenz Surgical, the latter being a resorbable device) fixed to the bone segments with various titanium or resorbable screws. The distraction devices were activated after 1 week, twice a day $(0.5$ to $1 \mathrm{~mm}$ per day for 5 to 7 days) until the desired amount of distraction was obtained (7 to $15 \mathrm{~mm}$ ). In two cases a prosthetic device was used to avoid lingual tipping. The bone segments were then left to consolidate for 3 to 4 months, the osteodistractors were removed and dental implants placed and left submerged for $3 / 4$ months. All augmentation procedures were performed under general anaesthesia. Dental implants of several brands were used (A-Z implant, Biohorizons, Biomet 3i, Friadent, Nobel Biocare). All patients were rehabilitated with partial provisional prostheses for 14 to 16 months until definitive prostheses were delivered.

- Autogenous inlay bone grafts harvested from the iliac crest versus blocks of anorganic bovine bone (Bio-Oss ${ }^{\circledR}$, Geistlich Pharma AG, Wolhusen, Switzerland) for vertically augmenting deficient posterior mandibles (Felice 2008). Patients were grafted with a two-stage approach: first a monocortical bone block was interposed between the basal bone and an osteotomised segment raised coronally without flap elevation at the lingual side to preserve blood supply and fixed with titanium miniplates and miniscrews (KLS Martin, Tuttlingen, Germany) and covered with a resorbable barrier (Bio-Gide ${ }^{\circledR}$, Geistlich Pharma AG). The contra-lateral side was treated with a similar technique but using a Bio-Oss bone block instead. The removable prostheses were allowed 1 month after the augmentation procedure. After 4 months miniplates were removed and implants were placed and left submerged for 4 months. All augmentation procedures were performed under general anaesthesia and patients remained hospitalised for 3 days. Dental implants of three different brands were used (Nanotite Biomet 3i cylindrical implants with external connection, Ankylos and XiVe Dentsply-Friadent implants). All patients were rehabilitated with fixed partial provisional acrylic prostheses for 4 months until definitive metal-ceramic fixed prostheses were delivered.

- Two-stage vertical GBR using non-resorbable titanium reinforced ePTFE barriers (Gore-Tex, WL Gore and Associates, Inc., Flagstone, USA), stabilized with miniscrews, comparing particulate autogenous bone harvested from the retromolar area with trephine drills and subsequently particulated with a bone mill versus an allograft made of malleable allogenic bone matrix (Regenaform, Regeneration Technologies, Alachua, FL, USA) (Fontana 2008). This allograft is a combination of assayed demineralized bone matrix (DFDBA) with cortico-cancellous bone chips uniformly dispersed in a thermoplastic biological carrier which became malleable when warmed between 43 to 49 degrees Celsius. The augmentation procedures were performed under local anaesthesia with sedative premedication half an hour prior to surgery. Two mini-implants were used as 'poles' to support the barrier. They were placed to protrude for the required height. One pole was a stainless steel miniscrew ( 6 to 12 mm long; Ace Dental Implant System, Brockton, MA, USA), and the other was an immediate provisional implant (IPI, SteriOss, Nobel Biocare, Göteborg, Sweden). This micro-implant (2 $\mathrm{mm}$ in diameter and $10 \mathrm{~mm}$ in length) was removed at implant installation with a $4 \mathrm{~mm}$ diameter trephine bur for histological examination. Several drill holes were made on the cortical bone to ensure bleeding. After 6 months of submerged healing, the barriers and the mini-implant were removed and Brånemark MK III (Nobel Biocare) implants with a TiUnite surface were placed. After 5 months of healing, implant stability was tested and abutments were placed.

- Ultrasound or placebo were applied using a sonic-accelerated fracture-healing system (SAFHS model 2000, Smith and Nephew, Memphis, TN, USA) by patients subjected to vertical osteodistraction osteogenesis in the anterior mandible when 
active osteodistraction was initiated after a latency period of about 5 days (Schortinghuis 2008). Ultrasound self treatment involved a daily treatment of 20 minutes for about 50 days on the skin of the chin covering the osteodistraction gap using 1.5 $\mathrm{MHz}$ pressure wave in pulses of $200 \mu \mathrm{s}$. Between pulses there was a $800 \mu$ s pause (on:off period $=1: 4$ ). Patient compliance was monitored by a memory chip inside the ultrasound equipment. Six weeks post-distraction the distraction devices were removed and two $12 \mathrm{~mm}$ long ITI Bonefit implants (Straumann AG, Waldenburg, Switzerland) were inserted and left to heal for 3 months before being loaded with an overdenture.

- Inlay versus onlay autogenous bone grafts harvested from the iliac crest to vertically augment deficient posterior mandibles (Felice 2009b). Patients were grafted with a two-stage approach: a monocortical bone block was either interposed between the basal bone and the osteotomised segment raised coronally without flap elevation at the lingual side to preserve blood supply or placed as an onlay. Grafts were fixed with titanium miniplates or miniscrews (Gebrüder Martin $\mathrm{GmbH}$ \& Co, Tuttlingen, Germany). The grafted areas were covered with resorbable barriers (Bio-Gide ${ }^{\circledast}$, Geistlich Pharma AG). All augmentation procedures were performed under general anaesthesia. Patients were instructed not to wear removable prostheses for 1 month after the augmentation procedure. After 3 to 4 months miniplates/screws were removed and two dental implants were placed and left submerged for 4 months. Dental implants of several brands were used (Biomet $3 \mathrm{i}$ and XiVe Dentsply-Friadent implants for the inlay group and Astra Tech, Biolok and Alpha Bio implants for the onlay group). All patients were rehabilitated with screw-retained acrylic partial provisional prostheses for 4 to 5 months until definitive screwretained prostheses were delivered.

\section{Characteristics of outcome measures}

- Prosthesis failure: Stellingsma 2003; Chiapasco 2004; Raghoebar 2005; Raghoebar 2006; Chiapasco 2007; Meijndert 2007; Merli 2007; Bianchi 2008; Fontana 2008; Schortinghuis 2008; Felice 2009a; Felice 2009b.

- Implant failure by individual implant stability assessment with removed prostheses (with the exception for single implants): Stellingsma 2003; Chiapasco 2004; Raghoebar 2005; Raghoebar 2006; Chiapasco 2007; Meijndert 2007; Merli 2007; Bianchi 2008; Fontana 2008; Schortinghuis 2008; Felice 2009a; Felice 2009b.

- Augmentation procedure failure: Stellingsma 2003; Chiapasco 2004; Raghoebar 2005; Raghoebar 2006; Chiapasco 2007; Meijndert 2007; Merli 2007; Bianchi 2008; Fontana 2008; Schortinghuis 2008; Felice 2009a; Felice 2009b.

- Major complications at augmented site: Stellingsma 2003; Chiapasco 2004; Raghoebar 2005; Raghoebar 2006; Chiapasco 2007; Meijndert 2007; Merli 2007; Bianchi 2008; Fontana 2008; Schortinghuis 2008; Felice 2009a; Felice 2009b.

- Major complications at bone donor site: Stellingsma 2003; Chiapasco 2004; Raghoebar 2005; Raghoebar 2006; Chiapasco 2007; Meijndert 2007; Merli 2007; Bianchi 2008; Fontana 2008; Felice 2009b.

- Patient satisfaction including aesthetics: Stellingsma 2003; Meijndert 2007. We could not use the data of one trial (Meijndert 2007) since they were not presented by study groups.

- Patient preference including aesthetics (only in split-mouth trials): Felice 2008.
- Bone gain vertically or horizontally or both expressed in $\mathrm{mm}$ or percentage including bone level changes over time: vertical bone gain was measured in $\mathrm{mm}$ by direct measurement in seven studies (Chiapasco 2004; Chiapasco 2007; Merli 2007; Bianchi 2008; Felice 2008; Fontana 2008; Felice 2009b). Perimplant marginal bone level changes were assessed in five trials (Chiapasco 2004; Chiapasco 2007; Meijndert 2007; Felice 2008; Felice 2009b), but in three trials (Chiapasco 2004; Meijndert 2007; Felice 2009b) data were presented in a way we could not use. One study included different types of implants followed at different follow-up times (Felice 2009b). The resorption pattern of the mandible after implant insertion was evaluated in one study (Stellingsma 2003) using the oblique lateral radiographic technique, but insufficient data were presented to enable us to evaluate bone height changes.

- Aesthetics assessed by dentist: one trial (Meijndert 2007). However, we could not use the data since they were not presented by study groups.

- Duration of the treatment period starting from the first intervention to the functional loading of the implants: all trials.

- Treatment costs: no trials. However, this outcome measure was indirectly extrapolated by us for all trials.

\section{Duration of follow-up}

- 4 months post-loading (Felice 2009a).

- 1 year post-loading (Meijndert 2007; Felice 2008; Fontana 2008; Felice 2009b).

- 1 year and a half post-loading (Bianchi 2008).

- 2 years post-loading (Stellingsma 2003; Raghoebar 2005; Raghoebar 2006; Schortinghuis 2008).

- 3 years post-loading (Chiapasco 2004; Chiapasco 2007; Merli 2007).

\section{Risk of bias in included studies}

The final quality scoring after having incorporated the additional information kindly provided by the authors of the trials is summarized in Additional Table 1. For each trial we assessed whether it was at low or high risk of bias. Seven studies were judged to be at low risk of bias (Chiapasco 2007; Merli 2007; Bianchi 2008; Fontana 2008; Schortinghuis 2008; Felice 2009a; Felice 2009b), and the remaining at high risk of bias.

\section{Allocation concealment}

When assessing the information presented in the articles, allocation concealment was scored adequate or 'yes' for three trials (Chiapasco 2004; Merli 2007; Felice 2009a), inadequate or 'no' for one trial (Felice 2008), and 'unclear' for all other trials. All authors replied to our request for clarification. When evaluating authors' replies, one trial scored as being adequately concealed became not concealed (Chiapasco 2004); five trials were judged to be properly concealed (Chiapasco 2007; Bianchi 2008; Fontana 2008; Schortinghuis 2008; Felice 2009b) whereas four trials remained unclear (Stellingsma 2003; Raghoebar 2005; Raghoebar 2006; Meijndert 2007).

\section{Blinding}

When assessing the information presented in the articles for the outcome measures of interest in the present review which were possible to be masked, blinding of the outcome assessor was 
scored as unclear for all trials with five exceptions (Raghoebar 2005; Meijndert 2007; Merli 2007; Schortinghuis 2008; Felice 2008). Three trials were scored as blinded (Raghoebar 2005; Meijndert 2007; Schortinghuis 2008) and two as blinded when possible (Merli 2007; Felice 2008). All authors replied to our request for clarification. When evaluating authors' replies, the outcome assessors of two trials were considered blinded (Fontana 2008; Felice 2009b), of three trials blinded when possible (Chiapasco 2007; Bianchi 2008; Felice 2009a) since complete blinding was not possible, and those of three trials as not blinded (Stellingsma 2003; Chiapasco 2004; Raghoebar 2006).

\section{Completeness of follow-up}

When assessing the information presented in the articles, information on drop outs was clearly presented in all trials, with one exception (Chiapasco 2004). All authors replied to our request for clarification and some provided additional follow-up data, including Chiapasco 2004 who confirmed that there were no withdrawals.

\section{Inclusion/exclusion criteria}

For more details see the Characteristics of included studies table.

\section{Main inclusion criteria}

- Severely resorbed maxillae (classes V-VI according to Cawood 1991) with maxillary sinuses having $<5 \mathrm{~mm}$ in height of residual alveolar bone with reduced stability and retention of upper dentures (Raghoebar 2005; Raghoebar 2006).

- Severely resorbed mandibles, i.e. symphyseal height 6 to $12 \mathrm{~mm}$ as measured on standardised lateral radiographs of patients who have been edentulous for at least 2 years and experienced severe functional problems with their lower dentures (Stellingsma 2003).

- Residual bone height over the mandibular canal of 5 to $9 \mathrm{~mm}$ (Bianchi 2008).

- Residual bone height over the mandibular canal of 5 to $7 \mathrm{~mm}$ and bone width of at least $5 \mathrm{~mm}$ (Felice 2008)

- Residual bone height over the mandibular canal of 7 to $8 \mathrm{~mm}$ and bone width of at least $5.5 \mathrm{~mm}$ (Felice 2009a).

- Residual bone height over the mandibular canal of at least 4.5 to $11 \mathrm{~mm}$ and bone width of at least $5 \mathrm{~mm}$ (Felice 2009b).

- Patients with bilateral posterior mandibular partial edentulism (Applegate-Kennedy Class I) having a defect of more than 3 $\mathrm{mm}$ considering the deepest portion of the edentulous ridge in relation to the bone adjacent the last tooth (Fontana 2008).

- Edentulous ridges requiring vertical regeneration (Chiapasco 2004; Chiapasco 2007; Merli 2007).

- Horizontal bone deficiency in a maxillary site (incisor, cuspid or first bicuspid) requiring a single implant (Meijndert 2007).

\section{Main exclusion criteria}

- Smoking more than 20 cigarettes per day (Merli 2007).

- Smoking more than 15 cigarettes per day (Chiapasco 2004; Chiapasco 2007; Bianchi 2008; Felice 2008).

- Smoking more than 10 cigarettes per day (Fontana 2008).

- Smokers (Meijndert 2007).

- Intravenous bisphosphonate (Felice 2008; Felice 2009a; Felice 2009b).
- Severe knife-edge ridges (Chiapasco 2004; Chiapasco 2007; Bianchi 2008).

- History of reconstructive, pre-prosthetic surgery or previous oral implantology (Raghoebar 2005; Raghoebar 2006; Meijndert 2007; Felice 2008; Felice 2009b).

- Edentulous period less than 3 months (Fontana 2008; Felice 2009a).

- Edentulous period less than 1 year (Raghoebar 2005; Raghoebar 2006).

- Mucosal disease, such as lichen planus, in the areas to be treated (Chiapasco 2004; Chiapasco 2007; Bianchi 2008; Felice 2008; Felice 2009b).

\section{Sample size}

A priori calculation for the sample size was undertaken in three trials (Merli 2007; Felice 2008; Felice 2009a). The calculation of one trial (Merli 2007) was based on the complications that occurred in another similar RCT (Friedmann 2002). Twenty-one patients were needed in each group to detect a difference between a proportion of complications from 0.27 to 0.80 . However, the trial included only 11 patients per group, therefore the sample size requirement was not fulfilled. In one trial of split-mouth design (Felice 2008), the sample size was calculated to detect patient preference of one procedure over the other against the alternative hypothesis that treatments were equally preferred. This reduced to a simple one sample proportion scenario. A one-group $\mathrm{Chi}^{2}$ test with a 0.050 two-sided significance level had $80 \%$ power to detect the difference between the null hypothesis proportion of 0.500 and the alternative proportion of 0.900 when the sample size is 10 . The sample size was achieved. The calculations for another trial (Felice 2009a) were based on implant failures. A two-group continuity corrected $\mathrm{Chi}^{2}$ test with a 0.050 two-sided significance level had $80 \%$ power to detect the difference between a proportion of 0.100 and a proportion of 0.300 for patients experiencing at least one implant failure (odds ratio of 3.857) when the sample size in each group was 72 . However, only 30 patients were recruited in each group and the size requirement was not fulfilled.

\section{Baseline comparability between treatment groups}

- No apparent major baseline differences (Stellingsma 2003; Chiapasco 2004; Raghoebar 2005; Raghoebar 2006; Meijndert 2007; Merli 2007; Felice 2008; Fontana 2008; Schortinghuis 2008; Felice 2009a; Felice 2009b).

- Unclear whether major baseline differences existed (Chiapasco 2007).

- The following major baseline differences existed: more bone (1.1 $\mathrm{mm}$ ) above the mandibular canal in the inlay group (Bianchi 2008).

\section{Effects of interventions}

\section{Different techniques for horizontal bone augmentation}

Is the augmentation procedure necessary? (no trial)

\section{Which is the most effective augmentation technique? (3 trials with 106 patients)}

- One trial compared two techniques for augmenting resorbed maxillae including atrophic maxillary sinuses (Raghoebar 2005) (data not shown). Only patients with less than $5 \mathrm{~mm}$ of alveolar bone height in the sinus floor were included. Five patients 
were treated with a split-mouth approach with two-stage sinus lift with autogenous bone together with buccal onlay grafts, harvested from the iliac crest, one side with platelet rich plasma (PRP) and the other without. All patients were followed for 2 years after implant loading and there were no drop outs. No serious complications occurred at the grafted sites: one sinus membrane was perforated during surgery but healing was uneventful. A small incision breakdown occurred in the first week at the non-PRP side of one patient. A seroma which healed uneventfully was the only complication that occurred at the donor sites. During the prosthetic phase one implant failed in the PRP side, but no prosthesis failed. There was no statistically significant difference for any of the outcomes considered in this review. The difference in cost and treatment time was the use of PRP. Prostheses were inserted about 10 months after augmentation. The trial was judged to be at high risk of bias.

- One split-mouth trial compared two titanium versus two resorbable screws for fixating two-stage buccal onlay grafts, harvested from the iliac crest, to resorbed maxillae (Raghoebar 2006) (data not shown). Eight patients were followed for 2 years after implant loading and there were no drop outs. No serious complications occurred at the grafted and donor sites. Two resorbable screws broke at insertion (one because of incorrect handling), but they could be removed and replaced. A small incision breakdown occurred in the first week at the titanium screw side of one patient. Another patient developed a slight submucosal swelling with redness of the mucosa above a resorbable screw 3 months after the augmentation procedure, that disappeared after implant placement. No prosthesis or implant failed. There was no statistically significant difference for any of the outcomes considered in this review. The difference in cost and treatment time was the use of different screws. Prostheses were inserted about 10 months after augmentation. The trial was judged to be at high risk of bias.

- One trial compared three two-stage techniques to horizontally augment bone at maxillary sites (incisor, cuspid or first bicuspid) to allow placement of single implants (Meijndert 2007). Thirtyone patients were included in each group and were followed up to 1 year after loading. The following procedures were tested: (1) autogenous bone block from the chin; (2) autogenous bone block from the chin plus a resorbable barrier; (3) $100 \%$ Bio-Oss plus a resorbable barrier. No patients dropped out. Not a single complication occurred. Two single implants failed early in the group treated with Bio-Oss plus resorbable barrier, though this difference was not statistically significant (Analysis 2.1; Analysis 2.2). Many other outcome measures (perimplant bone level changes, patient satisfaction, aesthetics judged by patients and by an independent dentist) could not be used in the present review because data were aggregated and not presented by study groups. With respect to cost and treatment time, the additional costs for the barriers, and Bio-Oss should be considered. Patients had to wait 9 months (bone block groups) or 1 year (Bio-Oss plus barrier group) to be rehabilitated. The trial was judged to be at high risk of bias.

\section{Different techniques for vertical bone augmentation}

\section{Is the augmentation procedure necessary? (2 trials with 100 patients)}

- One trial (Stellingsma 2003) evaluated the need to augment anterior atrophic mandibles (residual bone height between 6 to $12 \mathrm{~mm}$ ) up to 2 years after loading (Analysis 1.1). Twenty patients received four short implants ( 8 to $11 \mathrm{~mm}$ ), whereas 20 patients received interposed iliac bone grafts and four longer implants ( 13 to $18 \mathrm{~mm}$ ) to support overdentures. Two patients dropped out, one from each group about 3 months after overdenture delivery due to death and moving. In the short implant group two complications occurred: bleeding during surgery and permanent unilateral hypoaesthesia, and no early implant failure. In the augmented group six complications occurred: one life threatening complication (post-operative sublingual edema which left the patient in intensive care for 3 days); two wound dehiscences; two unilateral dysaesthesiae, one of which completely recovered; and one necrosis of the osteotomised cranial fragment of the mandibles. In the augmented group four patients lost one implant each and a fifth patient lost all implants (possibly for necrosis of the osteotomised cranial fragment of the mandible and had to be re-treated), before or at abutment connection. Although the RevMan $\mathrm{P}$ value for the odds ratio (OR) was not statistically significant $(P=0.08)$, Fisher's exact test (two-sided) found a significant difference $(P=0.048)$, with higher implant failure in the augmented mandibles, confirming the findings of the original article. Statistically significant differences were also found at 3 weeks after the first surgical intervention: (1) $85 \%$ of the patients in the augmentation group reported serious pain for more than 1 week versus $20 \%$ of the patients in the short implant group (OR 22.7; 95\% confidence interval (CI) 4.4 to 117.5 ); (2) $30 \%$ of the patients in the augmentation group reported no improvement in their facial appearance versus $80 \%$ of the patients in the short implant group (in this group, 70\% reported no change, and $10 \%$ reported a deterioration of their facial appearance) (OR $0.11 ; 95 \% \mathrm{Cl} 0.03$ to 0.46). The article also reported a statistically significant difference with $50 \%$ of the patients in the augmentation group experienced the operation more negatively than expected versus $25 \%$ of the patients in the short implant group, however we did not find this difference significant. With respect to prosthetic aftercare: four unplanned interventions were required in the short implant group versus 10 interventions in the graft group. Numerous aspects of patient satisfaction including aesthetics were investigated using validated questionnaires at 1 year and no statistically significant differences among groups were found. With respect to cost and treatment time, while short implants were placed under local anaesthesia, the graft procedures required general anaesthesia, a mean of 5.9 days of hospitalisation (range 3 to 9; standard deviation (SD) 1.3), and the double healing time (about 3 additional months) and patients could not wear the lower denture for 6 months. The trial was judged to be at high risk of bias.

- One trial (Felice 2009a) evaluated the need to augment posterior atrophic mandibles (residual bone height above the mandibular canal between 7 to $8 \mathrm{~mm}$ and width of at least $5.5 \mathrm{~mm}$ ) up to 4 months after loading (Analysis 1.1). Thirty patients received 2 to $37 \mathrm{~mm}$ short implants and 30 patients received an interposed anorganic bovine bone block (Bio-Oss) and, after 5 months of healing, 2 to 310 to $15 \mathrm{~mm}$ long implants to support fixed partial restorations. No patient dropped out. No complications occurred in the short implant group versus four complications (wound dehiscences/infections) in the augmented group: three of these dehiscences persisted until implant placement and in two patients partial loss of the bone graft occurred. Two augmentation procedures were considered a complete failure

Interventions for replacing missing teeth: horizontal and vertical bone augmentation techniques for dental implant treatment (Review) $\mathbf{1 1}$

Copyright $\odot 2019$ The Cochrane Collaboration. Published by John Wiley \& Sons, Ltd. 
because the planned augmentation was not obtained and 7 $\mathrm{mm}$ short implants had to be used instead of the planned 10 $\mathrm{mm}$ or longer implants. These graft failures were associated with the fracture of the Bio-Oss blocks at the augmentation procedure. In the augmented group three patients lost one implant each versus one patient in the short implant group and the related prostheses could not be placed when planned, however all failed implants were successfully replaced and loaded. No statistically significant differences between groups were observed. With respect to cost and treatment time, short implants were loaded about 4 months after initiation of the treatment whereas longer implants placed in augmented bone about 9 months after treatment start. The cost of one additional surgical intervention and of the Bio-Oss block for patients treated with the augmentation procedure should also be considered. The trial was judged to be at low risk of bias.

The meta-analysis of these two trials (Stellingsma 2003; Felice 2009a) resulted in more implant failures OR $=5.74(95 \% \mathrm{Cl} 0.92$ to 35.82 ; borderline significance, $\mathrm{P}=0.06$ ) and statistically more complications OR $=4.97(95 \% \mathrm{Cl} 1.10$ to 22.40$)$ in the vertically augmented group.

\section{Which is the most effective augmentation technique? (8 trials with 118 patients)}

- One trial compared distraction osteogenesis in 11 patients versus guided bone regeneration (GBR) with non-resorbable barriers and particulate autogenous bone grafts taken from the mandibular ramus (if not sufficient also from the chin) in 10 patients for vertically augmenting edentulous ridges for 3 years after loading (Chiapasco 2004). No patient dropped out. Two complications occurred in two patients of the osteodistraction group: the bone fragment inclined lingually during the distraction phase probably due to the traction on the osteotomized segment by muscle forces of the floor of the mouth. The complications were successfully treated by applying an orthodontic traction until the bone segment consolidated in the desired position. Five complications occurred in four patients of the GBR group: three barrier exposures occurred, one of which was associated with an infection, and two transient paraesthesiae of the chin area lasting 1 and 4 weeks. Both paraesthesiae were associated with the only two procedures for harvesting bone from the chin. All procedures for harvesting bone from the ramus were complication free. There was no statistically significant difference for complications between the two procedures (Analysis 3.5). No implants or prostheses failed over the 3-year follow-up period. The mean bone gain after the augmentation procedure was reported for both groups, however without explaining how it was recorded or which were the reference points. Also data on perimplant bone loss were unclear and could not be used. With respect to cost and treatment time, in the GBR group it should be considered the cost of the barriers and the fixing pins, versus the cost of the intraoral distractor and related orthodontic therapy when needed. In the osteodistraction group, the time occurring for exposing the implants ranged between 6 and a half months (mandibles) to 9 and a half months (maxillae) and patients were not allowed to use prostheses for about 3 and a half months. In the GBR group, the time occurring for exposing the implants ranged between 6 to 7 months, when implants were placed simultaneously with the GBR procedure, and 9 to 12 months, when implants were placed after the ridge had been vertically augmented. Patients were left without removable prostheses for 6 to 7 months. The trial was judged to be at high risk of bias.

- One trial compared distraction osteogenesis in nine patients versus autogenous onlay bone grafts taken from the mandibular ramus in eight patients for vertically augmenting mandibular edentulous ridges for 3 years after loading (Chiapasco 2007). No patient dropped out. Three complications occurred in three patients of the osteodistraction group: the bone fragment inclined lingually during the distraction phase probably due to the traction on the osteotomised segment by muscle forces of the floor of the mouth. The complications were successfully treated by applying an orthodontic traction until the bone segment consolidated in the desired position. In the third patient, distraction was interrupted before completion, because of the impossibility to move further the distracted segment. This was probably caused by an incorrect design of the vertical osteotomic lines. Shorter implants $(6 \mathrm{~mm}$ instead of the planned $8 \mathrm{~mm}$ ) could be placed anyway. Four complications occurred in four patients of the bone graft group: three paraesthesiae of the alveolar inferior nerve, two transient but one permanent. In the last patient the graft became exposed and was partially lost. The treatment could be completed anyway using short implants. There was no statistically significant difference for complications between the two groups (Analysis 3.3). No implants or prostheses failed over the 3-year follow-up period. The mean bone gain after the augmentation procedure was $5.3 \pm 1.58 \mathrm{~mm}$ for the osteodistracted sites and $5.0 \pm 1.07 \mathrm{~mm}$ for the grafted sites. No statistically significant differences were observed regarding marginal perimplant bone loss between groups at 1 and 3 years (Analysis 3.4). Three years after loading, implants in osteodistracted sites lost on average $0.9 \mathrm{~mm}$ of perimplant bone versus $1.3 \mathrm{~mm}$ in grafted sites. With respect to cost and treatment time, in the bone graft group it should be considered only the cost of the fixing pins, versus the cost of the intraoral distractor and related orthodontic therapy when needed, making bone grafting cheaper. In the bone graft group, the time occurring for exposing the implants ranged between $8 / 9$ months. Patients were left without removable prostheses for at least 2 months. In the osteodistraction group, the time occurring to expose implants was $7 / 8$ months and patients were not allowed to use prostheses for about 3 months. The trial was judged to be at low risk of bias.

- One trial, compared one-stage particulate autogenous bone grafts from intraoral locations in 11 patients treated with non-resorbable titanium reinforced barriers versus 11 patients treated with resorbable barriers supported by osteosynthesis plates (Merli 2007). One implant per patient was used for the statistical calculations. No patient dropped out. Four complications occurred in the resorbable group: two abscesses which determined the failure of the grafting procedures, and two minor complications not affecting the outcome of the therapy (barrier exposure without signs of infection, and a swelling suggesting an early infection successfully treated with antibiotics). Five complications occurred in the non-resorbable group: one infection which determined the failure of the graft and three fistulas in three patients. The last complication was lymph nodes swelling 1 month after intervention suggesting an infection which was treated with systemic antibiotics. No study implant failed and all planned prostheses could be delivered. Both treatments resulted in statistically significant vertical bone gain (2.2 $\mathrm{mm}$ for the resorbable group and $2.5 \mathrm{~mm}$ for 
the non-resorbable group), however no statistically significant differences were found among the two procedures (Analysis 3.8). Three years after loading, both groups lost perimplant bone in a statistically significant way (about $0.5 \mathrm{~mm}$ ) and there was no difference in bone loss between groups (Analysis 3.8). With respect to cost and treatment time, for the resorbable group it should be considered the cost of one or two barriers, the osteosynthesis plates and related fixating pins, versus the cost of a titanium-reinforced barrier and related pins in the nonresorbable group, which could be slightly cheaper. The healing time for both groups was about 4 and a half months; slightly less than originally planned (5 months), due to premature removal of some infected barriers. The trial was judged to be at low risk of bias.

- One trial compared distraction osteogenesis in five patients versus autogenous inlay bone grafts taken from the iliac crest in six patients for vertically augmenting mandibular edentulous ridges of 5 to $9 \mathrm{~mm}$ height above the mandibular canal for at least 1 year and a half after loading (Bianchi 2008). No patient dropped out. Three complications occurred in the distraction group and one in the inlay group. In the distraction group, two patients developed progressive lingual inclination of the distraction segments possibly due to traction by the muscles of the floor of the mouth. Orthodontic traction was applied to avoid consolidation of the distracted segments in an unfavourable position. One patient developed a minor infection at implant insertion time resolved with local debridement. There were no statistically significant differences for complications between groups (Analysis 3.1). In the inlay group recovery of the donor sites was uneventful in all cases with no complications. One patient developed a post-augmentation dehiscence of the distal fixation screw, infection and partial resorption of the cranial segment. This was resolved with local debridement. Those complications did not jeopardize the success of the augmentation procedures. No study implant failed and all planned prostheses could be delivered. Both treatments resulted in vertical bone gain $(8.4 \mathrm{~mm}$ for the distraction group and $5.1 \mathrm{~mm}$ for the inlay group), with osteodistraction gaining statistically more bone (Analysis 3.2). With respect to costs, for the distraction group it should be considered the cost of the distractor device, versus the cost of the osteosynthesis plates in the inlay group, which could be slightly cheaper. The time needed to achieve the desired outcome was similar.The trial was judged to be at low risk of bias.

- One split-mouth trial compared autogenous bone blocks taken from the iliac crest versus anorganic bovine bone blocks used as inlays in 10 patients for vertically augmenting posterior mandibular edentulous ridges of 5 to $7 \mathrm{~mm}$ height above the mandibular canal for 1 year after loading (Felice 2008). No patient dropped out. Three complications occurred in three patients: two infections at the sites grafted with autogenous bone, one determining the complete failure of the graft and the other a partial loss of the graft versus a minor soft tissue dehiscence at a Bio-Oss treated site. Because of the complete failures of one autogenous bone graft, the two planned implants and their prostheses could not be placed. One implant failed in the Bio-Oss group 11 weeks after loading. It was successfully replaced and a new prosthesis was made. There were not statistically significant failures for prosthesis and implant failures as well as complications (Analysis 3.10). Both treatments resulted in vertical bone gain $(6.2 \mathrm{~mm}$ for the bone substitute group and $5.1 \mathrm{~mm}$ for the autogenous bone group), and the difference of $1.1 \mathrm{~mm}$ was not statistically significant (Analysis 3.9). One year after loading, both groups lost statistically significant perimplant marginal bone $(0.82 \mathrm{~mm}$ the autogenous bone group and $0.59 \mathrm{~mm}$ the Bio-Oss group) but the $0.21 \mathrm{~mm}$ of difference between the two groups was not statistically significant. When asked for their preference, 1 month after delivery of the definitive prostheses, 8 out of 10 patients preferred the bone substitute versus two patients who had no preference since both interventions were fine for them. This difference was statistically significant (data not shown in RevMan graph, $\mathrm{OR}=0.03,95 \% \mathrm{Cl} 0.00$ to $0.64, \mathrm{P}=0.02$ ). With respect to costs, it should be considered the cost of the bone substitutes versus the need for an additional operation to retrieve autogenous bone for the iliac crest which has to be conducted in general anaesthesia. The time needed to achieve the desired outcome was similar.The trial was judged to be at high risk of bias.

- One split-mouth trial evaluated vertical GBR with titanium reinforced barriers supported by two 'poles' comparing particulate autogenous bone harvested from the retromolar area with a thermoplastic allogenic bone substitute (Regenaform) in five patients for vertically augmenting posterior mandibular edentulous ridges up to 1 year after loading (Fontana 2008). No patient dropped out. Two complications occurred in one patient one at each of treated site. The side treated with autogenous bone showed an infection without barrier exposure 2 months after augmentation. The barrier and the small tissue portion affected by the infection were removed. On the contra-lateral side a buccal bone dehiscence developed around one of the implants. It was treated with autogenous bone and a resorbable barrier. Those complications did not jeopardize the success of the augmentation procedures. No study implant failed and all planned prostheses could be delivered. Both treatments resulted in vertical bone gain $(4.7 \mathrm{~mm}$ for the bone substitute group and $4.1 \mathrm{~mm}$ for the autogenous bone group), and the difference of $0.6 \mathrm{~mm}$ was statistically significant (Analysis 3.6). With respect to costs, it should be considered the cost of the bone substitutes versus the need for an additional flap operation to retrieve autogenous bone. The time needed to achieve the desired outcome was similar.The trial was judged to be at low risk of bias.

- One trial evaluated the effect of ultrasounds on vertical distraction osteogenesis in anterior atrophic mandibles (Schortinghuis 2008). Five patients were treated with ultrasounds and four patients with a placebo. The ultrasounds or placebo were delivered at the start of the active osteodistraction phase for about 45 days. No patient dropped out. No complication occurred, no implant failed and all planned prostheses could be delivered and followed for 2 years after loading. The distraction distance obtained was $4.6 \mathrm{~mm}$ for the ultrasound group and $5.8 \mathrm{~mm}$ for the placebo group. The difference of $1.2 \mathrm{~mm}$ was not statistically significant but clearly in favour of the placebo group (data not shown). With respect to costs, it should be considered the cost of the ultrasound equipment. The time needed to achieve the desired outcome was similar, though patients had to spend about 20 minutes per day for about 45 days to deliver the treatment. The trial was judged to be at low risk of bias.

- One trial evaluated inlays (in 10 patients) versus onlays (in 13 patients) of autogenous bone grafts harvested from the 
iliac crest to vertically augment deficient posterior mandibles of 4.5 to $10 \mathrm{~mm}$ height above the mandibular canal for 1 year after loading (Felice 2009b). The number of patients in each group was unbalanced because toss of a coin was used to randomise patients. No patient dropped out. Four complications occurred in four patients of the inlay group (three dehiscences/infections with partial exposure of the miniplates, one determining the failure of the augmentation procedure; and one perimplantitis) versus six complications in five patients from the onlay group (three dehiscences/infections with partial exposure of the miniplates, one determining the failure of the augmentation procedure; two altered chin/lip sensations, one lasting 6 months and one permanent; and one perimplantitis in the same patient who had paraesthesia for 6 months) (Analysis 3.11). No implant failed. Both treatments resulted in vertical bone gain $(3.5 \mathrm{~mm}$ for the onlay group and $4.5 \mathrm{~mm}$ for the inlay group), and the difference between the two procedures of $1 \mathrm{~mm}$ was not statistically significant (Analysis 3.12) but was very close to significance $(P=0.07)$. There were no differences in costs and treatment time. The trial was judged to be at low risk of bias.

\section{DISCUSSION}

This review was originally conceived as having a broad focus and was aimed to include any randomised controlled trial (RCT) dealing with any aspect of bone augmentation in relation to dental implant rehabilitation. In the present update we decided to split the original review into three more focused reviews: the present one dealing with horizontal and vertical bone augmentation procedures, one dealing with procedures to augment the maxillary sinus, and a third one dealing with minor augmentation procedures at extraction sockets, immediate implants and implants with bone fenestration. We are fully aware that there are limitations in this classification, as in many classifications, since the exact borders among the different categories may not always be clearly identified. Trials reporting histological outcomes only or which did not report any implantrelated outcomes were not considered of interest since they would not be able to provide reliable clinical information for the prognosis of dental implant rehabilitation.

Sample size calculations were undertaken only in three trials (Merli 2007; Felice 2008; Felice 2009a). However, the planned sample sizes could only be achieved in one trial (Felice 2008). Sample sizes of all studies were relatively small. It is therefore likely that many of these studies were underpowered to demonstrate any significant difference in outcome measures between groups. Nevertheless some of the included trials did provide limited but indeed useful clinical information and indications which should be carefully evaluated by clinicians when deciding whether to perform an augmentation procedure or not, or which augmentation procedure to select. We have spent a great deal of time contacting RCTs' authors, who have kindly provided useful unpublished information on their trials. We feel that these contacts have made the present review more complete and useful for the readers. It is also worth observing that all authors of the included trials replied to our requests for clarifications. It is unusual to have such a high response rate. This might be partly explained by the serious research interests of the investigators conducting RCTs in the area, and may be indicative of a growing consciousness that high quality systematic reviews can be of great benefit to the entire society. We also noticed a considerable increase in the number of RCTs published over the last few years. This should be viewed positively since it may indicate that in the near future some currently unanswered clinical questions might finally get an evidencebased answer, going over the traditional 'opinion-biased' approach to clinical decision-making. The priority now is to concentrate research efforts on a few important clinical questions, increasing the sample size, and decreasing the number of treatment variables in the trials. This might be obtained through collaborative efforts among various research groups.

We tried to evaluate firstly whether a certain augmentation procedure is necessary, and secondly which could be the most effective augmentation techniques. This distinction is relevant since it is possible that many complicated, painful and even potentially dangerous procedures that are widely performed today, have no evidence-based justification and do not improve the prognosis or the patients' quality of life.

No trial evaluated whether and when horizontal bone augmentation is necessary, but two trials (Stellingsma 2003; Felice 2009a) evaluated whether vertical bone augmentation procedures are needed or whether shorter implants could be used instead. One trial (Stellingsma 2003) investigated whether it was better to use iliac crest bone for inlay augmentation procedures to allow the placement of 13 to $18 \mathrm{~mm}$ long implants rather than placing 8 to $11 \mathrm{~mm}$ long implants without augmentation to treat atrophic anterior mandibles with a residual bone height of 6 to $12 \mathrm{~mm}$. The other trial (Felice 2009a) compared an inlay augmentation technique with Bio-Oss blocks, to allow the placement of at least 10 $\mathrm{mm}$ long implants, with $7 \mathrm{~mm}$ long implants for treating posterior mandibles with a residual bone height above the mandibular canal of 7 to $8 \mathrm{~mm}$. The meta-analysis of these two trials showed that vertical augmentation was associated with more implant failures (borderline significance) and complications (statistically significant) than short implants. Caution should be exercised when extrapolating these results since in one trial (Stellingsma 2003) $11 \mathrm{~mm}$ implants were used, which are not considered to be short, and the other trial (Felice 2009a) had a follow-up of only 4 months after loading. Nevertheless, when considering resorbed mandibles, inlay augmentation techniques to allow the placement of longer implants may not be the optimal treatment choice. It is therefore useful to underline that when evaluating the only two properly designed trials to test whether augmentation procedures are needed (Stellingsma 2003; Felice 2009a), the augmentation procedures resulted in more serious complications (including a life threatening sublingual edema), major discomfort and pain, significant more costs for society, longer treatment time, and clinically poorer outcomes. These examples clearly illustrate that a more critical approach should be taken when evaluating the need for vertical bone augmentation procedures for dental implants.

When evaluating which are the most effective augmentation techniques for horizontal ridge augmentation for single implants, only one trial was designed in a way to provide clinical useful information (Meijndert 2007). This trial, which had the largest sample size included in this review, compared three different two-stage techniques to horizontally augment bone to allow placement of single implants (Meijndert 2007). Thirty-one patients were included in each group and aesthetic outcomes were assessed both by the patients and a blinded experienced evaluator. Unfortunately most of the data were presented aggregated and not by study group, meaning that it was not possible to use them to compare advantages or disadvantages of the individual 
techniques. For 62 patients a block of bone was retrieved from the chin, whereas in 31 patients the defects were reconstructed with $100 \%$ bone substitute (Bio-Oss) and a resorbable barrier. Despite these relatively high numbers, the authors confirmed to us that not a single complication occurred. These are remarkable results not confirmed by other trials included in the present review. Only two implants failed early in the bone substitute group, although they were successfully replaced. The healing period used for the bone substitute group was 3 months longer, but on the other hand no autogenous bone was needed to complete the procedure. At present it is still difficult to recommend which should be the procedure to be used and additional information is needed to confirm these results. The other two trials evaluating aspects for horizontal bone augmentation (Raghoebar 2005; Raghoebar 2006) had too small sample sizes to provide any reliable evidence. In fact, only five patients treated with a split-mouth design were recruited to evaluate the clinical efficacy, if any, of platelet rich plasma (PRP) (Raghoebar 2005). When comparing titanium versus resorbable screws for holding buccal onlay autogenous grafts, despite no significant differences being observed (Raghoebar 2006), although the sample size of eight patients was too small to be able to detect any difference, the observation that two resorbable screws broke at insertion and that a considerable amount of remnants of the resorbable screws were still visible after 9 months and were surrounded by fibrotic tissue rich in giant cells may suggest that titanium screws are still the best choice.

When evaluating which are the most effective augmentation techniques for vertical ridge augmentation eight trials were included (Chiapasco 2004; Chiapasco 2007; Merli 2007; Bianchi 2008; Fontana 2008; Felice 2008; Schortinghuis 2008; Felice 2009b). Osteodistraction osteogenesis, various GBR techniques, autogenous onlay block grafting, and inlay grafting with both autogenous bone and bone substitutes can be successful for augmenting bone vertically, however, there is insufficient evidence to suggest if one technique is preferable. The osteodistraction technique may not be used in all circumstances (for instance in the presence of thin knife-edge bone), it is more expensive than GBR and bone grafting, but may reduce treatment time and allow for more vertical ridge augmentation, if needed. On the other hand, GBR and onlay bone grafting techniques also allow for simultaneous bone widening, if needed. All the vertical augmentation techniques evaluated were associated with high complication rates ranging from $60 \%$ (Bianchi 2008) to 20\% (Felice 2008) with only one study on osteodistraction osteogenesis that reported no complications (Schortinghuis 2008). However, in few cases (10\% in Felice 2008 and $15 \%$ in Merli 2007) the vertical augmentation procedure failed. It is therefore recommended that both clinicians and patients carefully evaluate the pros and cons in relation to the desired outcome before deciding whether to use vertical ridge augmentation techniques. Results from some of these trials (Chiapasco 2007; Merli 2007) also suggested that the vertically augmented bone can be successfully maintained up to 3 years after loading with just a minimal bone loss in the range of 0.5 to $1 \mathrm{~mm}$.

One study evaluated the efficacy of ultrasounds to stimulate osteogenesis at vertically distracted mandibular bone (Schortinghuis 2008). Ultrasounds are used to stimulate healing in bone fractures especially in delayed healing and non-union fractures. The results of this pilot study suggested that ultrasounds had no positive effects on bone healing. When looking at the data it can be observed that ultrasound treated sites were distracted for
$4.6 \mathrm{~mm}$ and placebo sites for $5.8 \mathrm{~mm}$. The difference among the two procedures in amount of distracted bone $(1.2 \mathrm{~mm})$ was not statistically significant but it was clearly in favour of the placebo group. Ultrasounds were applied when the active osteodistraction phase was initiated. A possible interpretation of the results is that ultrasounds were effective in stimulating bone healing and this could explain why the placebo group gained more bone. It is possible that ultrasounds were delivered at the wrong time (the active osteodistraction phase) and stimulated bone healing reducing the osteodistraction potential. The results of this study remain difficult to interpret, but it is possible that ultrasounds should be delivered when the active osteodistraction phase is completed.

Autogenous bone is often considered the 'gold standard' material for bone augmentation. Three trials compared autogenous bone with bone substitutes (Meijndert 2007; Felice 2008; Fontana 2008) and curiously the indications that these trials gave were not consistently in favour of autogenous bone. When augmenting bone horizontally to allow the placement of single implants, a bone substitute (Bio-Oss) could be successfully used (Meijndert 2007). Implants placed in bone augmented with Bio-Oss showed trends to increased failure rates, though all failed implants could be successfully replaced without the need for additional augmentation. Another disadvantage with Bio-Oss was that the healing time was increased by 3 months. On the other hand, no autogenous bone had to be collected from the chin, meaning also a less invasive operation. Therefore, additional information is needed to establish which could be the most cost-effective procedure. A split-mouth pilot study evaluated whether anorganic bovine bone blocks (Bio-Oss) could replace autogenous bone harvested from the iliac crest for vertically augmenting atrophic posterior mandibles with an inlay technique (Felice 2008). Though no statistical differences for clinical outcomes could be found, 8 out of 10 patients preferred the augmentation procedure with the bone substitute and this was statistically significant. In addition, general anaesthesia is not needed when using blocks of bone substitute to augment atrophic posterior mandibles. Finally, another split-mouth pilot study, including only five patients, compared a malleable bone substitute (Regenaform) with particulate autogenous bone for vertical GBR at posterior mandibles (Fontana 2008). Significantly more bone $(0.6 \mathrm{~mm})$ was vertically augmented at the sites treated with the bone substitute. While a $0.6 \mathrm{~mm}$ of additional vertical bone gain may not have a significant clinical impact, it is also true that the bone substitute behaved similarly, if not better, than autogenous bone.

With respect to generalization of the results of the present review to general practice, many of the augmentation procedures evaluated were rather complex, were performed by experienced and skilful clinicians, patients were undergoing strict post-operative control regimens, complications were common, and in few instances serious. Caution is therefore recommended when deciding to use any augmentation procedure. The first clinical question that clinicians should ask themselves is which could be the added benefits for the patient by applying such procedures. Then the expected benefits need to be carefully weighted against the risk of complications of the chosen procedure. 


\section{AUTHORS' CONCLUSIONS}

\section{Implications for practice}

These conclusions are based on few trials with small or very small sample sizes, relatively short follow-ups, and being sometimes judged to be at high risk of bias, therefore they should be viewed with great caution.

- Two trials investigated whether vertical augmentation procedures are necessary to allow placement of longer implants when compared to simple placement of short implants.

Vertical augmentation of resorbed mandibles with inlay techniques resulted in more implant failures (statistically borderline significance), complications (statistically significant), pain, days of hospitalisation, costs, and longer treatment time than using short implants, therefore the current available scientific evidence does not justify these procedures for placing longer implants in resorbed mandibles. However, the long-term prognosis of shorter implants is yet unknown.

- Three trials investigated which are the most effective techniques for horizontal bone augmentation.

(1) Various augmentation techniques are able to regenerate bone in a horizontal direction, however, there is insufficient evidence to indicate which technique could be preferable. It appears that a bone substitute (Bio-Oss) can be used with a slightly higher risk (not statistically significant) of having an implant failure.

(2) There is insufficient evidence supporting or confuting the efficacy of various active agents such as platelet rich plasma in conjunction with implant treatment.

(3) Titanium screws might be preferable to resorbable poly (D, Llactide) acid screws to fix onlay bone blocks.

- Eight trials investigated which are the most effective techniques for vertical bone augmentation.

(1) Various augmentation techniques are able to augment bone in a vertical direction, however, there is insufficient evidence to indicate which could be the preferable technique.

(2) Bone substitutes, such as Bio-Oss blocks, may be a valid, cheaper alternative to autogenous bone particularly when harvested from extra-oral locations since they are associated to less postoperative morbidity.

(3) Osteodistraction allows for more vertical augmentation but it is of little use in the presence of thin ridges.

(4) Complications were common, and in some cases determined the failure of the augmentation procedure.

(5) Clinicians and patients should carefully evaluate the benefits and risks in relation to the desired outcome when deciding whether to use vertical ridge augmentation techniques.

\section{Implications for research}

In order to understand when bone augmentation procedures are needed and which are the most effective techniques, larger and well designed trials are needed. Such trials should be reported according to the Consolidated Standards of Reporting Trials (CONSORT) guidelines (Moher 2001) (www.consortstatement.org/). It is difficult to provide clear indications with respect of which augmentation procedures should be tested first, however, once established in which clinical situations augmentation procedures are actually needed, priority could be given to those interventions which look simpler, less invasive, involve less risk of complications, and reach their goals within the shortest timeframe. Indications for using various bone substitutes should be explored in more detail and it should be evaluated which donor sites could provide the sufficient amount of bone with less risk of complications and patient discomfort. Patient-centred outcomes should also be considered when designing such trials.

\section{ACKNOWLEDGEMENTS}

We wish to thank Sylvia Bickley and Anne Littlewood (Cochrane Oral Health Group) for their assistance with literature searching; Luisa Fernandez Mauleffinch and Philip Riley (Cochrane Oral Health Group) for their help with the preparation of this review; Stella Kwan who co-authored a previous version of this review; Matteo Chiapasco, Filippo Fontana, Giuseppe Lizio, Gerry Raghoebar, Jurjen Schortinghuis and Kees Stellingsma for kindly providing us with additional information on their trials. We would also like to thank the following referees: Stephen Chen, Matteo Chiapasco, Christer Dahlin, Filippo Fontana, Mats Hallman, Jayne Harrison, Jan Hirsch, Anne Littlewood, David Moles, Ian Needleman, Michele Nieri, Gerry Raghoebar and Bill Shaw. 


\section{RE F E R E N C E S}

\section{References to studies included in this review}

\section{Bianchi 2008 \{published and unpublished data\}}

Bianchi A, Felice P, Lizio G, Marchetti C. Alveolar distraction osteogenesis versus inlay bone grafting in posterior mandibular atrophy: a prospective study. Oral Surgery, Oral Medicine, Oral Pathology, Oral Radiology and Endodontics 208;105(3):282-92.

\section{Chiapasco 2004 \{published and unpublished data\}}

Chiapasco M, Romeo E, Casentini P, Rimondini L. Alveolar distraction osteogenesis vs. vertical guided bone regeneration for the correction of vertically deficient edentulous ridges: a 1-3-year prospective study on humans. Clinical Oral Implants Research 2004;15(1):82-95.

\section{Chiapasco 2007 \{published and unpublished data\}}

Chiapasco M, Zaniboni M, Rimondini L. Autogenous onlay bone grafts vs. alveolar distraction osteogenesis for the correction of vertically deficient edentulous ridges: a 2-4-year prospective study on humans. Clinical Oral Implants Research 2007;18(4):432-40.

\section{Felice 2008 \{published data only\}}

Felice P, Marchetti C, lezzi G, Piattelli A, Pellegrino G, Esposito M. Vertical augmentation of the posterior mandible with inlay grafts: bone from the iliac crest versus bovine bone. Results up to 1 year after loading from a randomized controlled clinical trial. Clinical Oral Implants Research in press.

* Felice P, Marchetti C, Piattelli A, Pellegrino G, Checchi V, Worthington $\mathrm{H}$, et al. Vertical ridge augmentation of the atrophic posterior mandible with interpositional bloc grafts: bone from the iliac crest versus bovine anorganic bone. Results up to delivery of the final prostheses from a split-mouth, randomised controlled clinical trial. European Journal of Oral Implantology 2008;1:183-7.

\section{Felice 2009a \{published data only\}}

Felice P, Cannizzaro G, Checchi V, Pellegrino G, Censi P, Esposito M. Vertical bone augmentation versus $7 \mathrm{~mm}$ long dental implants in posterior atrophic mandibles. A randomized controlled clinical trial. European Journal of Oral Implantology 2009;2:7-20.

\section{Felice 2009b \{published and unpublished data\}}

Felice P, Pistilli R, Lizio G, Pellegrino G, Nisii A, Marchetti C. Inlay versus onlay iliac bone grafting in atrophic posterior mandible: a prospective controlled clinical trial for the comparison of two techniques. Clinical Implant Dentistry and Related Research in press.

\section{Fontana 2008 \{published and unpublished data\}}

Fontana F, Santoro F, Maiorana C, lezzi G, Piattelli A, Simion M. Clinical and histologic evaluation of allogeneic bone matrix versus autogenous bone chips associated with titaniumreinforced e-PTFE membrane for vertical ridge augmentation: a prospective pilot study. International Journal of Oral and Maxillofacial Implants 2008;23(6):1003-12.
Meijndert 2007 \{published and unpublished data\}

${ }^{*}$ Meijndert L, Meijer HJ, Stellingsma K, Stegenga B, Raghoebar GM. Evaluation of aesthetics of implant-supported single-tooth replacements using different bone augmentation procedures: a prospective randomized clinical study. Clinical Oral Implants Research 2007;18(6):715-9.

Meijndert L, Raghoebar GM, Meijer HJ, Vissink A. Clinical and radiographic characteristics of single-tooth replacements preceded by local ridge augmentation: a prospective randomized clinical trial. Clinical Oral Implants Research 2008;19(12):1295-303.

\section{Merli 2007 \{published data only\}}

Merli M, Lombardini F, Esposito M. Vertical ridge augmentation with autogenous bone grafts 3 years after loading: resorbable barriers supported by osteosynthesis plates versus titanium reinforced barriers. A randomized controlled clinical trial. International Journal of Oral and Maxillofacial Implants submitted.

* Merli M, Migani M, Esposito M. Vertical ridge augmentation with autogenous bone grafts: resorbable barriers supported by osteosynthesis plates versus titanium-reinforced barriers. A preliminary report of a blinded, randomized controlled clinical trial. International Journal of Oral and Maxillofacial Implants 2007;22(3):373-82.

\section{Raghoebar 2005 \{published and unpublished data\}}

Raghoebar GM, Schortinghuis J, Liem RS, Ruben JL, van der Wal JE, Vissink A. Does platelet-rich plasma promote remodeling of autologous bone grafts used for augmentation of the maxillary sinus floor?. Clinical Oral Implants Research 2005;16(3):349-56.

Raghoebar 2006 \{published and unpublished data\} Raghoebar GM, Liem RS, Bos RR, van der Wal JE, Vissink A. Resorbable screws for fixation of autologous bone grafts. Clinical Oral Implants Research 2006;17(3):288-93.

Schortinghuis 2008 \{published and unpublished data\} Schortinghuis J, Bronckers AL, Gravendeel J, Stegenga B, Raghoebar GM. The effect of ultrasound on osteogenesis in the vertically distracted edentulous mandible: a double-blind trial. International Journal of Oral and Maxillofacial Surgery 2008;37(11):1014-21.

\section{Stellingsma 2003 \{published and unpublished data\}}

* Stellingsma K, Bouma J, Stegenga B, Meijer HJ, Raghoebar GM. Satisfaction and psychosocial aspects of patients with an extremely resorbed mandible treated with implant-retained overdentures. A prospective, comparative study. Clinical Oral Implants Research 2003;14(2):166-72.

Stellingsma K, Raghoebar GM, Meijer HJ. Short implants versus augmentation to treat the extremely resorbed mandible. Clinical Oral Implants Research 2007;18:(Abs No 40).

Stellingsma K, Raghoebar GM, Meijer HJ. Three implantological treatment modalities for the extremely resorbed mandible. 
Journal of Dental Research 2000;79 (Special Issue) (Abs No 2587):467.

Stellingsma K, Raghoebar GM, Meijer HJ, Stegenga B. The extremely resorbed mandible: a comparative prospective study of 2-year results with 3 treatment strategies. International Journal of Oral and Maxillofacial Implants 2004;19(4):563-77.

Stellingsma K, Slagter AP, Stegenga B, Raghoebar GM, Meijer HJ. Masticatory function in patients with an extremely resorbed mandible restored with mandibular implantretained overdentures: comparison of three types of treatment protocols. Journal of Oral Rehabilitation 2005;32(6):403-10.

\section{References to studies excluded from this review}

\section{Antoun 2001 \{published data only\}}

Antoun H, Sitbon JM, Martinez H, Missika P. A prospective randomized study comparing two techniques of bone augmentation: onlay graft alone or associated with a membrane. Clinical Oral Implants Research 2001;12(6):632-9.

\section{Friedmann 2002 \{published data only\}}

Friedmann A, Strietzel FP, Maretzki B, Pitaru S, Bernimoulin JP. Histological assessment of augmented jaw bone utilizing a new collagen barrier membrane compared to a standard barrier membrane to protect a granular bone substitute material. Clinical Oral Implants Research 2002;13(6):587-94.

\section{Roccuzzo 2007 \{published data only\}}

Roccuzzo M, Ramieri G, Bunino M, Berrone S. Autogenous bone graft alone or associated with titanium mesh for vertical alveolar ridge augmentation: a controlled clinical trial. Clinical Oral Implants Research 2007;18(3):286-94.

\section{Schortinghuis 2005 \{published data only\}}

Schortinghuis J, Bronckers AL, Stegenga B, Raghoebar GM, de Bont LG. Ultrasound to stimulate early bone formation in a distraction gap: a double blind randomised clinical pilot trial in the edentulous mandible. Archives of Oral Biology 2005;50(4):411-20.

\section{Van der Zee 2004 \{published data only\}}

Van der Zee E, Oosterveld P, Van Waas MA. Effect of GBR and fixture installation on gingiva and bone levels at adjacent teeth. Clinical Oral Implants Research 2004;15:62-5.

\section{Additional references}

\section{Branemark 1977}

Brånemark PI, Hansson BO, Adell R, Breine U, Lindstrom J, Hallen $\mathrm{O}$, et al. Osseointegrated implants in the treatment of the edentulous jaw. Experience from a 10 -year period. Scandinavian Journal of Plastic and Reconstructive Surgery. Supplementum 1977;16:1-132.

\section{Branemark 2004}

Brånemark PI, Gröndahl K, Öhrnell LO, Nilsson, P, Petruson B, Svensson B, et al. Zygoma fixture in the management of advanced atrophy of the maxilla: technique and long-term results. Scandinavian Journal of Plastic and Reconstructive Surgery 2004;38(2):70-85.

\section{Cawood 1991}

Cawood JI, Howell RA. Reconstructive preprosthetic surgery. I. Anatomical considerations. International Journal of Oral and Maxillofacial Surgery 1991;20(2):75-82.

\section{Chin 1999}

Chin M. Distraction osteogenesis for dental implants. Atlas of Oral and Maxillofacial Surgery Clinic North America 1999;7(1):41-63.

\section{Elbourne 2002}

Elbourne DR, Altman DG, Higgins JP, Curtin F, Worthington HV, Vail A. Meta-analyses involving cross-over trials: methodological issues. International Journal of Epidemiology 2002;31(1):140-9.

\section{Esposito 1998}

Esposito M, Hirsch JM, Lekholm U, Thomsen P. Biological factors contributing to failures of osseointegrated oral implants. (I). Success criteria and epidemiology. European Journal of Oral Sciences 1998;106(1):527-51.

\section{Esposito 2001}

Esposito M, Coulthard P, Worthington HV, Jokstad A. Quality assessment of randomized controlled trials of oral implants. International Journal of Oral and Maxillofacial Implants 2001;16(6):783-92.

\section{Esposito 2005}

Esposito M, Worthington HV, Coulthard P. Interventions for replacing missing teeth: dental implants in zygomatic bone for the rehabilitation of the severely deficient edentulous maxilla. Cochrane Database of Systematic Reviews 2005, Issue 4. [DOI: 10.1002/14651858.CD004151.pub2]

\section{Esposito 2008b}

Esposito M, Grusovin MG, Kakisis I, Coulthard P, Worthington HV. Interventions for replacing missing teeth: treatment of perimplantitis. Cochrane Database of Systematic Reviews 2008, Issue 2. [DOI: 10.1002/14651858.CD004970.pub3]

\section{Fiorellini 2003}

Fiorellini JP, Nevins ML. Localized ridge augmentation/ preservation. A systematic review. Annals of Periodontology 2003;8(1):321-7.

\section{Graziani 2007}

Graziani F, Cei S, Ivanovski S, La Ferla F, Gabriele M. A systematic review of the effectiveness of bone collectors. International Journal of Oral and Maxillofacial Implants 2007;22(5):729-35.

\section{Higgins 2008}

Higgins JPT, Green S, editors. Cochrane Handbook for Systematic Reviews of Interventions Version 5.0.1 (updated September 2008). The Cochrane Collaboration, 2008. Available from: www.cochrane-handbook.org. 


\section{Kahnberg 1989}

Kahnberg KE, Nystrom E, Bartholdsson L. Combined use of bone grafts and Brånemark fixtures in the treatment of severely resorbed maxillae. International Journal of Oral and Maxillofacial Implants 1989;4(4):297-304.

\section{Keller 1992}

Keller EE. The maxillary interpositional composite graft. In: Worthington P, Brånemark P-I editor(s). Advanced Osseointegration Surgery. Applications in the Maxillofacial Region. Chicago: Quintessence Publishing Company, Inc, 1992:162-74.

\section{Moher 2001}

Moher D, Schulz KF, Altman DG. The CONSORT statement revised recommendations for improving the quality of reports of parallel-group randomised trials. Lancet 2001;357(9263):1191-4.

\section{Obwegeser 1969}

Obwegeser HL. Surgical correction of small or retrodisplaced maxillae. The 'dish-face' deformity. Plastic and Reconstructive Surgery 1969;43(4):351-65.

\section{Palmer 2000}

Palmer P, Palmer R. Implant surgery to overcome anatomical difficulties. In: Palmer R editor(s). A Clinical Guide to Implants in Dentistry. London: British Dental Association, 2000:57-65.

\section{Rocchietta 2008}

Rocchietta I, Fontana F, Simion M. Clinical outcomes of vertical bone augmentation to enable dental implant placement: a systematic review. Journal of Clinical Periodontology 2008;35(8 Suppl):203-15.

\section{Tolman 1995}

Tolman DE. Reconstructive procedures with endosseous implants in grafted bone: a review of the literature. International Journal of Oral and Maxillofacial Implants 1995;10(3):275-94.

\section{Valentin-Opran 2002}

Valentin-Opran A, Wozney J, Csimma C, Lilly L, Riedel GE. Clinical evaluation of recombinant human bone morphogenic protein-2. Clinical Orthopaedics and Related Research 2002;395:110-20.

\section{Wenz 2001}

Wenz B, Oesch B, Horst M. Analysis of the risk of transmitting bovine spongiform encephalopathy through bone grafts derived from bovine bone. Biomaterials 2001;22(12):1599-606.

\section{References to other published versions of this review Coulthard 2003}

Coulthard P, Esposito M, Jokstad A, Worthington HV. Interventions for replacing missing teeth: bone augmentation techniques for dental implant treatment. Cochrane Database of Systematic Reviews 2003, Issue 3. [DOI: 10.1002/14651858.CD3607]

\section{Esposito 2006a}

Esposito M, Grusovin MG, Worthington HV, Coulthard P. Interventions for replacing missing teeth: bone augmentation techniques for dental implant treatment. Cochrane Database of Systematic Reviews 2006, Issue 1. [DOI: 10.1002/14651858.CD3607.pub2]

\section{Esposito 2006b}

Esposito M, Grusovin MG, Coulthard P, Worthington HV. The efficacy of various bone augmentation procedures for dental implants: a Cochrane systematic review of randomized controlled clinical trials. International Journal of Oral and Maxillofacial Implants 2006;21(5):696-710.

\section{Esposito 2008C}

Esposito M, Grusovin MG, Kwan S, Worthington HV, Coulthard P. Interventions for replacing missing teeth: bone augmentation techniques for dental implant treatment. Cochrane Database of Systematic Reviews 2008, Issue 3. [DOI: 10.1002/14651858.CD003607.pub3]

* Indicates the major publication for the study

\section{CHARACTERISTICS OF STUDIES}

Characteristics of included studies [ordered by study ID]

\section{Bianchi 2008}

\begin{tabular}{|c|c|}
\hline Methods & 1-year and a half post-loading follow-up randomised, parallel group study. There were no withdrawals. \\
\hline Participants & $\begin{array}{l}\text { Patients subjected to vertical augmentation procedures having residual bone above the mandibular } \\
\text { canal of } 5 \text { to } 9 \mathrm{~mm} \text {. Adults treated at the University of Bologna, Italy. Patients were excluded if they pre- } \\
\text { sented a severe knife-edge ridge, bone defect following tumour resection, smoking more than } 15 \text { cig- } \\
\text { arettes per day, severe renal and liver disease, history of radiotherapy in the head and neck region, } \\
\text { chemotherapy at the time of the surgical intervention, non-compensated diabetes, active periodontal } \\
\text { disease, mucosal disease such as lichen planus in the areas to be treated, poor oral hygiene, non-com- } \\
\text { pliant. } 11 \text { patients enrolled, } 6 \text { in the GBR group (1 patient treated bilaterally) and } 5 \text { in the osteodistrac- } \\
\text { tion group. }\end{array}$ \\
\hline
\end{tabular}


Bianchi 2008 (Continued)

Interventions

Autogenous inlay bone grafts harvested from the iliac crest versus vertical distraction osteogenesis to vertically augment deficient posterior mandibles. Patients were grafted with a 2-stage approach: first a monocortical bone block was interposed between the basal bone and an osteotomised segment raised coronally without flap elevation at the lingual side to preserve blood supply and fixed with titanium miniplates and miniscrews (KLS Martin, Tuttlingen, Germany). No barriers were used. After $3 / 4$ months miniplates were removed and implants were placed and left submerged for 3 to 4 months. The distraction procedure was accomplished by using osteodistractors of various brands (Track by KLS Martin, AlMar by Cizeta, LactoSorb by Wakterl Lorenz Surgical, the latter being a resorbable device) fixed to the bone segments with various titanium or resorbable screws. The distraction devices were activated after 1 week, twice a day ( 0.5 to $1 \mathrm{~mm}$ per day for 5 to 7 days) until the desired amount of distraction was obtained ( 7 to $15 \mathrm{~mm}$ ). In 2 cases a prosthetic device was used to avoid lingual tipping. The bone segments were then left to consolidate for 3 to 4 months, the osteodistractors were removed and dental implants placed and left submerged for 3 to 4 months. All augmentation procedures were performed under general anaesthesia. Dental implants of several brands were used (A-Z implant, Biohorizons, Biomet 3i, Friadent, Nobel Biocare). All patients were rehabilitated with partial provisional prostheses for 14 to 16 months until definitive prostheses were delivered.

Outcomes

Prosthesis and implant failure, intra- and post-operative complications at both augmented and donor sites, bone gain/loss from augmentation to implant placement.

\section{Notes}

\section{Risk of bias}

\begin{tabular}{lll}
\hline Bias & Authors' judgement & Support for judgement \\
\hline $\begin{array}{l}\text { Random sequence genera- } \\
\text { tion (selection bias) }\end{array}$ & Low risk & $\begin{array}{l}\text { Article: No information presented. } \\
\text { Author's reply: "Computer generated randomisation list". }\end{array}$ \\
\hline $\begin{array}{l}\text { Allocation concealment } \\
\text { (selection bias) }\end{array}$ & Low risk & Article: Information not presented. \\
& $\begin{array}{l}\text { Author's reply: "Randomisation codes were placed in envelopes by an investi- } \\
\text { gator not involved in patient recruitment. Envelopes were opened after surgi- } \\
\text { cal incision". }\end{array}$ \\
\hline
\end{tabular}

\begin{tabular}{|c|c|c|}
\hline $\begin{array}{l}\text { Blinding (performance } \\
\text { bias and detection bias) }\end{array}$ & Low risk & Article: Information not presented. \\
\hline All outcomes & & $\begin{array}{l}\text { Author's reply: "Outcome assessors were independent, but could not be blind- } \\
\text { ed during the augmentation phase. After implant placement, they were com- } \\
\text { pletely blinded". }\end{array}$ \\
\hline
\end{tabular}

It is judged as adequate.

Incomplete outcome data Low risk All data were reported adequately. No drop outs.

(attrition bias)

All outcomes

\begin{tabular}{|c|c|c|}
\hline $\begin{array}{l}\text { Selective reporting (re- } \\
\text { porting bias) }\end{array}$ & Low risk & \\
\hline Other bias & Unclear risk & $\begin{array}{l}\text { Different types of implants were used. It is unclear if this could have influenced } \\
\text { the results. }\end{array}$ \\
\hline
\end{tabular}

\section{Chiapasco 2004}

Methods 3-year post-loading follow-up randomised, parallel group study. There were no withdrawals.


Chiapasco 2004 (Continued)

Participants
Patients subjected to vertical augmentation procedures. Adults treated at the University of Milan, Italy. Patients were excluded if they presented a severe knife-edge ridge, bone defect following tumour resection, smoking more than 15 cigarettes per day, severe renal and liver disease, history of radiotherapy in the head and neck region, chemotherapy at the time of the surgical intervention, non-compensated diabetes, active periodontal disease, mucosal disease such as lichen planus in the areas to be treated, poor oral hygiene, non-compliant. 21 patients enrolled, 11 in the GBR group and 10 in the osteodistraction group.

Non-resorbable titanium-reinforced ePTFE barrier (Gore-Tex, WL Gore and Associates, Inc., Flagstone, USA) supported by particulate autogenous bone harvested from the mandibular ramus and sometimes from the chin versus vertical distraction osteogenesis. 2 different vertical GBR procedures were used: 6 patients were treated with a 1-stage approach (implants were inserted and the augmentation procedure was performed on the same occasion) whereas 5 patients were treated with a 2-stage approach (first the bone at the site was augmented and left to heal for 6 to 7 months, and then implants were placed). The 2-stage approach was used when the risk of insufficient primary implant stability of implants was subjectively expected. With the 2-stage approach 1 or 2 titanium miniscrews were used as additional support for the barriers. All barriers were stabilized with titanium fixating pins (Frios, Friadent GmbH, Mannheim, Germany) or miniscrews (Gebrüder Martin GmbH \& Co., Tuttlingen, Germany) or both. The distraction procedure was accomplished by using osteodistractors (Gebrüder Martin $\mathrm{GmbH} \&$ Co.) fixed to the bone segments with $1.5 \mathrm{~mm}$ large titanium screws. The distraction devices were activated after 1 week, twice a day $(0.5 \mathrm{~mm}$ every $12 \mathrm{~h})$ until the desired amount of distraction was obtained. Surgical templates were used to optimise implant insertion. 2 implant systems were used: Brånemark Mark III implants (Nobel Biocare, Göteborg, Sweden), and ITI SLA implants (Institut Straumann AG, Waldenburg, Switzerland). All patients were rehabilitated with screw-retained metal-ceramic fixed prostheses.

Outcomes Prosthesis and implant failure and marginal bone level changes on intraoral radiographs taken with a paralleling technique at abutment connection, 1 and 3 years. Complications at both augmented and donor sites. Bone gain from augmentation to abutment connection.

Notes

\section{Risk of bias}

\begin{tabular}{|c|c|c|}
\hline Bias & Authors' judgement & Support for judgement \\
\hline $\begin{array}{l}\text { Random sequence genera- } \\
\text { tion (selection bias) }\end{array}$ & Low risk & $\begin{array}{l}\text { Article: No information presented. } \\
\text { Author's reply: "Toss of a coin". }\end{array}$ \\
\hline $\begin{array}{l}\text { Allocation concealment } \\
\text { (selection bias) }\end{array}$ & High risk & $\begin{array}{l}\text { Article: "Randomisation was concealed to the author until the surgical proce- } \\
\text { dure". } \\
\text { Author's reply after request for details: "Allocation was made just after patient } \\
\text { recruitment and before ordering the osteodistractors". }\end{array}$ \\
\hline $\begin{array}{l}\text { Blinding (performance } \\
\text { bias and detection bias) } \\
\text { All outcomes }\end{array}$ & High risk & $\begin{array}{l}\text { Article: No information presented. } \\
\text { Author's reply: "Outcome assessor could not be blinded and was not blinded". } \\
\text { It is unclear if it was an independent assessor, therefore it is judged as inade- } \\
\text { quate. }\end{array}$ \\
\hline $\begin{array}{l}\text { Incomplete outcome data } \\
\text { (attrition bias) } \\
\text { All outcomes }\end{array}$ & High risk & $\begin{array}{l}\text { Article: Some withdrawals described. } \\
\text { Author's reply: "Withdrawals, as described in the text, were not drop outs, but } \\
\text { patients that had not completed the follow-up period at the time of publica- } \\
\text { tion. There were no withdrawals". }\end{array}$ \\
\hline
\end{tabular}


Chiapasco 2004 (Continued)

Selective reporting (re- Low risk porting bias)

Other bias

Unclear risk

2 different types of implants were used (Branemark, ITI). It is unclear if this could have influenced the results.

Chiapasco 2007

Methods 3-year post-loading follow-up randomised, parallel group study. There were no withdrawals.

Participants

Patients subjected to vertical augmentation procedures. Adults treated at the University of Milan, Italy. Patients were excluded if they presented a severe knife-edge ridge, bone defect following tumour resection, smoking more than 15 cigarettes per day, severe renal and liver disease, history of radiotherapy in the head and neck region, chemotherapy at the time of the surgical intervention, non-compensated diabetes, active periodontal disease, mucosal disease such as lichen planus in the areas to be treated, poor oral hygiene, non-compliant. 17 patients enrolled, 8 in the bone graft group and 9 in the osteodistraction group.

Interventions

Autogenous onlay bone grafts harvested from the mandibular ramus versus vertical distraction osteogenesis to vertically augment deficient mandibles. Patients were grafted with a 2-stage approach: first bone blocks were fixed with $1.5 \mathrm{~mm}$ diameter miniscrews (Gebrüder Martin GmbH \& Co., KG, Tuttlingen, Germany). Empty spaces were filled with cancellous bone chips. In case of severe vertical resorption, grafts were assembled in a multilayered fashion. No barriers were used. Bone grafts were harvested from the mandibular ramus of the same side of reconstruction in 6 patients, while in 2 patients, where larger defects were present, bone was harvested bilaterally. After 4 to 5 months implants were placed and left submerged for an additional 3 to 4 months. The distraction procedure was accomplished by using osteodistractors (Gebrüder Martin GmbH \& Co., Tuttlingen, Germany) fixed to the bone segments with $1.5 \mathrm{~mm}$ large titanium screws. The distraction devices were activated after 1 week, twice a day $(0.5 \mathrm{~mm}$ every $12 \mathrm{~h}$ ) until the desired amount of distraction was obtained ( 2 to $7 \mathrm{~mm}$ ). The bone segments were then left to consolidate for 2 to 3 months, the osteodistractors were then removed and dental implants placed and left submerged for 3 to 4 months. The augmentation procedures were performed under local anaesthesia, local anaesthesia with intravenous sedation and general anaesthesia according to operator and patient preferences. Surgical templates were used to optimise implant insertion. ITI SLA implants (Institut Straumann AG, Waldenburg, Switzerland) were used. All patients were rehabilitated with screw-retained metal-ceramic fixed prostheses.

Outcomes Prosthesis and implant failure, marginal bone level changes on intraoral radiographs taken with a paralleling technique at abutment connection, 1, 3 and 5 years, complications at both augmented and donor sites, bone gain from augmentation to implant placement.

Notes

\section{Risk of bias}

\begin{tabular}{lll}
\hline Bias & Authors' judgement & Support for judgement \\
\hline $\begin{array}{l}\text { Random sequence genera- } \\
\text { tion (selection bias) }\end{array}$ & Low risk & $\begin{array}{l}\text { Article: No information presented. } \\
\text { Author's reply: "Drawing lot". }\end{array}$ \\
\hline $\begin{array}{l}\text { Allocation concealment } \\
\text { (selection bias) }\end{array}$ & Low risk & $\begin{array}{l}\text { Article: "Randomisation was concealed to the surgeon until the surgical proce- } \\
\text { dure". }\end{array}$ \\
& $\begin{array}{l}\text { Author's reply: "There were two envelopes, one was randomly selected after } \\
\text { anaesthesia was done". }\end{array}$ \\
\hline
\end{tabular}


Chiapasco 2007 (Continued)
Blinding (performance
Low risk
Article: No information presented.
bias and detection bias)
All outcomes
Author's reply: "Blinded outcome assessors, but often they could tell the groups".
It is judged as adequate.

Incomplete outcome data Low risk All data were reported adequately. No drop outs.
(attrition bias)
All outcomes

Selective reporting (re- Low risk
porting bias)

Other bias Low risk

Felice 2008

Methods 1-year post-loading follow-up randomised, split-mouth group study. There were no withdrawals.

Participants Patients having residual bone above the mandibular canal of 5 to $7 \mathrm{~mm}$ and a width of at least $5 \mathrm{~mm}$. Adults treated at the Department of Oral and Maxillofacial surgery of the S Orsola-Malphighi Hospital in Bologna, Italy. Patients were excluded if they had general contraindications to implant surgery, subjected to irradiation in the head and neck area, under chemo- or immuno-suppressive therapy over the previous 5 years, treated or under treatment with intravenous amino-bisphosphonates, poor oral hygiene and motivation, uncontrolled diabetes, pregnant or lactating, substance abusers, psychiatric problems or unrealistic expectations, smoking more than 15 cigarettes per day, acute infection in the area intended for implant placement, positive to HIV, hepatitis Cor D, affected by autoimmune diseases such as rheumatoid arthritis, systemic lupus erythematosus, sclerodermia, Sjögren syndrome and dermatomyositis/polymyositis, previously subjected to reconstructive procedures of the posterior mandible, and under chronic treatment with steroids or non-steroidal anti-inflammatory drugs (NSAIDs). 10 patients enrolled.

Interventions Autogenous inlay bone grafts harvested from the iliac crest versus blocks of anorganic bovine bone (Bio-Oss ${ }^{\circledR}$, Geistlich Pharma AG, Wolhusen, Switzerland) for vertically augmenting deficient posterior mandibles. Patients were grafted with a 2-stage approach: first a monocortical bone block was interposed between the basal bone and an osteotomised segment raised coronally without flap elevation at the lingual side to preserve blood supply and fixed with titanium miniplates and miniscrews (KLS Martin, Tuttlingen, Germany) and covered with a resorbable barrier (Bio-Gide ${ }^{\circledR}$, Geistlich Pharma AG). The contra-lateral side was treated with a similar technique but using a Bio-Oss bone block instead. The removable prostheses were allowed for 1 month after the augmentation procedure. After 4 months miniplates were removed and implants were placed and left submerged for 4 months. All augmentation procedures were performed under general anaesthesia and patients remained hospitalised for 3 days. Dental implants of 3 different brands were used (Nanotite Biomet 3i cylindrical implants with external connection, Ankylos and XiVe Dentsply-Friadent implants). All patients were rehabilitated with fixed partial provisional acrylic prostheses for 4 months until definitive metal-ceramic fixed prostheses were delivered.

Outcomes

Prosthesis and implant failures, complications, bone gain, perimplant marginal bone levels, patient preference, and histomorphometric evaluation.

Notes

\section{Risk of bias}

Bias Authors' judgement Support for judgement


Felice 2008 (Continued)
Random sequence genera- Low risk
Article: "Computer generated randomisation list". tion (selection bias)

Allocation concealment High risk (selection bias)
Article: The envelopes were sequentially numbered, opaque, identical, sealed, however, "the day before the augmentation procedure, the envelopes containing the randomised codes were opened and the surgeon knew which side to treat with each procedure".

\section{Blinding (performance Low risk} bias and detection bias) All outcomes
Article: "Two dentists not involved in the treatment of the patients made all the clinical and radiographic assessments without knowledge of the group allocation, therefore, outcome assessors were blind to these assessments. However, Bio-Oss treated sites could be identified on radiographs because they appeared more radio-opaque".

It is judged as adequate.

Incomplete outcome data Low risk All data were reported adequately. No drop outs.

(attrition bias)

All outcomes

\begin{tabular}{|c|c|c|}
\hline $\begin{array}{l}\text { Selective reporting (re- } \\
\text { porting bias) }\end{array}$ & Low risk & \\
\hline \multirow[t]{2}{*}{ Other bias } & Unclear risk & $\begin{array}{l}\text { Commercial funding: "Geistlich (Italy) is acknowledged for generously donat- } \\
\text { ing the ten Bio-Oss blocks and } 20 \text { resorbable barriers used in the investiga- } \\
\text { tion". }\end{array}$ \\
\hline & & $\begin{array}{l}\text { Different implant systems used, however, this may not have influenced the re- } \\
\text { sults. }\end{array}$ \\
\hline
\end{tabular}

\section{Felice 2009a}

$\begin{array}{ll}\text { Methods } & \begin{array}{l}\text { 4-month post-loading follow-up randomised, parallel group study including } 2 \text { groups. There were no } \\ \text { withdrawals. }\end{array}\end{array}$
withdrawals.

Participants

Patients having residual bone above the mandibular canal of 7 to $8 \mathrm{~mm}$ and a width of at least $5.5 \mathrm{~mm}$. Adults treated at a private practice in Bologna, Italy. Patients were excluded if they had general contraindications to implant surgery, subjected to irradiation in the head and neck area less than 1 year ago, under chemotherapy for malignant tumour, treated or under treatment with intravenous aminobisphosphonates, poor oral hygiene and motivation, uncontrolled diabetes, pregnant or lactating, substance abusers, psychiatric problems or unrealistic expectations, lack of opposite occluding dentition in the area intended for implant placement, acute infection in the area intended for implant placement, extraction sites with less than 3 months of healing. 60 patients enrolled, 30 in each group.

Interventions

$7 \mathrm{~mm}$ short implants versus $10 \mathrm{~mm}$ or longer implants placed in atrophic posterior mandibles augmented with a bone substitute block (Bio-Oss, Geistlich Pharma, Wolhusen, Switzerland) placed according to an inlay technique. Posterior mandibles with $7-8 \mathrm{~mm}$ of bone height above the mandibular canal and a width of at least $5.5 \mathrm{~mm}$ as measured on CT scans were treated under local anaesthesia. In brief, after a paracrestal buccal incision, a horizontal osteotomy was made 2 to $4 \mathrm{~mm}$ above the mandibular canal. 2 oblique cuts were made, the bone segment was raised sparing the lingual periosteum, and a Bio-Oss block was modelled and positioned between the 2 segments which were stabilized with osteosynthesis miniplates, covered with a resorbable membrane (Bio-Gide, Geistlich Pharma) and left to heal for 5 months. Patients were not allowed to wear their removable prostheses for 1 month after the augmentation procedure. 2 to 3 implants (NanoTite, parallel walled, with external connection, Biomet 3i, Palm Beach, FL, USA) were placed $0.6 \mathrm{~mm}$ supracrestally and left to heal for 4 months in both groups. Provisional screw-retained acrylic restorations were delivered and replaced after 4 months by screw-retained metal ceramic restorations. 
Felice 2009a (Continued)

Outcomes

Prosthesis and implant failure, complications, and days needed to fully recover mental sensitivity.

Notes

Risk of bias

\begin{tabular}{lll}
\hline Bias & Authors' judgement & Support for judgement \\
\hline $\begin{array}{l}\text { Random sequence genera- } \\
\text { tion (selection bias) }\end{array}$ & Low risk & Article: "Computer generated randomisation list". \\
\hline $\begin{array}{l}\text { Allocation concealment } \\
\text { (selection bias) }\end{array}$ & Low risk & $\begin{array}{l}\text { Article: "Only one of the investigators, not involved in the selection and } \\
\text { treatment of the patients, was aware of the randomisation sequence and } \\
\text { could have access to the randomisation list stored in his password-protected } \\
\text { portable computer. The randomised codes were enclosed in sequentially num- } \\
\text { bered, identical, opaque, sealed envelopes. Envelopes were opened sequen- } \\
\text { tially after eligible patients signed the informed consent form to be enrolled in } \\
\text { the trial. Therefore, treatment allocation was concealed to the investigators in } \\
\text { charge of enrolling and treating the patients". }\end{array}$ \\
\hline
\end{tabular}

Blinding (performance Low risk

bias and detection bias)

All outcomes
Article: "One clinician not involved in the treatment of the patients performed all clinical and radiographic assessments without knowing group allocation, therefore the outcome assessor was blind. However the Bio-Oss augmented sites could be identified on radiographs because they appeared more radiopaque and implants were longer".

It is judged as adequate.

Incomplete outcome data Low risk

All data were reported adequately. No drop outs.

(attrition bias)

All outcomes

Selective reporting (re- Low risk porting bias)

Other bias Low risk

Felice 2009b

Methods 1 -year post-loading follow-up randomised, parallel group study including 2 groups. There were no withdrawals.

Participants

Patients having residual bone above the mandibular canal of between 4.5 to $11 \mathrm{~mm}$ and a width of at least $5 \mathrm{~mm}$. Adults treated at the Oral and Maxilofacial Surgery Unit, S. Filippo Nieri Hospital, Rome, Italy. Patients were excluded if they had general contraindications to implant surgery, irradiation, chemotherapy, immunosuppressive therapy, or amino-bisphosphonates in the previous 5 years, poor oral hygiene and motivation, uncontrolled diabetes, pregnant or lactating, previously subjected to reconstructive procedures of the posterior mandible, active periodontal disease, and mucosal disease such as lichen planus, in the areas to be treated. 23 patients enrolled, 13 in the onlay group and 10 in the inlay group.

Interventions

Autogenous inlay versus onlay bone grafts harvested from the iliac crest to vertically augment deficient posterior mandibles. Patients were grafted with a 2-stage approach: a monocortical bone block was either interposed between the basal bone and an osteotomised segment raised coronally without flap elevation at the lingual side to preserve blood supply or placed as an onlay. Grafts were fixed with titanium miniplates or miniscrews (Gebrüder Martin GmbH \& Co, Tuttlingen, Germany). The graft- 
Felice 2009b (Continued)

ed areas were covered with resorbable barriers (Bio-Gide ${ }^{\circledR}$, Geistlich Pharma AG). All augmentation procedures were performed under general anaesthesia. Patients were instructed not to wear removable prostheses for 1 month after the augmentation procedure. After 3 to 4 months miniplates/screws were removed and 2 dental implants were placed and left submerged for 4 months. Dental implants of several brands were used (Biomet $3 \mathrm{i}$ and XiVe Dentsply-Friadent implants for the inlay group and Astra Tech, Biolok and Alpha Bio implants for the onlay group). All patients were rehabilitated with screw-retained acrylic partial provisional prostheses for 4 to 5 months until definitive screw-retained prostheses were delivered.

Outcomes Prosthesis and implant failure, complications, bone gain, and perimplant marginal bone loss.

\section{Notes}

\section{Risk of bias}

\begin{tabular}{|c|c|c|}
\hline Bias & Authors' judgement & Support for judgement \\
\hline $\begin{array}{l}\text { Random sequence genera- } \\
\text { tion (selection bias) }\end{array}$ & Low risk & $\begin{array}{l}\text { Article: No information presented. } \\
\text { Author's reply: "Toss of a coin". }\end{array}$ \\
\hline $\begin{array}{l}\text { Allocation concealment } \\
\text { (selection bias) }\end{array}$ & Low risk & $\begin{array}{l}\text { Article: "The surgeons were blind to the group assignment until the surgical } \\
\text { procedure". } \\
\text { Author's reply: "The surgeon was informed about the intervention after the pa- } \\
\text { tient was anaesthetised". }\end{array}$ \\
\hline $\begin{array}{l}\text { Blinding (performance } \\
\text { bias and detection bias) } \\
\text { All outcomes }\end{array}$ & Low risk & $\begin{array}{l}\text { Article: No information presented. } \\
\text { Author's reply: "Independent outcome assessor could understand which inter- } \\
\text { vention was delivered, however they were completely blinded after implant } \\
\text { placement". } \\
\text { It is judged as adequate. }\end{array}$ \\
\hline $\begin{array}{l}\text { Incomplete outcome data } \\
\text { (attrition bias) } \\
\text { All outcomes }\end{array}$ & Low risk & $\begin{array}{l}\text { In the article, data of } 20 \text { patients were presented. However, after our query } \\
\text { about how they ended up having } 10 \text { patients in each group by tossing a coin, } \\
\text { which is quite unlikely to happen, the author replied that there were actually } \\
23 \text { patients enrolled, but they excluded data of } 3 \text { patients from } 1 \text { group to bal- } \\
\text { ance the numbers. After our request, they gave us the complete data. }\end{array}$ \\
\hline $\begin{array}{l}\text { Selective reporting (re- } \\
\text { porting bias) }\end{array}$ & Low risk & \\
\hline Other bias & Unclear risk & $\begin{array}{l}\text { Different types of implants were used. It is unclear if this could have influenced } \\
\text { the results. }\end{array}$ \\
\hline
\end{tabular}

Fontana 2008

\begin{tabular}{|c|c|}
\hline Methods & Randomised, split-mouth study up 1 year after loading. There were no withdrawals. \\
\hline Participants & $\begin{array}{l}\text { Patients with bilateral posterior mandibular partial edentulism having a defect of more than } 3 \mathrm{~mm} \text { con- } \\
\text { sidering the deepest portion of the edentulous ridge in relation to the bone adjacent to the last tooth. } \\
\text { Adults treated at the University of Milan, Italy. Patients were excluded if they had an interarch distance } \\
\text { less than } 10 \mathrm{~mm} \text {, any relevant medical condition, smoking more than } 10 \text { cigarettes per day, history of } \\
\text { radiotherapy in the head and neck region, active periodontal disease, daily intake of anticoagulants, } \\
\text { antiplatelets, bisphosphonates, glucocorticoids, heavy bruxers, tooth extraction sites in the previous } 2\end{array}$ \\
\hline
\end{tabular}


Fontana 2008 (Continued) months, pregnancy or lactation, full plaque and bleeding scores equal or more than $25 \% .5$ patients enrolled.

Interventions

2-stage vertical GBR using non-resorbable titanium reinforced ePTFE barriers (Gore-Tex, WL Gore and Associates, Inc., Flagstone, USA), stabilized with miniscrews, comparing particulate autogenous bone harvested from the retromolar area with trephine drills and subsequently particulated with a bone mill versus an allograft made of malleable allogenic bone matrix (Regenaform, Regeneration Technologies, Alachua, FL, USA). This allograft is a combination of assayed demineralized bone matrix (DFDBA) with cortico-cancellous bone chips uniformly dispersed in a termoplastic biological carrier which became malleable when warmed between 43 to 49 degrees Celsius. The augmentation procedures were performed under local anaesthesia with sedative premedication half an hour prior to surgery. 2 mini-implants were used as 'poles' to support the barrier. They were placed to protrude for the required height. 1 pole was a stainless steel miniscrew (6 to $12 \mathrm{~mm}$ long; Ace Dental Implant System, Brockton, MA, USA), and the other was an immediate provisional implant (IPI, Steri-Oss, Nobel Biocare, Göteborg, Sweden, $2 \mathrm{~mm}$ in diameter and $10 \mathrm{~mm}$ in length) which was removed at implant installation with a 4 $\mathrm{mm}$ diameter trephine bur for histological examination. Several drill holes were made on the cortical bone to ensure bleeding. After 6 months of submerged healing the barriers and the mini-implant were removed and Brånemark MK III (Nobel Biocare) implants with a TiUnite surface were placed. After 5 months of healing implant stability was tested and abutments were placed.

Outcomes

Prosthesis and implant failure, complications at both augmented and donor sites, bone gain from augmentation to implant placement, histomorphometric evaluation.

Notes

Risk of bias

\begin{tabular}{lll}
\hline Bias & Authors' judgement & Support for judgement \\
\hline $\begin{array}{ll}\text { Random sequence genera- } \\
\text { tion (selection bias) }\end{array}$ & Low risk & Article: No information presented. \\
& & Author's reply: "Toss of a coin". \\
\hline
\end{tabular}

Allocation concealment Low risk (selection bias)
Article: "At the time of the first surgery, one side was randomly assigned to either the test group or the control group by opening an envelope with the group assignment sealed inside".

However, the protocol, as described in the materials and methods section, was not followed.

Author's reply: "In each patient one side was randomly assigned to receive allograft or autograft as described in the text. The randomization was done at the time of the surgery with a coin 'by pitch and toss'. After the full thickness flap was elevated by the surgeon, two 'tenting screws' were positioned in the residual bone and left to protrude for the required height and the membrane was bent and trimmed to adapt to the recipient site. Only at this time, an investigator completely extraneous to the surgery and not involved in the selection of the patients was invited to toss. Of course the surgeon could not be completely blinded, but he was informed of the graft to use only after flap elevation in order not to interfere with flap design, membrane preparation and tending screws positioning. In this way the DSB measurements (the first step to evaluate the amount of vertical bone gained) were performed prior to group allocation".

Additional request: "In the original paper it was written that assignment was done "by opening an envelope with the group assignment sealed inside", I wonder what was actually used: Toss of a coin or envelopes".

Author's reply: "The randomization was supposed to be done by opening an envelope as reported in the protocol that we wrote before the beginning of 
Fontana 2008 (Continued)

the study. This data has been then reported in the text. However, at the beginning of the RCT we found easier and quicker to use the 'pitch and toss'".

Nevertheless, allocation was judged to be adequately concealed.

$\begin{array}{ll}\begin{array}{l}\text { Blinding (performance } \\ \text { bias and detection bias) }\end{array} & \text { Text: No information presented. } \\ \text { All outcomes } & \text { Author's reply: "A single clinical examiner was used to record all the informa- } \\ & \text { tion and all the measurements. The clinician was blinded to group allocation } \\ & \text { and did not participate to the entire surgery. After DSB measurements and pri- } \\ \text { or to the pitch and toss (i.e. group allocation) he was invited to leave the surgi- } & \text { cal room. At the second stage surgery (membrane removal and implant inser- } \\ & \text { tion), at the third surgery (abutment connection) and for the follow-up period } \\ \text { this examiner was totally unaware of the treatment group." }\end{array}$

Incomplete outcome data Low risk All data were reported adequately. No drop outs.

(attrition bias)

All outcomes

Selective reporting (re- Low risk
porting bias)

\begin{tabular}{|c|c|c|}
\hline Other bias & Unclear risk & $\begin{array}{l}\text { The study protocol was not followed in (at least) } 1 \text { occasion (randomisation } \\
\text { and allocation concealment, see above). }\end{array}$ \\
\hline
\end{tabular}

\section{Meijndert 2007}

$\begin{array}{ll}\text { Methods } & \begin{array}{l}\text { 1-year post-loading follow-up randomised, parallel group study including } 3 \text { groups. There were no } \\ \text { withdrawals. }\end{array}\end{array}$

Participants Patients with a horizontal bone deficit in the anterior maxilla (incisor, cuspid and first bicuspid) requiring a single implant. Adults treated at the University Hospital Groningen and at Nij Smellinghe Christian Hospital in Drachten. Patients were excluded if smoked, had active periodontitis, diabetes, radiotherapy in the head and neck region, chemotherapy, acute inflammatory oral disease, mental or physical disabilities impairing oral hygiene, and history of reconstructive preprosthetic surgery or previous implant surgery. 31 patients included in each group.

Interventions

3 different techniques to horizontally augment local ridge maxillary defects (from 1st to 1st premolars) for allowing placement of single implants were tested: (1) bone graft from the chin; (2) bone graft from the chin with a resorbable barrier (Bio-Gide, Geistlich Pharmaceutical, Wolhusen, Switzerland); (3) $100 \%$ bovine anorganic bone (Bio-Oss, spongiosa granules of $0.25-1 \mathrm{~mm}$, Geistlich Pharmaceutical, Wolhusen, Switzerland) with a Bio-Gide resorbable barrier. The cortical bone of the recipient sites was perforated to create a bleeding bone surface and to open the cancellous bone. Bone blocks from the chin were fixed with a $1.5 \mathrm{~mm}$ diameter titanium screw (Martin Medizin Technik, Tuttlingen, Germany) and particulate bone from the chin was placed around the fixed bone grafts. Implants were placed 3 months after autogenous bone grafting and 6 months after augmenting sites with Bio-Oss. Single ITIEstheticPlus implants (Institut Straumann AG, Waldenburg, Switzerland) were placed using templates and left healing submerged for 6 months. On the day of uncovering provisional single crowns were screwed on the implants and were replaced 1 month after by final porcelain crowns with a zirconium oxide core (Procera, Nobel Biocare, Göteborg, Sweden).
Outcomes
Prosthesis and implant failure, marginal bone level changes on intraoral radiographs taken with a par- alleling technique 1 and 12 months after loading, patient satisfaction, aesthetics by patient and by den- tist at 1 year.

Notes 
Meijndert 2007 (Continued)

Risk of bias

\begin{tabular}{lll}
\hline Bias & Authors' judgement & Support for judgement \\
\hline $\begin{array}{l}\text { Random sequence genera- } \\
\text { tion (selection bias) }\end{array}$ & Low risk & Article: "A computer program was used". \\
\hline $\begin{array}{l}\text { Allocation concealment } \\
\text { (selection bias) }\end{array}$ & Unclear risk & $\begin{array}{l}\text { Article: No information presented. } \\
\text { Author's reply: "If a patient met the inclusion criteria of the study, the patient's } \\
\text { record was handed to the investigator. The group allocation was done by the } \\
\text { investigator and told to the oral surgeon. The surgeon explained the treatment } \\
\text { method to the patient. From that moment on, the patient's treatment method } \\
\text { was concealed for the investigator". }\end{array}$ \\
$\begin{array}{l}\text { The above reply failed to clarify whether the allocation concealment was ade- } \\
\text { quate or not. }\end{array}$
\end{tabular}

\begin{tabular}{|c|c|c|}
\hline $\begin{array}{l}\text { Blinding (performance } \\
\text { bias and detection bias) }\end{array}$ & Low risk & $\begin{array}{l}\text { Article: "It was unknown to the observer which patient was rated and what } \\
\text { kind of augmentation procedure had been carried out". }\end{array}$ \\
\hline
\end{tabular}

All outcomes

$\begin{array}{ll}\begin{array}{l}\text { Incomplete outcome data } \\ \text { (attrition bias) }\end{array} & \text { High risk } \\ \text { All outcomes } & \begin{array}{l}\text { Data of the following outcomes were not presented at group level: marginal } \\ \text { bone level changes on intraoral radiographs, patient satisfaction, aesthetics } \\ \text { by patient and by dentist. }\end{array}\end{array}$

All outcomes by patient and by dentist.

Selective reporting (re- High risk Outcomes were inadequately reported, see above.
porting bias)

\begin{tabular}{ll}
\hline Other bias & The study wask commercially supported by Straumann and Geistlich. \\
& $\begin{array}{l}\text { Only combined data were reported, not at group level. After request of the } \\
\text { original data, the author's reply was: "we are working on it". }\end{array}$ \\
\hline
\end{tabular}

Merli 2007

\begin{tabular}{ll} 
Methods & 3-year post-loading follow-up randomised, parallel group study. There were no withdrawals. \\
\hline Participants & $\begin{array}{l}\text { Patients subjected to vertical GBR procedures. Adults treated at a private practice in Rimini, Italy. Pa- } \\
\text { tients were excluded if they had any general contraindication to implant surgery, history of irradiation } \\
\text { in the head and neck area, poor oral hygiene and motivation, uncontrolled diabetes, pregnant or lac- } \\
\text { tating, substance abusers, smoking more than } 20 \text { cigarettes per day. } 22 \text { patients enrolled, } 11 \text { in each } \\
\text { group. }\end{array}$
\end{tabular}

Interventions

Autogenous particulate bone harvested from intraoral locations contained under non-resorbable titanium-reinforced ePTFE barrier (Gore-Tex, WL Gore and Associates, Inc.) fixed with miniscrews (Gebrüder Martin GmbH \& Co. KG, Tuttlingen, Germany) versus osteosynthesis plates (Gebrüder Martin $\mathrm{GmbH} \& \mathrm{Co} . \mathrm{KG}$, Tuttlingen, Germany), appropriately shaped and fixed with miniscrews, supporting resorbable collagen barriers (Bio-Gide ${ }^{\circledR}$, Geistlich Pharma AG, Wolhusen, Switzerland). All patients were treated with a 1-stage approach, i.e. implants were inserted and the augmentation procedure was performed on the same occasion with or without intravenous sedation. Surgical templates were used to optimise implant insertion. XiVE ${ }^{\circledR}$ S CELLplus (Friadent GmbH, Mannheim, Germany) implants were used. All patients were rehabilitated with provisional resin fixed prostheses, replaced by metal ceramic definitive prostheses. 
Merli 2007 (Continued)

Outcomes

Prosthesis and implant failure, vertical bone gain, measured intrasurgically pre-operatively and at abutment connection, complications and bone level changes after loading.

Notes

\section{Risk of bias}

\begin{tabular}{lll}
\hline Bias & Authors' judgement & Support for judgement \\
\hline $\begin{array}{l}\text { Random sequence genera- } \\
\text { tion (selection bias) }\end{array}$ & Low risk & Article: "Manually created randomisation list". \\
\hline $\begin{array}{l}\text { Allocation concealment } \\
\text { (selection bias) }\end{array}$ & Low risk & $\begin{array}{l}\text { Article: "The outcome of the randomisation was kept in sequentially num- } \\
\text { bered, opaque, identical, sealed envelopes, which were opened at the time of } \\
\text { surgery, after implant placement". }\end{array}$ \\
\hline $\begin{array}{l}\text { Blinding (performance } \\
\text { bias and detection bias) } \\
\text { All outcomes }\end{array}$ & Low risk & $\begin{array}{l}\text { Article: "Independent assessors were used but blinding was not always pos- } \\
\text { sible". "All (bone gain) measurements were then check on clinical pho- } \\
\text { tographs by a second blind and independent assessor". "Blind outcome asses- } \\
\text { sors were used after loading". }\end{array}$ \\
& It is judged as adequate. \\
\hline
\end{tabular}

Incomplete outcome data Low risk (attrition bias)

Data of 4 patients were missing at the 1-year evaluation but all data were All outcomes present at the 3-year follow-up.

\section{Selective reporting (re- Low risk} porting bias)

Other bias Low risk

Raghoebar 2005

Methods 2-year post-loading follow-up randomised, split-mouth study. There were no withdrawals.

Participants

Patients with severely resorbed maxillae and reduced stability and retention of the upper dentures. Adults treated at the University Hospital Groningen, The Netherlands. Patients were excluded if they were edentulous for a period of less than 1 year, history of irradiation in the head and neck area, history of reconstructive preprosthetic surgery or previous implant surgery. 5 patients were treated.

Interventions 2-stage sinus lift with autogenous blocks and particulate bone together with buccal onlay monocorti-
co-cancellous bone grafts, to reconstruct the width of the maxilla, fixed with titanium screws harvest-
ed from the iliac crest with or without PRP left to heal for 3 months in a split-mouth trial. Barriers were
not used. PRP was made using the Platelet Concentration Collection System kit (PCCS kit, 3i Implant In-
novations Inc. Palm Beach Gardens, FL, USA). 54 ml of blood were mixed with 6 ml of anticoagulant (cit-
rate dextrose) and processed with the platelet concentration system. To promote the release of growth
factors from the platelets, $10 \%$ calcium chloride solution and the patient's serum, as a source of autol-
ogous thrombin, were added before actual reconstruction of the defect with the bone graft. The result-
ing gel was mixed with the bone graft and some gel was applied at the closure of the wound at the side
treated with PRP. 3 implants were inserted into the healed graft of each side and were left to heal for an
additional 6 months. All the augmentation procedures were performed under general anaesthesia. Sur-
gical templates were used to optimise implant insertion. All implants were turned titanium self tapping
(Nobel Biocare, Göteborg, Sweden) and were rehabilitated with 2 implant-supported prostheses. 
Raghoebar 2005 (Continued)

Outcomes

Prosthesis and implant failure, complications at the augmented and donor sites, histomorphometric evaluation.

Notes

\section{Risk of bias}

\begin{tabular}{|c|c|c|}
\hline Bias & Authors' judgement & Support for judgement \\
\hline $\begin{array}{l}\text { Random sequence genera- } \\
\text { tion (selection bias) }\end{array}$ & Low risk & $\begin{array}{l}\text { Article: No information presented. } \\
\text { Author's reply: "Randomisation by lot". }\end{array}$ \\
\hline $\begin{array}{l}\text { Allocation concealment } \\
\text { (selection bias) }\end{array}$ & Unclear risk & $\begin{array}{l}\text { Article: No information presented. } \\
\text { Author's reply failed to clarify the issue. }\end{array}$ \\
\hline $\begin{array}{l}\text { Blinding (performance } \\
\text { bias and detection bias) } \\
\text { All outcomes }\end{array}$ & Low risk & $\begin{array}{l}\text { Article: "The investigators were blinded for both the clinical and laboratory in- } \\
\text { vestigations with regard to the PRP- treated side". }\end{array}$ \\
\hline $\begin{array}{l}\text { Incomplete outcome data } \\
\text { (attrition bias) } \\
\text { All outcomes }\end{array}$ & Low risk & All data presented, no drop outs. \\
\hline $\begin{array}{l}\text { Selective reporting (re- } \\
\text { porting bias) }\end{array}$ & Low risk & \\
\hline Other bias & Low risk & $\begin{array}{l}\text { Author: "The apparatus was gift from the company promoting the use of PRP". } \\
\text { This is considered to be irrelevant. }\end{array}$ \\
\hline
\end{tabular}

Raghoebar 2006

\begin{tabular}{ll}
\hline Methods & 2-year post-loading follow-up randomised, split-mouth study. There were no withdrawals. \\
\hline Participants & $\begin{array}{l}\text { Patients with severely resorbed maxillae and reduced stability and retention of the upper dentures. } \\
\text { Adults treated at the University Hospital Groningen, The Netherlands. Patients were excluded if they } \\
\text { were edentulous for a period of less than } 1 \text { year, history of irradiation in the head and neck area, history } \\
\text { of reconstructive preprosthetic surgery or previous implant surgery. } 8 \text { patients were treated. }\end{array}$ \\
\hline
\end{tabular}

Interventions

2-stage buccal onlay monocortico-cancellous bone grafts fixed with 2 titanium (diameter $1.5 \mathrm{~mm}$, Martin Medizin Technik, Tuttlingen, Germany) or resorbable poly (D, L-lactide) acid (PDLLA, diameter 2.1 $\mathrm{mm}$, Resorb X, Martin Medizin Technik) screws in a split-mouth trial, to reconstruct the width of the maxilla. Grafts were covered with resorbable barriers (Bio-Gide, Geistlich Pharmaceutical, Wolhusen, Switzerland). Grafts were harvested from the iliac crest and bilateral sinus lifts were performed at the same time with autogenous blocks and particulate bone. After 3 months, implants were inserted into the healed graft of each side and were left to heal for additional 6 months. All the augmentation procedures were performed under general anaesthesia. Surgical templates were used to optimise implant in sertion. All implants were turned titanium self tapping (Nobel Biocare, Göteborg, Sweden) and were rehabilitated with implant-supported prostheses.

Outcomes Prosthesis and implant failure, complications at the augmented and donor sites, histomorphometric evaluation.

\section{Notes}


Raghoebar 2006 (Continued)

Risk of bias

\begin{tabular}{|c|c|c|}
\hline Bias & Authors' judgement & Support for judgement \\
\hline \multirow{2}{*}{$\begin{array}{l}\text { Random sequence genera- } \\
\text { tion (selection bias) }\end{array}$} & Low risk & Article: No information presented. \\
\hline & & Author's reply: "By lot". \\
\hline \multirow{2}{*}{$\begin{array}{l}\text { Allocation concealment } \\
\text { (selection bias) }\end{array}$} & Unclear risk & Article: No information presented. \\
\hline & & Author's reply failed to clarify the issue. \\
\hline \multirow{2}{*}{$\begin{array}{l}\text { Blinding (performance } \\
\text { bias and detection bias) } \\
\text { All outcomes }\end{array}$} & High risk & Article: No information presented. \\
\hline & & Author's reply: "No". \\
\hline \multirow{2}{*}{$\begin{array}{l}\text { Incomplete outcome data } \\
\text { (attrition bias) } \\
\text { All outcomes }\end{array}$} & Low risk & \\
\hline & & Author's reply: "No drop outs". \\
\hline $\begin{array}{l}\text { Selective reporting (re- } \\
\text { porting bias) }\end{array}$ & Low risk & \\
\hline \multirow[t]{3}{*}{ Other bias } & Low risk & No information on funding was found in the article. \\
\hline & & $\begin{array}{l}\text { Author: "We received the resorbable screws for free from the company. They } \\
\text { did not pay for the research performed". }\end{array}$ \\
\hline & & This is not judged as a potential source of bias. \\
\hline
\end{tabular}

Schortinghuis 2008

Methods 2-year post-loading follow-up randomised, parallel group study. There were no withdrawals.

Participants

Patients with severely resorbed mandibles (height at canine region $<8 \mathrm{~mm}$ ) and reduced stability and retention of the lower denture. Adults treated at the University Hospital Groningen, The Netherlands.

Patients were excluded if they had contraindication to general anesthesia. 9 patients were treated, 5 in the ultrasound group and 4 in the placebo group.

Interventions

Ultrasound or placebo were applied using a sonic-accelerated fracture-healing system (SAFHS model 2000, Smith and Nephew, Memphis, TN, USA) by patients subjected to vertical osteodistraction osteogenesis in the anterior mandible when active osteodistraction was initiated after a latency period of about 5 days. Ultrasound self treatment involved a daily treatment of 20 minutes for about 50 days on the skin of the chin covering the osteodistraction gap using $1.5 \mathrm{MHz}$ pressure wave in pulses of $200 \mu \mathrm{s}$. Between pulses there was a $800 \mu$ s pause (on:off period $=1: 4$ ). Patient compliance was monitored by a memory chip inside the ultrasound equipment. 6 weeks post-distraction the distraction devices were removed and $212 \mathrm{~mm}$ long ITI Bonefit implants (Straumann AG, Waldenburg, Switzerland) were inserted and left to heal for 3 months before being loaded with an overdenture.

\section{Notes}

\section{Risk of bias}

\section{Bias \\ Authors' judgement Support for judgement}


Stellingsma 2003 (Continued)

evaluated prior to the intervention and after 1 year of loading. The following aspects were investigated: denture satisfaction, denture complaints, overall denture satisfaction, the impact of denture problems on social activities, psychological well-being and experience of the surgical phase.

\begin{tabular}{|c|c|c|}
\hline \multicolumn{3}{|l|}{ Notes } \\
\hline Risk of bias & & \\
\hline Bias & Authors' judgement & Support for judgement \\
\hline $\begin{array}{l}\text { Random sequence genera- } \\
\text { tion (selection bias) }\end{array}$ & Low risk & Article: "A computer program was used for the allocation of the patients". \\
\hline $\begin{array}{l}\text { Allocation concealment } \\
\text { (selection bias) }\end{array}$ & Unclear risk & $\begin{array}{l}\text { Article: No information presented. } \\
\text { Author's reply failed to clarify the issue. }\end{array}$ \\
\hline $\begin{array}{l}\text { Blinding (performance } \\
\text { bias and detection bias) } \\
\text { All outcomes }\end{array}$ & High risk & $\begin{array}{l}\text { Article: No information presented. } \\
\text { Author's reply: "No". }\end{array}$ \\
\hline $\begin{array}{l}\text { Incomplete outcome data } \\
\text { (attrition bias) } \\
\text { All outcomes }\end{array}$ & Low risk & Drop outs explained in the text. No missing data. \\
\hline $\begin{array}{l}\text { Selective reporting (re- } \\
\text { porting bias) }\end{array}$ & Low risk & \\
\hline Other bias & Unclear risk & $\begin{array}{l}\text { Different types of implants were used in } 2 \text { groups. We are unsure if it could } \\
\text { have influenced the outcome of treatment. } \\
\text { Author clarified that "for all the patients we received some funding of the man- } \\
\text { ufacturers of the implants". This is judged as not having affected the results. }\end{array}$ \\
\hline
\end{tabular}

GBR - guided bone regeneration

PRP - platelet rich plasma

$\mathrm{RCT}$ - randomised controlled trial

Characteristics of excluded studies [ordered by study ID]

\begin{tabular}{ll}
\hline Study & Reason for exclusion \\
\hline Antoun 2001 & $\begin{array}{l}\text { Study previously included. Now excluded since it does not contain any outcome measures related } \\
\text { to implant treatment. }\end{array}$
\end{tabular}

Friedmann 2002

Study previously included. Now excluded since it does not contain any outcome measures related to implant treatment.

\begin{tabular}{ll}
\hline Roccuzzo 2007 & No clinical outcome measures related to implant treatment. \\
\hline Schortinghuis 2005 & $\begin{array}{l}\text { Interesting placebo-controlled pilot trial evaluating the efficacy of ultrasound in stimulating bone } \\
\text { formation in a distraction gap. Excluded since only reporting histological outcomes, however } \\
\text { worth reading. }\end{array}$
\end{tabular}

Van der Zee 2004

3 groups of 10 patients each treated with various augmentation procedures followed-up to abutment connection. No outcome of interest with the exception of gingiva levels at adjacent teeth 
(aesthetics), however data presented in aggregate form. 1 withdrawal but unclear from which group.

\section{DATA AND ANALYSES}

\section{Comparison 1. Vertical augmentation versus no augmentation}

\begin{tabular}{|c|c|c|c|c|}
\hline Outcome or subgroup title & $\begin{array}{l}\text { No. of } \\
\text { studies }\end{array}$ & $\begin{array}{l}\text { No. of } \\
\text { partici- } \\
\text { pants }\end{array}$ & Statistical method & Effect size \\
\hline $\begin{array}{l}1 \text { Inlay bone grafts versus short } \\
\text { implants in atrophic mandibles }\end{array}$ & 2 & & Odds Ratio (M-H, Random, 95\% Cl) & Subtotals only \\
\hline 1.1 Prosthetic failure & 2 & 98 & Odds Ratio (M-H, Random, 95\% Cl) & $3.20[0.48,21.25]$ \\
\hline 1.2 Implant failure & 2 & 98 & Odds Ratio (M-H, Random, 95\% Cl) & $5.74[0.92,35.82]$ \\
\hline 1.3 Major complications & 2 & 100 & Odds Ratio (M-H, Random, 95\% Cl) & $4.97[1.10,22.40]$ \\
\hline $\begin{array}{l}\text { 1.4 Experienced the operation } \\
\text { negatively }\end{array}$ & 1 & 40 & Odds Ratio (M-H, Random, 95\% Cl) & $3.0[0.79,11.44]$ \\
\hline 1.5 Severe pain for $>1$ week & 1 & 40 & Odds Ratio (M-H, Random, 95\% Cl) & $22.67[4.37,117.47]$ \\
\hline $\begin{array}{l}\text { 1.6 No improvement of facial } \\
\text { appearance ( } 3 \text { weeks) }\end{array}$ & 1 & 40 & Odds Ratio (M-H, Random, 95\% Cl) & $0.11[0.03,0.46]$ \\
\hline
\end{tabular}

Analysis 1.1. Comparison 1 Vertical augmentation versus no augmentation, Outcome 1 Inlay bone grafts versus short implants in atrophic mandibles.

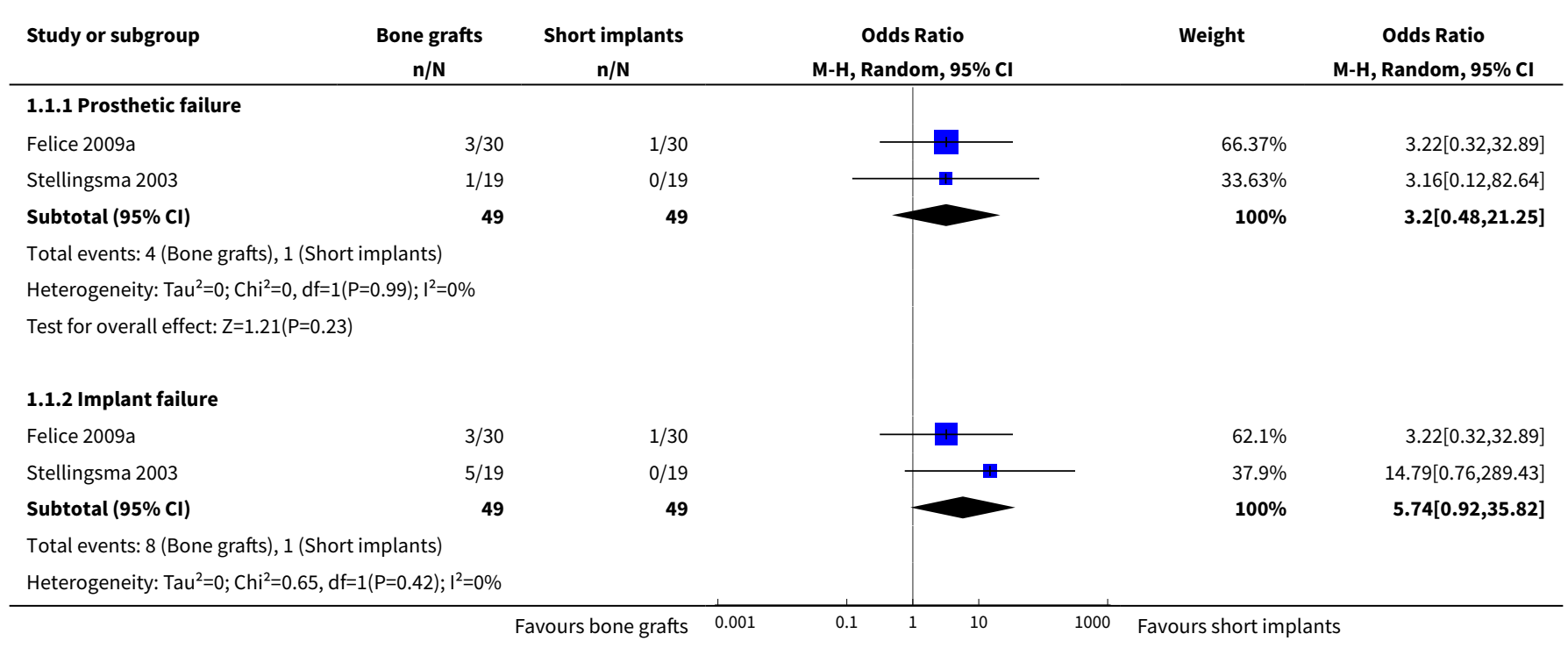




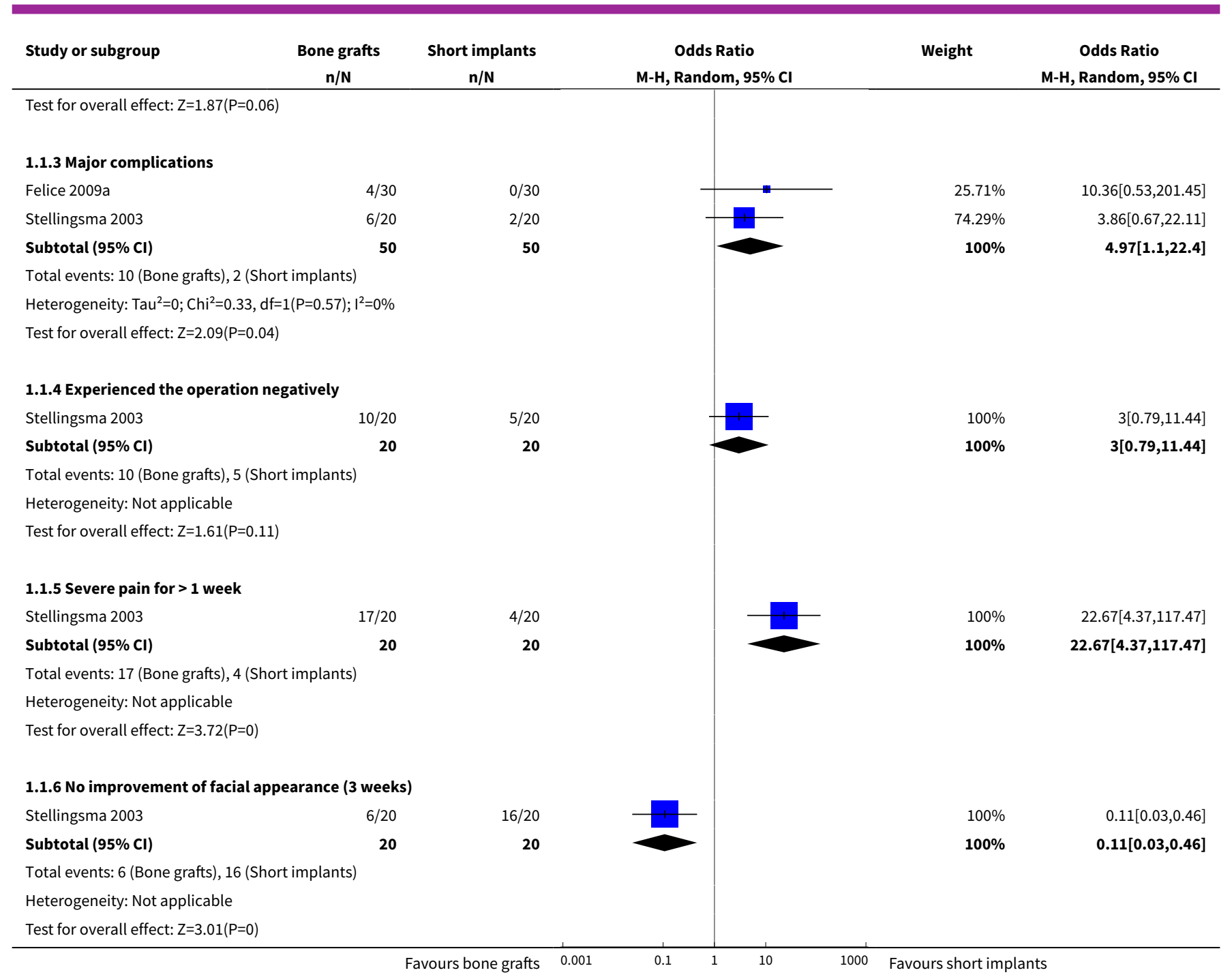

\section{Comparison 2. Horizontal augmentation versus horizontal augmentation}

\begin{tabular}{lllll}
\hline Outcome or subgroup title & $\begin{array}{l}\text { No. of } \\
\text { studies }\end{array}$ & $\begin{array}{l}\text { No. of } \\
\text { partici- } \\
\text { pants }\end{array}$ & Statistical method & Effect size \\
\hline $\begin{array}{l}1 \text { Horizontal augmentation: bone versus } \\
100 \% \text { Bio-Oss + barrier }\end{array}$ & 1 & & Odds Ratio (M-H, Random, 95\% Cl) & Subtotals only \\
\hline $\begin{array}{lllll}1.1 \text { Prosthesis/implant failure (1 year) } \\
2 \text { Horizontal augmentation: bone + barrier } \\
\text { versus 100\% Bio-Oss + barrier }\end{array}$ & 1 & 62 & Odds Ratio (M-H, Random, 95\% Cl) & $0.19[0.01,4.07]$ \\
\hline \begin{tabular}{l}
2.1 Prosthesis/implant failure (1 year) \\
\hline
\end{tabular} & 1 & 62 & Odds Ratio (M-H, Fixed, 95\% Cl) & Subtotals only \\
\hline
\end{tabular}


Analysis 2.1. Comparison 2 Horizontal augmentation versus horizontal augmentation, Outcome 1 Horizontal augmentation: bone versus $100 \%$ Bio-Oss + barrier.

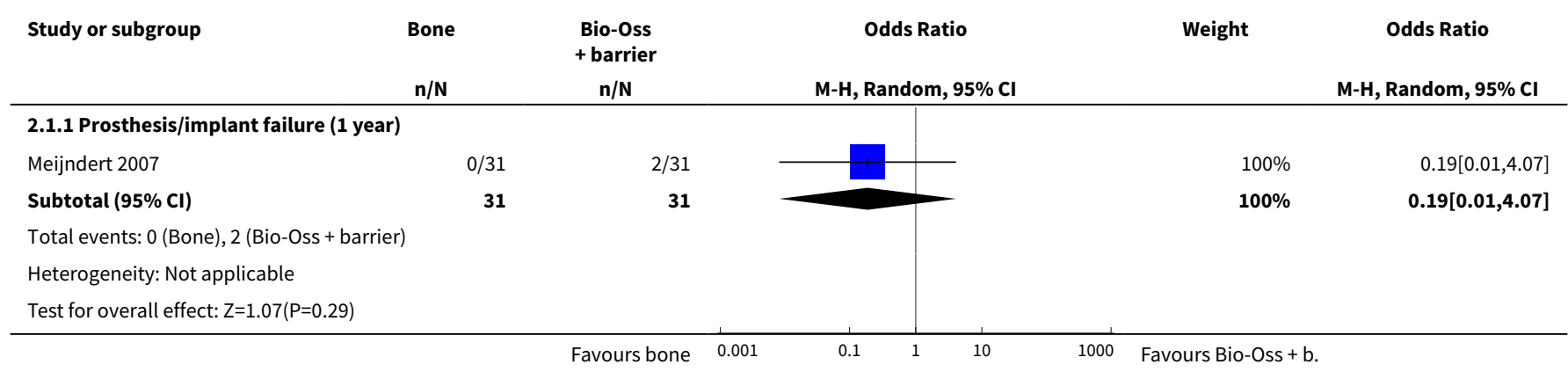

\section{Analysis 2.2. Comparison 2 Horizontal augmentation versus horizontal augmentation, Outcome 2 Horizontal augmentation: bone + barrier versus 100\% Bio-Oss + barrier.}

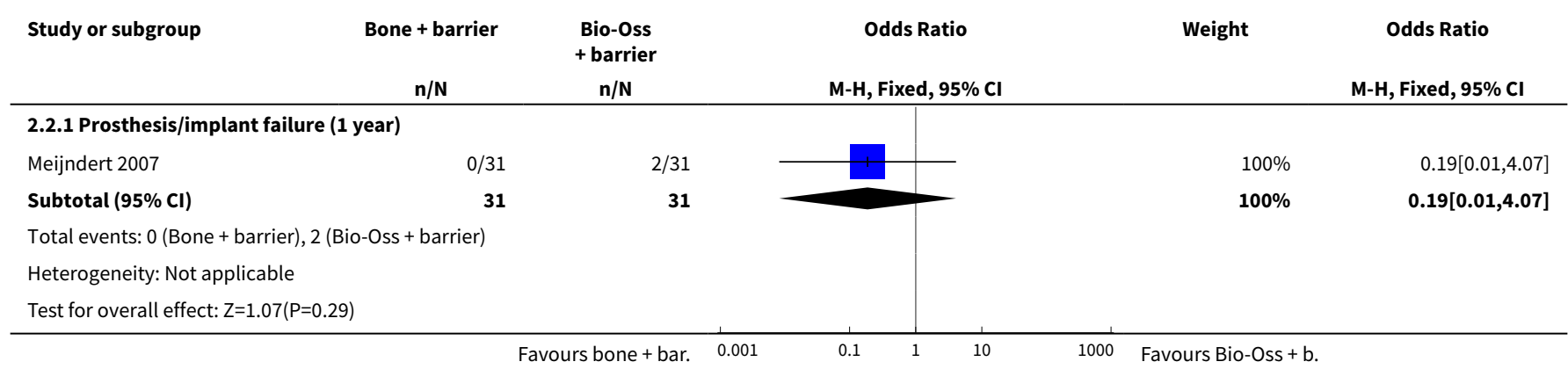

\section{Comparison 3. Vertical augmentation versus vertical augmentation}

\begin{tabular}{|c|c|c|c|c|}
\hline Outcome or subgroup title & $\begin{array}{l}\text { No. of } \\
\text { studies }\end{array}$ & $\begin{array}{l}\text { No. of } \\
\text { partici- } \\
\text { pants }\end{array}$ & Statistical method & Effect size \\
\hline $\begin{array}{l}1 \text { Osteodistraction versus inlay } \\
\text { bone graft (binary) }\end{array}$ & 1 & & Odds Ratio (M-H, Fixed, 95\% Cl) & Subtotals only \\
\hline 1.1 Complications & 1 & 11 & Odds Ratio (M-H, Fixed, 95\% Cl) & $7.50[0.46,122.70]$ \\
\hline $\begin{array}{l}2 \text { Osteodistraction versus inlay } \\
\text { bone graft (continuous) }\end{array}$ & 1 & & Mean Difference (IV, Fixed, 95\% CI) & Subtotals only \\
\hline 2.1 Bone gain & 1 & 11 & Mean Difference (IV, Fixed, 95\% CI) & $3.25[1.66,4.84]$ \\
\hline $\begin{array}{l}3 \text { Osteodistraction versus on- } \\
\text { lay bone graft (binary) }\end{array}$ & 1 & & Odds Ratio (M-H, Fixed, 95\% Cl) & Subtotals only \\
\hline $\begin{array}{l}\text { 3.1 Augmentation procedure } \\
\text { (partial) failure }\end{array}$ & 1 & 17 & Odds Ratio (M-H, Fixed, 95\% Cl) & $0.88[0.05,16.74]$ \\
\hline $\begin{array}{l}3.2 \text { Complication at augment- } \\
\text { ed + donor site }\end{array}$ & 1 & 17 & Odds Ratio (M-H, Fixed, 95\% Cl) & $0.5[0.07,3.55]$ \\
\hline
\end{tabular}




\begin{tabular}{|c|c|c|c|c|}
\hline Outcome or subgroup title & $\begin{array}{l}\text { No. of } \\
\text { studies }\end{array}$ & $\begin{array}{l}\text { No. of } \\
\text { partici- } \\
\text { pants }\end{array}$ & Statistical method & Effect size \\
\hline $\begin{array}{l}4 \text { Osteodistraction versus on- } \\
\text { lay bone graft (continuous) }\end{array}$ & 1 & & Mean Difference (IV, Fixed, 95\% CI) & Subtotals only \\
\hline 4.1 Vertical bone gain & 1 & 17 & Mean Difference (IV, Fixed, 95\% CI) & $0.30[-0.97,1.57]$ \\
\hline $\begin{array}{l}4.21 \text {-year post-loading bone } \\
\text { level changes }\end{array}$ & 1 & 17 & Mean Difference (IV, Fixed, 95\% CI) & $0.09[-0.26,0.44]$ \\
\hline $\begin{array}{l}4.33 \text {-year post-loading bone } \\
\text { level changes }\end{array}$ & 1 & 17 & Mean Difference (IV, Fixed, 95\% CI) & $0.29[-0.14,0.72]$ \\
\hline $\begin{array}{l}5 \text { Osteodistraction versus GBR } \\
\text { (binary) }\end{array}$ & 1 & & Odds Ratio (M-H, Fixed, 95\% Cl) & Subtotals only \\
\hline $\begin{array}{l}5.1 \text { Complication at augmenta- } \\
\text { tion + donor site }\end{array}$ & 1 & 21 & Odds Ratio (M-H, Fixed, 95\% Cl) & $0.3[0.04,2.11]$ \\
\hline $\begin{array}{l}6 \text { GBR: autogenous bone ver- } \\
\text { sus bone substitute (continu- } \\
\text { ous) }\end{array}$ & 1 & & Mean Difference (Fixed, 95\% Cl) & Subtotals only \\
\hline 6.1 Vertical bone gain & 1 & & Mean Difference (Fixed, 95\% Cl) & $0.6[0.21,0.99]$ \\
\hline $\begin{array}{l}7 \text { GBR: non-resorbable versus } \\
\text { resorbable barriers (binary) }\end{array}$ & 1 & & Odds Ratio (M-H, Fixed, 95\% Cl) & Subtotals only \\
\hline $\begin{array}{l}\text { 7.1 Augmentation procedure } \\
\text { failure }\end{array}$ & 1 & 22 & Odds Ratio (M-H, Fixed, 95\% Cl) & $2.22[0.17,28.86]$ \\
\hline $\begin{array}{l}7.2 \text { Complication at augment- } \\
\text { ed site }\end{array}$ & 1 & 22 & Odds Ratio (M-H, Fixed, 95\% Cl) & $1.46[0.26,8.05]$ \\
\hline $\begin{array}{l}8 \text { GBR: non-resorbable versus } \\
\text { resorbable barriers (continu- } \\
\text { ous) }\end{array}$ & 1 & & Mean Difference (IV, Fixed, 95\% CI) & Subtotals only \\
\hline 8.1 Vertical bone gain & 1 & 22 & Mean Difference (IV, Fixed, 95\% CI) & $0.32[-0.79,1.43]$ \\
\hline $\begin{array}{l}8.2 \text { Perimplant bone loss ( } 3 \\
\text { years) }\end{array}$ & 1 & 22 & Mean Difference (IV, Fixed, 95\% CI) & $0.02[-0.50,0.54]$ \\
\hline $\begin{array}{l}9 \text { Inlay graft: autogenous bone } \\
\text { versus bone substitute (con- } \\
\text { tinuous) }\end{array}$ & 1 & & Mean Difference (Fixed, 95\% Cl) & Subtotals only \\
\hline 9.1 Bone gain & 1 & & Mean Difference (Fixed, 95\% Cl) & $-1.1[-2.61,0.41]$ \\
\hline 9.2 Perimplant bone loss & 1 & & Mean Difference (Fixed, 95\% Cl) & $-0.21[-0.76,0.34]$ \\
\hline $\begin{array}{l}10 \text { Inlay graft: autogenous } \\
\text { bone versus bone substitute } \\
\text { (binary) }\end{array}$ & 1 & & Odds Ratio (Fixed, 95\% Cl) & Subtotals only \\
\hline 10.1 Prosthesis failure & 1 & & Odds Ratio (Fixed, 95\% Cl) & $1.0[0.01,82.26]$ \\
\hline
\end{tabular}




\begin{tabular}{|c|c|c|c|c|}
\hline Outcome or subgroup title & $\begin{array}{l}\text { No. of } \\
\text { studies }\end{array}$ & $\begin{array}{l}\text { No. of } \\
\text { partici- } \\
\text { pants }\end{array}$ & Statistical method & Effect size \\
\hline 10.2 Implant failure & 1 & & Odds Ratio (Fixed, 95\% Cl) & $1.0[0.01,82.26]$ \\
\hline 10.3 Major complications & 1 & & Odds Ratio (Fixed, 95\% Cl) & $2.00[0.11,37.83]$ \\
\hline $\begin{array}{l}11 \text { Autogenous bone: inlay ver- } \\
\text { sus onlay (binary) }\end{array}$ & 1 & & Odds Ratio (M-H, Fixed, 95\% Cl) & Subtotals only \\
\hline 11.1 Graft failure & 1 & 23 & Odds Ratio (M-H, Fixed, 95\% Cl) & $1.33[0.07,24.32]$ \\
\hline 11.2 Major complications & 1 & 23 & Odds Ratio (M-H, Fixed, 95\% Cl) & $1.07[0.20,5.77]$ \\
\hline $\begin{array}{l}12 \text { Autogenous bone: inlay ver- } \\
\text { sus onlay (continuous) }\end{array}$ & 1 & & Mean Difference (IV, Fixed, 95\% CI) & Subtotals only \\
\hline 12.1 Vertical bone gain & 1 & 23 & Mean Difference (IV, Fixed, 95\% CI) & $0.97[-0.07,2.01]$ \\
\hline
\end{tabular}

Analysis 3.1. Comparison 3 Vertical augmentation versus vertical augmentation, Outcome 1 Osteodistraction versus inlay bone graft (binary).

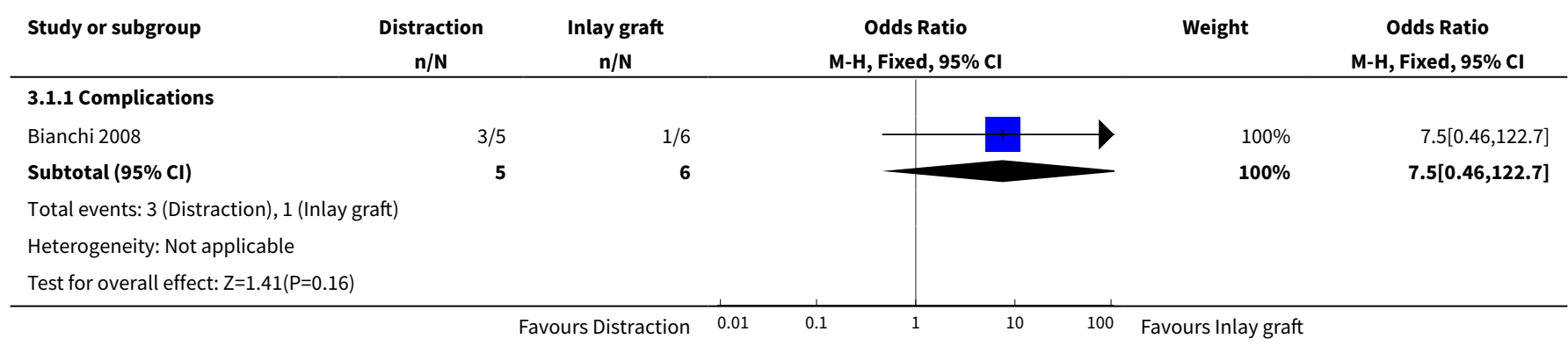

Analysis 3.2. Comparison 3 Vertical augmentation versus vertical augmentation, Outcome 2 Osteodistraction versus inlay bone graft (continuous).

\begin{tabular}{|c|c|c|c|c|c|c|c|}
\hline \multirow[t]{2}{*}{ Study or subgroup } & \multicolumn{2}{|c|}{ Osteodistraction } & \multicolumn{2}{|c|}{ Inlay graft } & \multirow{2}{*}{$\begin{array}{c}\text { Mean Difference } \\
\text { Fixed, } 95 \% \mathrm{Cl}\end{array}$} & \multirow[t]{2}{*}{ Weight } & \multirow{2}{*}{$\begin{array}{c}\text { Mean Difference } \\
\text { Fixed, } 95 \% \mathrm{Cl}\end{array}$} \\
\hline & $\mathbf{N}$ & Mean(SD) & $\mathbf{N}$ & Mean(SD) & & & \\
\hline \multicolumn{8}{|l|}{ 3.2.1 Bone gain } \\
\hline Bianchi 2008 & 5 & $8.4(1.7)$ & 6 & $5.1(0.6)$ & & $100 \%$ & $3.25[1.66,4.84]$ \\
\hline 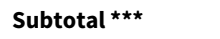 & 5 & & 6 & & & $100 \%$ & $3.25[1.66,4.84]$ \\
\hline \multicolumn{8}{|c|}{ Heterogeneity: $\mathrm{Tau}^{2}=0 ; \mathrm{Chi}^{2}=0, \mathrm{df}=0(\mathrm{P}<0.0001) ; \mathrm{I}^{2}=100 \%$} \\
\hline \multicolumn{8}{|c|}{ Test for overall effect: $Z=4.01(P<0.0001)$} \\
\hline
\end{tabular}


Analysis 3.3. Comparison 3 Vertical augmentation versus vertical augmentation, Outcome 3 Osteodistraction versus onlay bone graft (binary).

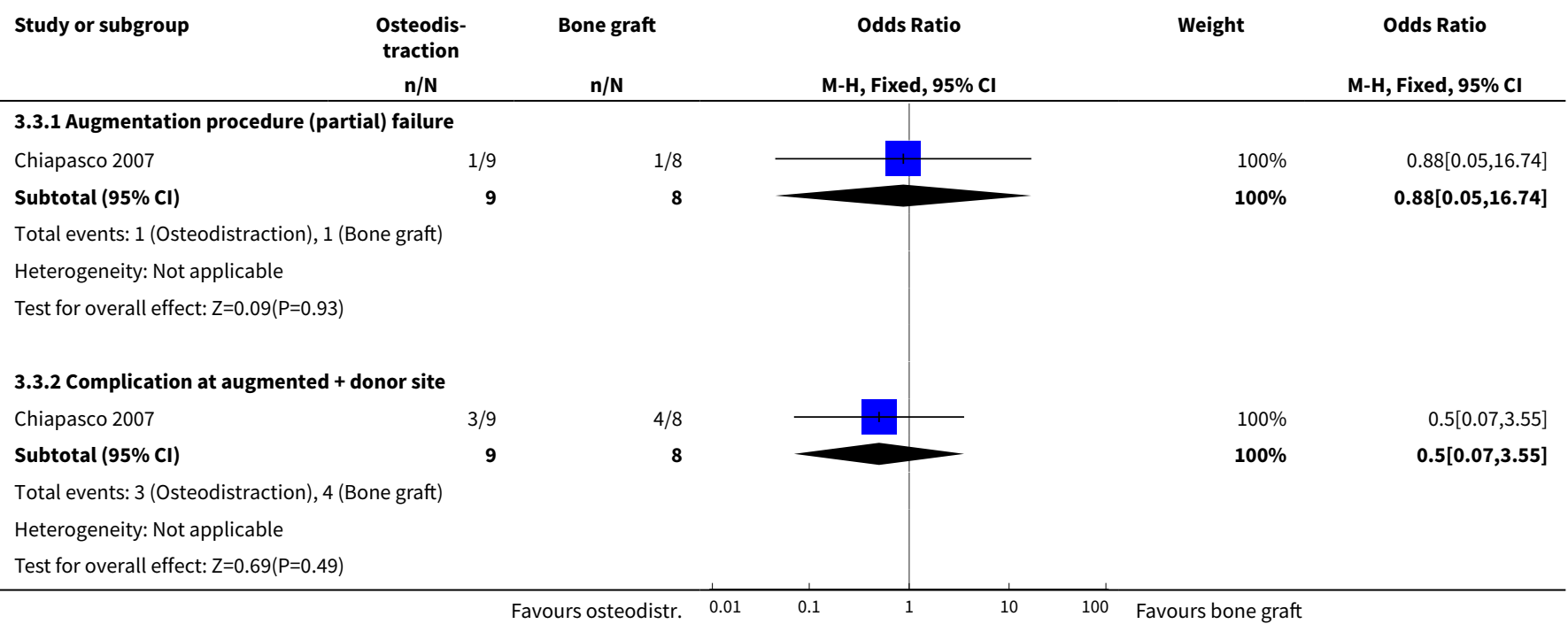

\section{Analysis 3.4. Comparison 3 Vertical augmentation versus vertical augmentation, Outcome 4 Osteodistraction versus onlay bone graft (continuous).}

\begin{tabular}{|c|c|c|c|c|c|c|c|}
\hline \multirow[t]{2}{*}{ Study or subgroup } & \multicolumn{2}{|c|}{ Osteodistraction } & \multicolumn{2}{|c|}{ Bone graft } & \multirow{2}{*}{$\begin{array}{c}\text { Mean Difference } \\
\text { Fixed, } 95 \% \mathrm{Cl}\end{array}$} & \multirow[t]{2}{*}{ Weight } & \multirow{2}{*}{$\begin{array}{c}\text { Mean Difference } \\
\text { Fixed, } 95 \% \mathrm{Cl}\end{array}$} \\
\hline & $\mathbf{N}$ & $\operatorname{Mean}(S D)$ & $\mathbf{N}$ & $\operatorname{Mean}(S D)$ & & & \\
\hline \multicolumn{8}{|c|}{ 3.4.1 Vertical bone gain } \\
\hline Chiapasco 2007 & 9 & $5.3(1.6)$ & 8 & $5(1.1)$ & & $100 \%$ & $0.3[-0.97,1.57]$ \\
\hline Subtotal $\star \star \star ~$ & 9 & & 8 & & & $100 \%$ & $0.3[-0.97,1.57]$ \\
\hline \multicolumn{8}{|c|}{ Heterogeneity: Not applicable } \\
\hline \multicolumn{8}{|c|}{ Test for overall effect: $Z=0.46(P=0.64)$} \\
\hline \multicolumn{8}{|c|}{ 3.4.2 1-year post-loading bone level changes } \\
\hline Chiapasco 2007 & 9 & $-0.8(0.4)$ & 8 & $-0.9(0.4)$ & + & $100 \%$ & $0.09[-0.26,0.44]$ \\
\hline 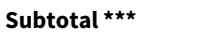 & 9 & & 8 & & 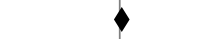 & $100 \%$ & $0.09[-0.26,0.44]$ \\
\hline \multicolumn{8}{|c|}{ Heterogeneity: Not applicable } \\
\hline \multicolumn{8}{|c|}{ Test for overall effect: $Z=0.51(P=0.61)$} \\
\hline Chiapasco 2007 & 9 & $-0.9(0.4)$ & 8 & $-1.2(0.5)$ & + & $100 \%$ & $0.29[-0.14,0.72]$ \\
\hline Subtotal $* \star \star$ & 9 & & 8 & & 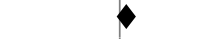 & $100 \%$ & $0.29[-0.14,0.72]$ \\
\hline \multicolumn{8}{|c|}{ Heterogeneity: Not applicable } \\
\hline \multicolumn{8}{|c|}{ Test for overall effect: $\mathrm{Z}=1.33(\mathrm{P}=0.18)$} \\
\hline \multicolumn{8}{|c|}{ Test for subgroup differences: $\mathrm{Chi}^{2}=0.55, \mathrm{df}=1(\mathrm{P}=0.76), \mathrm{I}^{2}=0 \%$} \\
\hline & & & Favo & bone graft -10 & 0 & Favour & str. \\
\hline
\end{tabular}


Analysis 3.5. Comparison 3 Vertical augmentation versus vertical augmentation, Outcome 5 Osteodistraction versus GBR (binary).

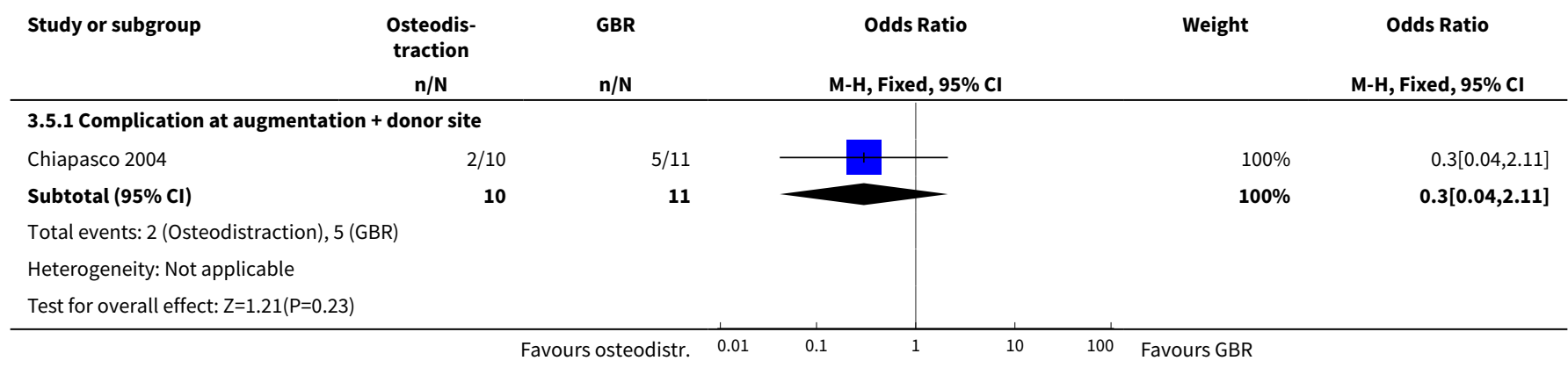

Analysis 3.6. Comparison 3 Vertical augmentation versus vertical augmentation, Outcome 6 GBR: autogenous bone versus bone substitute (continuous).

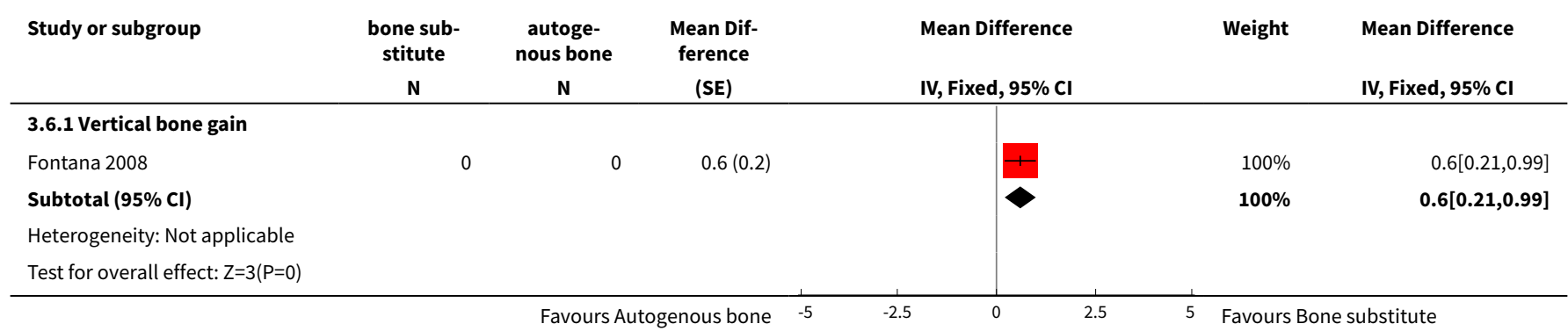

Analysis 3.7. Comparison 3 Vertical augmentation versus vertical augmentation, Outcome 7 GBR: non-resorbable versus resorbable barriers (binary).

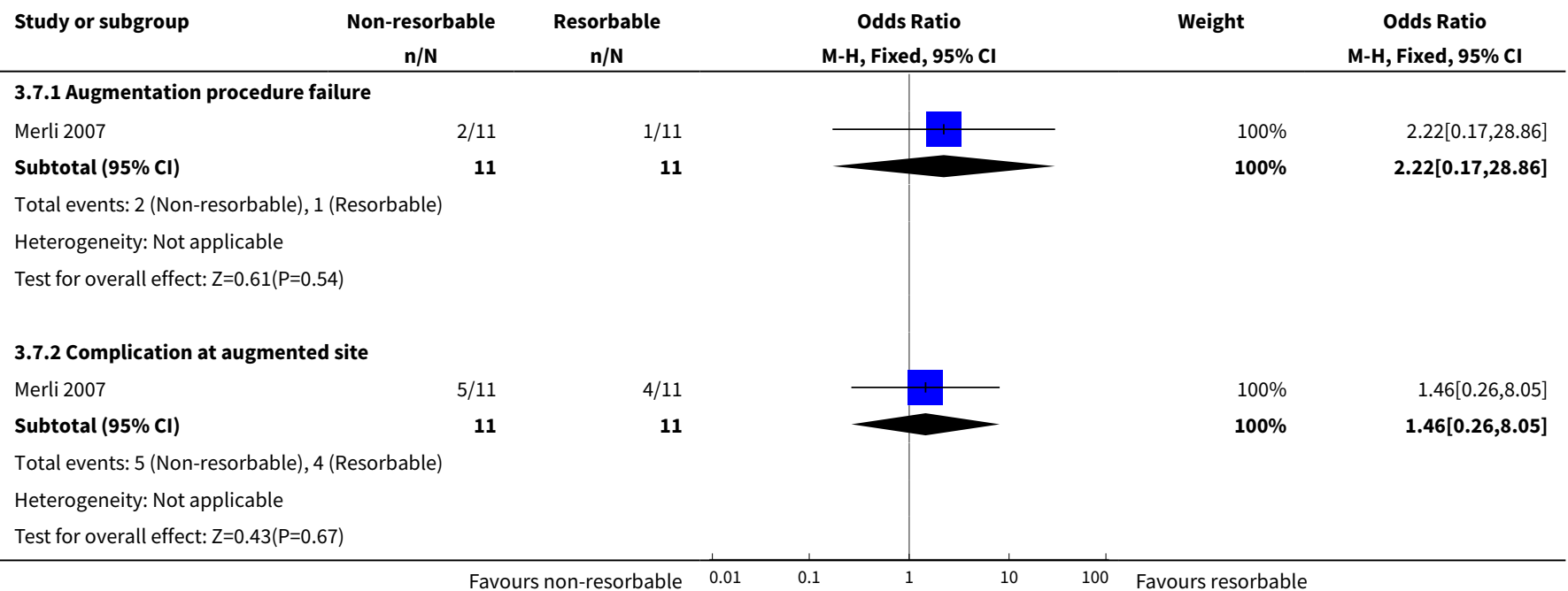


Analysis 3.8. Comparison 3 Vertical augmentation versus vertical augmentation, Outcome 8 GBR: non-resorbable versus resorbable barriers (continuous).

\begin{tabular}{|c|c|c|c|c|c|c|c|}
\hline \multirow[t]{2}{*}{ Study or subgroup } & \multicolumn{2}{|c|}{ Non-resorb. } & \multicolumn{2}{|c|}{ Resorb. } & \multirow{2}{*}{$\begin{array}{c}\text { Mean Difference } \\
\text { Fixed, } 95 \% \mathrm{Cl}\end{array}$} & \multirow[t]{2}{*}{ Weight } & \multirow{2}{*}{$\begin{array}{c}\text { Mean Difference } \\
\text { Fixed, } 95 \% \mathrm{Cl}\end{array}$} \\
\hline & $\mathbf{N}$ & $\operatorname{Mean}(S D)$ & $\mathbf{N}$ & $\operatorname{Mean}(S D)$ & & & \\
\hline \multicolumn{8}{|c|}{ 3.8.1 Vertical bone gain } \\
\hline Merli 2007 & 11 & $2.5(1.1)$ & 11 & $2.2(1.5)$ & & $100 \%$ & $0.32[-0.79,1.43]$ \\
\hline Subtotal $* \star \star$ & 11 & & 11 & & & $100 \%$ & $0.32[-0.79,1.43]$ \\
\hline \multicolumn{8}{|c|}{ Heterogeneity: Not applicable } \\
\hline \multicolumn{8}{|c|}{ Test for overall effect: $Z=0.56(P=0.57)$} \\
\hline \multicolumn{8}{|c|}{ 3.8.2 Perimplant bone loss ( 3 years) } \\
\hline Merli 2007 & 11 & $-0.5(0.7)$ & 11 & $-0.5(0.6)$ & & $100 \%$ & $0.02[-0.5,0.54]$ \\
\hline Subtotal $* \star \star$ & 11 & & 11 & & & $100 \%$ & $0.02[-0.5,0.54]$ \\
\hline \multicolumn{8}{|c|}{ Heterogeneity: Not applicable } \\
\hline \multicolumn{8}{|c|}{ Test for overall effect: $Z=0.08(P=0.94)$} \\
\hline \multicolumn{8}{|c|}{ Test for subgroup differences: $\mathrm{Chi}^{2}=0.23, \mathrm{df}=1(\mathrm{P}=0.63), \mathrm{I}^{2}=0 \%$} \\
\hline
\end{tabular}

Analysis 3.9. Comparison 3 Vertical augmentation versus vertical augmentation, Outcome 9 Inlay graft: autogenous bone versus bone substitute (continuous).

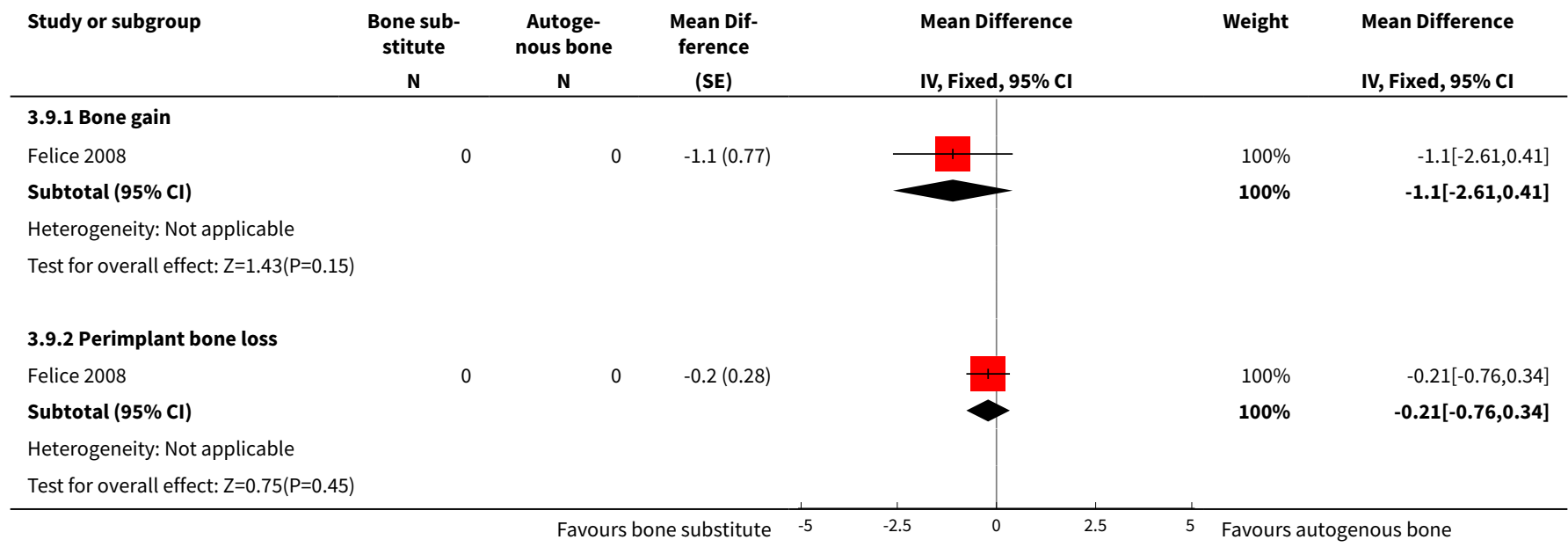

Analysis 3.10. Comparison 3 Vertical augmentation versus vertical augmentation, Outcome 10 Inlay graft: autogenous bone versus bone substitute (binary).

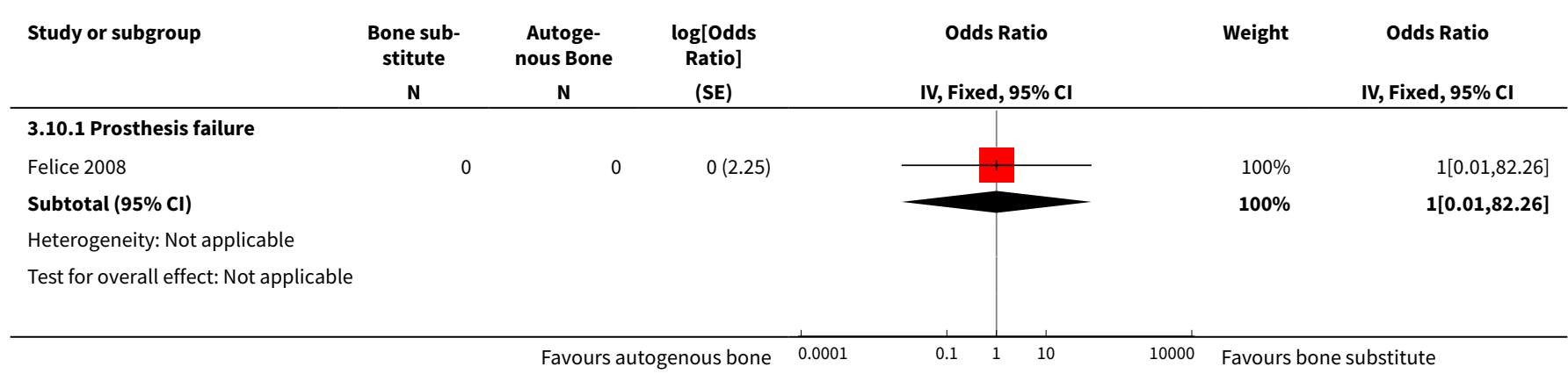




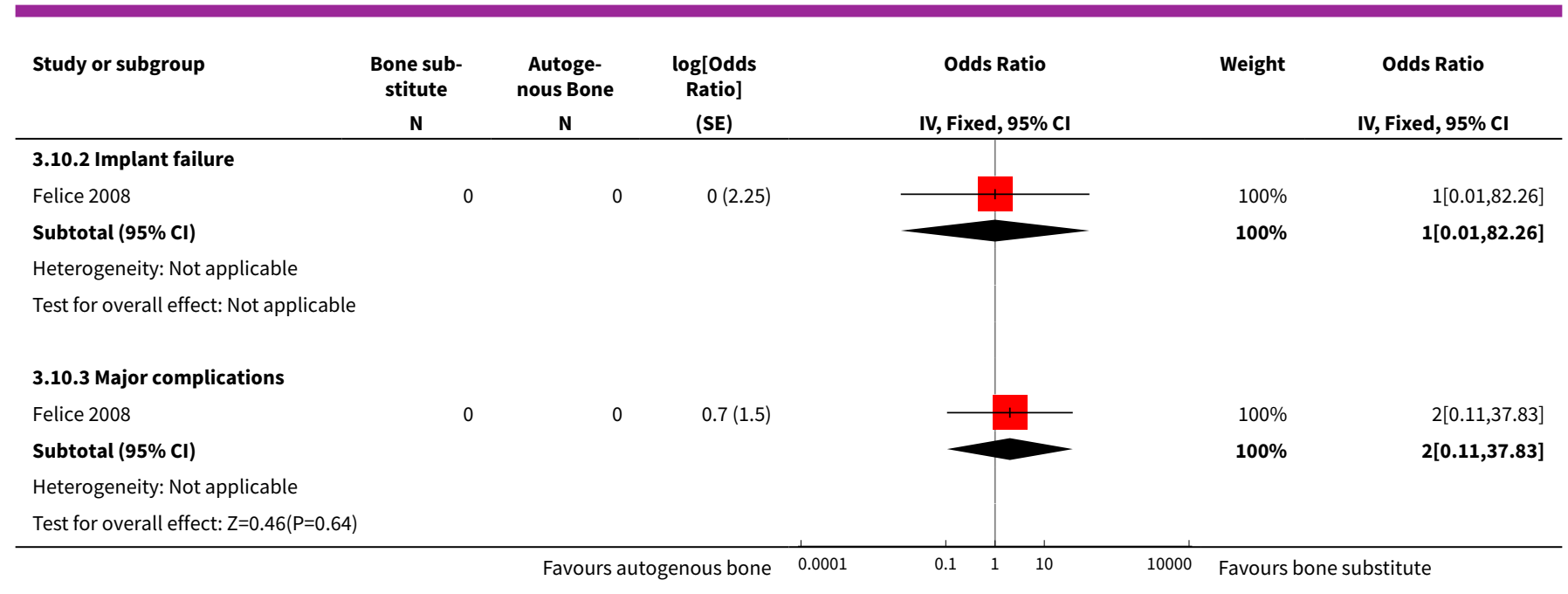

Analysis 3.11. Comparison 3 Vertical augmentation versus vertical augmentation, Outcome 11 Autogenous bone: inlay versus onlay (binary).

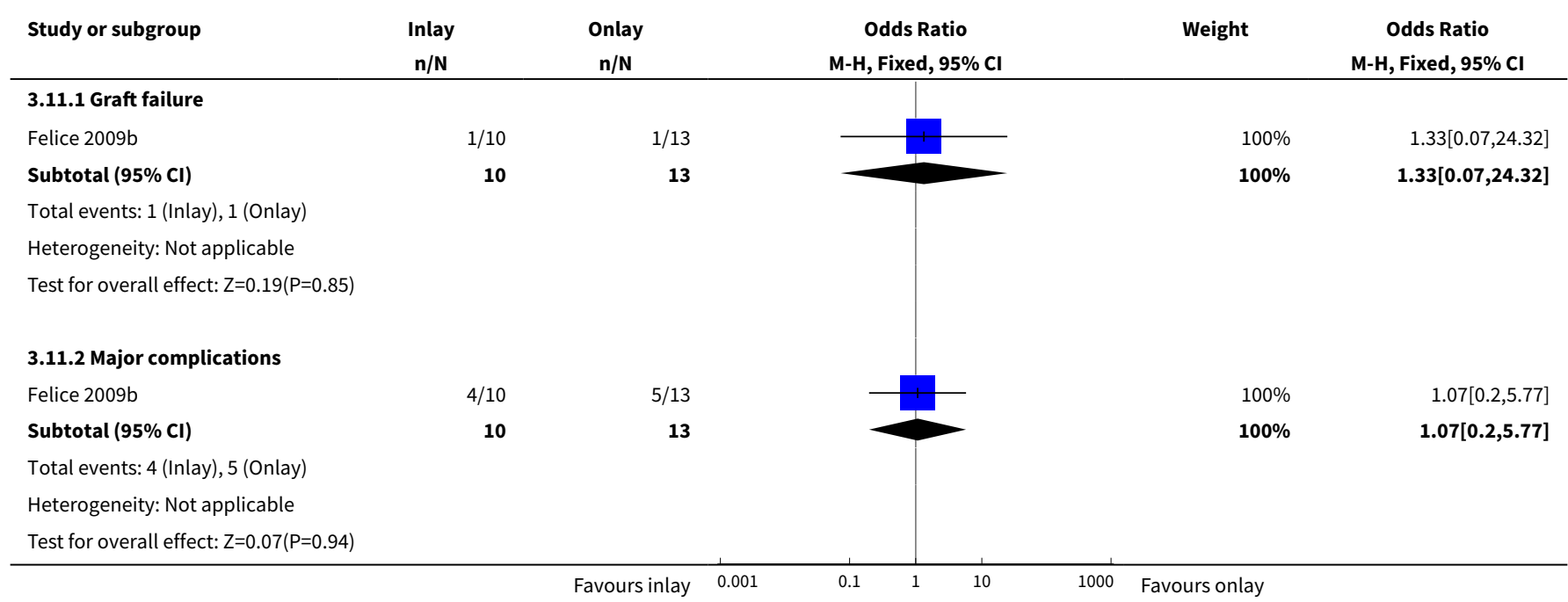

Analysis 3.12. Comparison 3 Vertical augmentation versus vertical augmentation, Outcome 12 Autogenous bone: inlay versus onlay (continuous).

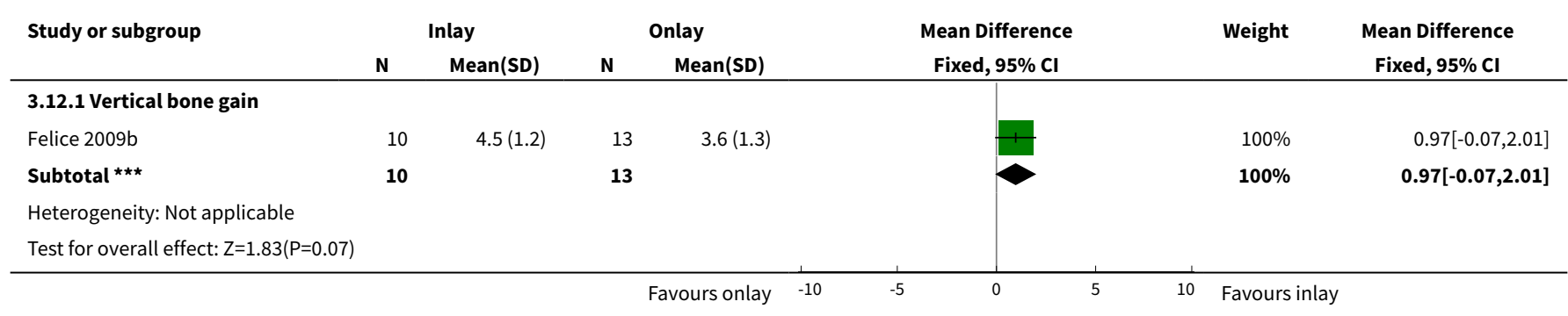




\section{ADDITIONAL TABLES}

Table 1. Quality assessment

\begin{tabular}{|c|c|c|c|c|}
\hline Study & $\begin{array}{l}\text { Allocation con- } \\
\text { cealment }\end{array}$ & Outcome assessor blinded & Withdrawals & $\begin{array}{l}\text { Risk of } \\
\text { bias }\end{array}$ \\
\hline Stellingsma 2003 & Unclear & No & $\begin{array}{l}\text { Yes, reasons giv- } \\
\text { en }\end{array}$ & High \\
\hline Chiapasco 2004 & No & No & None & High \\
\hline Raghoebar 2005 & Unclear & Yes & None & High \\
\hline Raghoebar 2006 & Unclear & No & None & High \\
\hline Chiapasco 2007 & Yes & Yes, when possible & None & Low \\
\hline Meijndert 2007 & Unclear & Yes & None & High \\
\hline Merli 2007 & Yes & Yes, when possible & None & Low \\
\hline Bianchi 2008 & Yes & Yes, when possible & None & Low \\
\hline Felice 2008 & No & Yes, when possible & None & High \\
\hline Fontana 2008 & Yes & Yes & None & Low \\
\hline Schortinghuis 2008 & Yes & Yes & None & Low \\
\hline Felice 2009a & Yes & Yes, when possible & None & Low \\
\hline Felice 2009b & Yes & Yes & None & Low \\
\hline
\end{tabular}

\section{AP PEN DICES}

\section{Appendix 1. MEDLINE (OVID) search strategy}

1. exp Dental Implants/

2. exp Dental Implantation/ or dental implantation

3. exp Dental Prosthesis, Implant-Supported/

4. ((osseointegrated adj implant\$) and (dental or oral))

5. dental implant\$

6. (implant\$ adj5 dent\$)

7. (((overdenture\$ or crown $\$$ or bridge $\$$ or prosthesis or restoration $\$$ ) adj5 (Dental or oral)) and implant\$)

8. "implant supported dental prosthesis"

9. ("blade implant\$" and (dental or oral))

10. ((endosseous adj5 implant\$) and (dental or oral))

11. ((dental or oral) adj5 implant\$)

12. OR/1-11

\section{Appendix 2. Cochrane Oral Health Group's Trials Register search strategy}

(dental-implants OR "dental implant*" OR "oral implant*" OR dental-implantation OR dental-prosthesis-implant-supported OR "implant supported" OR "implant supported prosthesis" OR dental-implantation-endosseous-endodontic OR "endosseous implant*" OR bladeimplantation OR "blade implant*" OR (implant* AND (oral OR dental)) or dental-implantation-subperiosteal OR "subperiosteal implant" 
OR (implant* AND overdenture*) OR ((overdenture* OR crown* OR bridge* OR prosthesis OR prostheses OR restoration*) AND ("dental implant" OR "Oral implant" OR (zygoma* AND implant*))))

\section{Appendix 3. CENTRAL search strategy}

\#1 DENTAL IMPLANTS explode all trees (MeSH)

\#2 DENTAL IMPLANTATION explode all trees (MeSH)

\#3 DENTAL PROSTHESIS IMPLANT-SUPPORTED single term (MeSH)

\#4 ((osseointegrat ${ }^{\star}$ near implant $\left.{ }^{\star}\right)$ and $\left(\right.$ dental $^{\star}$ or oral $\left.{ }^{\star}\right)$ )

\#5 (dental next implant ${ }^{\star}$ )

\#6 (implant* near dent*)

\#7 dental-implant*

\#8 ((overdenture* near dental $\left.{ }^{\star}\right)$ and implant $\left.{ }^{\star}\right)$

\#9 ((overdenture ${ }^{\star}$ near oral $\left.{ }^{\star}\right)$ and implant $\left.{ }^{\star}\right)$

\#10 ((crown* near dental $\left.{ }^{\star}\right)$ and implant $\left.{ }^{\star}\right)$

$\# 11$ ((crown* near oral $\left.{ }^{\star}\right)$ and implant $\left.{ }^{\star}\right)$

\#12 ((bridge* near dental $\left.{ }^{\star}\right)$ and implant $\left.{ }^{\star}\right)$

\#13 ((bridge* near oral $\left.{ }^{\star}\right)$ and implant $\left.{ }^{\star}\right)$

\#14 ((prosthesis near dental $\left.{ }^{\star}\right)$ and implant $\left.{ }^{\star}\right)$

\#15 ((prosthesis near oral $\left.{ }^{\star}\right)$ and implant $\left.{ }^{\star}\right)$

\#16 ((prostheses near dental $\left.{ }^{\star}\right)$ and implant $\left.{ }^{\star}\right)$

\#17 ((prostheses near oral $\left.{ }^{\star}\right)$ and implant $\left.{ }^{\star}\right)$

\#18 ((restoration* near dental $\left.{ }^{\star}\right)$ and implant $\left.{ }^{\star}\right)$

\#19 ((restoration ${ }^{\star}$ near oral $\left.{ }^{\star}\right)$ and implant $\left.{ }^{\star}\right)$

\#20 (implant next supported next dental next prosthesis)

\#21 (blade next implant*)

\#22 ((endosseous near implant $\left.{ }^{\star}\right)$ and dental)

\#23 ((endosseous near implant $\left.{ }^{\star}\right)$ and oral $^{*}$ )

\#24 ((dental ${ }^{\star}$ near implant $\left.{ }^{\star}\right)$ or (oral ${ }^{\star}$ near implant $\left.{ }^{\star}\right)$ )

$\# 25$ (\#1 or \#2 or \#3 or \#4 or \#5 or \#6 or \#7 or \#8 or \#9 or \#10 or \#11 or \#12 or \#13 or \#14 or \#15 or \#16 or \#17 or \#18 or \#19 or \#20 or \#21 or \#22 or \#23 or \#24)

\section{Appendix 4. EMBASE (OVID) search strategy}

1. tooth implantation/

2. ((implant-supported or implant\$) adj support\$).mp. [mp=title, abstract, subject headings, drug trade name, original title, device manufacturer, drug manufacturer name]

3. ((osseointegrated adj implant\$) and (dental or oral)).mp. [mp=title, abstract, subject headings, drug trade name, original title, device manufacturer, drug manufacturer name]

4. ((dental implant\$ or dental-implant or implant\$) adj (dent\$ or oral or tooth)).mp. [mp=title, abstract, subject headings, drug trade name, original title, device manufacturer, drug manufacturer name]

5. (((overdenture or crown\$ or bridge $\$$ or prosthesis or prostheses or restoration\$) adj5 (dental or oral)) and implant\$).mp. [mp=title, abstract, subject headings, drug trade name, original title, device manufacturer, drug manufacturer name]

6. "implant supported dental prosthesis".mp. [mp=title, abstract, subject headings, drug trade name, original title, device manufacturer, drug manufacturer name]

7. ("blade implant\$" and (dental or oral or tooth or teeth)).mp. [mp=title, abstract, subject headings, drug trade name, original title, device manufacturer, drug manufacturer name]

8. ((endosseous adj5 implant\$) and (dental or oral or tooth or teeth)).mp. [mp=title, abstract, subject headings, drug trade name, original title, device manufacturer, drug manufacturer name]

9. ((dental or oral or tooth or teeth) and implant\$).mp. [mp=title, abstract, subject headings, drug trade name, original title, device manufacturer, drug manufacturer name]

10. or/1-9

The above subject search was combined with the following filter for finding randomised controlled trials in EMBASE:

1. random\$.ti,ab.

2. factorial\$.ti,ab.

3. (crossover $\$$ or cross over $\$$ or cross-over $\$$ ).ti,ab.

4. placebo\$.ti,ab.

5. (doubl\$ adj blind\$).ti,ab.

6. (singl\$ adj blind\$).ti,ab.

7. assign\$.ti,ab.

8. allocat\$.ti,ab.

9. volunteer\$.ti,ab. 
10. CROSSOVER PROCEDURE.sh.

11. DOUBLE-BLIND PROCEDURE.sh.

12. RANDOMIZED CONTROLLED TRIAL.sh.

13. SINGLE BLIND PROCEDURE.sh.

14. or/1-13

15. ANIMAL/ or NONHUMAN/ or ANIMAL EXPERIMENT/

16. HUMAN/

17. 16 and 15

18. 15 not 17

19. 14 not 18

\section{WHAT'S NEW}

\begin{tabular}{lll}
\hline Date & Event & Description \\
\hline 10 October 2019 & Review declared as stable & $\begin{array}{l}\text { This Cochrane Review is currently not a priority for updating. } \\
\text { However, following the results of Cochrane Oral Health's latest } \\
\text { priority setting exercise and if a substantial body of evidence on } \\
\text { the topic becomes available, the review would be updated in the } \\
\text { future. }\end{array}$ \\
& \\
\hline
\end{tabular}

\section{H I S T O R Y}

Protocol first published: Issue 2, 2002

Review first published: Issue 3, 2003

\begin{tabular}{|c|c|c|}
\hline Date & Event & Description \\
\hline 5 November 2009 & Amended & Minor edit. \\
\hline 11 June 2009 & New search has been performed & Search updated to June 2009. \\
\hline 11 June 2009 & $\begin{array}{l}\text { New citation required and conclusions } \\
\text { have changed }\end{array}$ & $\begin{array}{l}\text { This review was originally conceived as having a broad focus and } \\
\text { was aimed to include any randomised controlled trial dealing } \\
\text { with any aspect of bone augmentation in relation to dental im- } \\
\text { plant rehabilitation. In the present update we decided to split } \\
\text { the original review into } 3 \text { more focused reviews: the present one } \\
\text { is dealing with horizontal and vertical bone augmentation proce- } \\
\text { dures. } \\
\text { Change in review authors. }\end{array}$ \\
\hline 19 June 2008 & Amended & Minor edit. \\
\hline 6 May 2008 & New search has been performed & Search updated to January 2008. \\
\hline 6 May 2008 & Amended & Converted to new review format. \\
\hline 6 May 2008 & $\begin{array}{l}\text { New citation required and conclusions } \\
\text { have changed }\end{array}$ & $\begin{array}{l}\text { The review has been updated in the following way: } 4 \text { addition- } \\
\text { al new trials were included and } 6 \text { were excluded. Slight changes } \\
\text { were made to the conclusions. }\end{array}$ \\
\hline
\end{tabular}

\section{CONTRIBUTIONS OF AUTHORS}

Conceiving, designing and co-ordinating the review (Marco Esposito (ME), Paul Coulthard (PC)). 
Developing search strategy and undertaking searches (ME, PC).

Screening search results and retrieved papers against inclusion criteria (ME, PC, Maria Gabriella Grusovin (GG), Pietro Felice (PF), Georgios Karatzopoulos (GK))

Writing to authors for additional information (ME, Helen Worthington (HW), PC).

Appraising quality (ME, PC, GG, PF, GK).

Data extraction (ME, HW, PC, GG).

Analysis and interpretation of the data (ME, HW).

Writing the review (ME).

Performing previous work that was the foundation of the current study (PC, ME, HW).

\section{DECLARATIONS OF INTEREST}

Pietro Felice and Marco Esposito are among the authors of some of the included trials. However, they were not involved in the quality assessment of these trials.

\section{SOURCES OF SUPPORT}

\section{Internal sources}

- Division of Dentistry, The University of Manchester, UK.

\section{External sources}

- National Institute for Health Research (NIHR), UK.

This project was supported by the NIHR, via Cochrane Infrastructure funding to Cochrane Oral Health. The views and opinions expressed are those of the authors and not necessarily those of the Systematic Reviews Programme, NIHR, NHS or the Department of Health and Social Care.

\section{NOTES}

This Cochrane Review is currently not a priority for updating. However, following the results of Cochrane Oral Health's latest priority setting exercise and if a substantial body of evidence on the topic becomes available, the review would be updated in the future.

\section{INDEX TERMS}

\section{Medical Subject Headings (MeSH)}

Alveolar Ridge Augmentation [methods]; Bone Transplantation [ ${ }^{*}$ methods]; Dental Implantation [methods]; Jaw, Edentulous, Partially [*surgery]; Oral Surgical Procedures, Preprosthetic [ ${ }^{*}$ methods]; Randomized Controlled Trials as Topic

\section{MeSH check words}

Animals; Humans 